\title{
Análise de Regressão Incorporando o Esquema Amostral
}

\author{
Cléber da Costa Figueiredo
}

\author{
Dissertação Apresentada ao \\ Instituto de Matemática e Estatística \\ da Universidade de São Paulo \\ COMo Requerimento Parcial \\ para Obtenção do Título de \\ Mestre em Estatística
}

\section{Área de Concentração: Estatística \\ Orientadora: Profa. Dra. Mônica Carneiro Sandoval}

Durante a elaboração deste trabalho o autor

recebeu apoio financeiro da FAPESP (processo $N^{o}$. 02/04927-7)

São Paulo, junho de 2004. 


\title{
Análise de regressão incorporando o esquema amostral
}

\author{
Este exemplar corresponde à redação \\ final da dissertação devidamente corrigida \\ e defendida por Cléber da Costa Figueiredo \\ e aprovada pela comissão julgadora.
}

São Paulo, 22 de julho de 2004.

Banca examinadora:

- Titulares

- Profa. Dra. Mônica Carneiro Sandoval (orientadora) - IME-USP

- Prof. Dr. Heleno Bolfarine - IME-USP

- Prof. Dr. Pedro Luis do Nascimento Silva - ENCE-IBGE

- Suplentes

- Prof. Dr. Rinaldo Artes - IME-USP/IBMEC

- Prof. Dr. Djalma Galvão Carneiro Pessoa - ENCE-IBGE 
À minha mãe, família e amigos. 


\section{Agradecimentos}

Quero agradecer...

A Deus por ter me dado o prazer de viver e conhecer todos que listarei abaixo e que diretamente, ou indiretamente, ajudaram-me para que este trabalho tivesse começo, meio e fim. Para alguns, este agradecimento é um ínfimo, porque compartilharam horas de suas vidas ao meu lado tanto nas horas de estudo, quanto nas horas de farra ou de simples divagações sobre a vida.

À minha mãe, Meire, que acreditou em mim e sempre me incentivou a continuar meus estudos, mesmo quando a vida deixou de ser tão ilusória e a obrigação exigia outra postura. Meu agradecimento por sua atenção e carinho e, principalmente, por sua tolerância em entender a minha ausência em "almost eventually" todos os eventos sociais.

Aos meus irmãos. Ao Flávio que cresceu comigo, ao Felipe que carreguei no colo e à Daniele que trouxe alegria para nosso lar desde o momento de sua adoção.

À minha cunhada Dulce e sobrinha Anneliese que me suportaram até tarde, quando nas noites de sábado, ia estudar na casa delas.

A toda minha família e ao meu pai que mesmo sendo ausente, de vez em quando, fazia-me algumas ligações. Aos meus tios Ari, Isabel, Roseli e Silvia. Ao amigo de família Luciano.

Aos únicos amigos que tive na infância Luciano e Vagner que acabei me dis- 
tanciando devido aos estudos.

Aos meus alunos de violino que entenderam minha ausência nos últimos meses e aos amigos Daniel, Denis, Guigo, Kitão, Ramon e Samuel que foram os poucos amigos que fiz na igreja e que, hoje, estou tão distante deles.

Aos amigos Ana Paula, Daniela, Edvaldo, Lázaro, Oleg, Salomé, Sandra, Thiago, Victor que dividiram suas vidas comigo desde os anos de graduação e não só a vida, mas os quartos, a comida etc. Em especial, ao Márcio que dividiu comigo o apartamento desde que cheguei em São Paulo. Por tudo que passamos juntos, meus mais siceros agradecimentos.

Aos amigos que conheci durante o curso de mestrado Adrilayne, Diana, Elias, Frederico, José Marcelo, Juvêncio, Lívia, Sueli, Tatiana e Vaudeluci, que foram especiais durante todo o decorrer do curso. Aqui estou abrindo aspas para três que superaram minhas expectativas: Daniela, Marcos e Mayra. Pelos domingos e feriados felizes que passamos juntos estudando para as provas de probabilidade, ou pelas simples conversas informais que tivemos ao longo do curso. Ainda ao Marcos, pelos ovos que comemos juntos e que foram cozidos no forno de microondas da Gisela.

Aos amigos cruspianos Amanda, Fabiana, Flávio, Jefferson, Luciana, Marco Antonio, Rogério, Sonia, Vanessa que me ajudaram a gostar do CRUSP e querer ficar nos finais de semana trabalhando "duro". Especialmente, ao meu grande amigo Wellington que foi o que mais me suportou com toda a minha chatice. Também quero agradecê-lo por sua tão sincera amizade e pelas madrugadas que passamos conversando; pelo companheirismo: Wellington, você é maior legal!

A todos meus professores. Às professoras Célia, Conceição e Maria Antônia que me incentivaram a prosseguir os estudos ainda no Ginásio. Às professoras do CEFAM II - Suzano, em especial, às professoras Alice, Aparecida, Dalila, Heloísa e Shirley. Ainda quero agradecer à Alice pelos livros de matemática que me emprestou e por ter-me incentivado a participar da minha primeira olimpíada de matemática 
no segundo ano do colégio, despertando em mim o interesse pelas ciências exatas. A todos os professores do Instituto de Matemática e Estatística.

\begin{abstract}
$* * *$
Em especial, às minhas orientadoras Mônica Sandoval e Denise Botter por terem me ensinado a ler e a escrever. Pelas horas que passamos discutindo a inclusão e exclusão de tópicos no "consultório" da Denise que tive o prazer de conhecer no segundo ano do meu curso de graduação em matemática e que me fez ter gosto pela estatística. Ainda, à Denise por ter-me aceito como orientando de iniciação científica, onde conheci a Mônica, uma pessoa maravilhosa, e hoje estamos apresentando à comunidade científica este trabalho.
\end{abstract}

Ao Prof. Rinaldo Artes que conheci a pouco tempo, mas que me ajudou muito. Pela amizade e por suas dicas que foram a alavanca para que este trabalho chegasse ao fim. À Profa. Silvia Schor que gentilmente forneceu os dados da pesquisa de moradores de rua realizada pela FIPE.

À FAPESP pelo apoio financeiro. 


\section{Resumo}

Neste trabalho estudamos modelos lineares de regressão para análise de dados obtidos de pesquisas amostrais complexas. Foram considerados aspectos teóricos e aplicações a conjuntos de dados reais por meio do uso do aplicativo SUDAAN e da biblioteca ADAC da linguagem R. Nas aplicações foram abordados os modelos de regressão normal e logística. Foram realizados também estudos comparativos dos métodos estudados com os que assumem que as observações são selecionadas segundo amostragem aleatória simples. 


\section{Abstract}

We have studied linear regression models for data analysis when the data set comes from a complex sampling survey. We have considered theoretical aspects and some applications utilizing the SUDAAN software and the ADAC library for R language. The applications involved the normal and logistic regression models. The studied methods were compared with those obtained from simple random samples. 


\section{Índice}

Agradecimentos iv

Resumo vii

Abstract viii

1 Introdução 1

2 Esquemas amostrais complexos $\quad 4$

2.1 Introdução . . . . . . . . . . . . . . . . . . . . . . . . . 4

2.2 Principais esquemas amostrais . . . . . . . . . . . . . . . . 4

2.2.1 Amostragem aleatória simples . . . . . . . . . . . . . . 4

2.2.2 Amostragem por estratificação . . . . . . . . . . . . . 5

2.2.3 Amostragem aleatória por conglomeração . . . . . . . . . . 7

2.2.4 Amostragem com probabilidades desiguais . . . . . . . . . 8

3 Métodos de estimação 11

3.1 Introdução . . . . . . . . . . . . . . . . . . . . . . . . 11

3.2 Estimação dos parâmetros de um modelo de superpopulação . . . . . 12

3.3 Estimação simultânea dos parâmetros populacionais e dos parâmetros do modelo de superpopulação . . . . . . . . . . . . . . . . . 16

3.4 Testes de hipóteses . . . . . . . . . . . . . . . . . . . 21

3.5 Seleção de modelos . . . . . . . . . . . . . . . . . . 23 
4 Efeito do plano amostral $\quad 24$

4.1 Exemplo do cálculo do EPA . . . . . . . . . . . . . . . 25

5 Uso do computador na incorporação do esquema amostral 28

5.1 O pacote SUDAAN . . . . . . . . . . . . . . . . 29

5.1.1 Fundamentos básicos . . . . . . . . . . . . . 29

5.1.2 Estrutura de um programa . . . . . . . . . . . . . 31

5.1.3 Tratamento padrão dos dados . . . . . . . . . . . . . 39

5.1.4 Alguns exemplos de programas no SUDAAN . . . . . . . . . 41

5.2 A biblioteca ADAC da linguagem R . . . . . . . . . . . . . 46

5.2.1 Principais funções da biblioteca ADAC . . . . . . . . . . . . . 47

6 Aplicações $\quad 51$

6.1 Ajuste de um modelo de regressão linear normal . . . . . . . . . . . . 51

6.2 Ajuste de um modelo de regressão logística . . . . . . . . . . . . . 65

6.3 Comparação entre a biblioteca ADAC e o

SUDAAN utilizando um modelo de regressão

logística . . . . . . . . . . . . . . . . . . 74

6.3.1 Ajuste do modelo . . . . . . . . . . . . . 76

6.4 Uso de regressão linear para a caracterização sócio-econômica da população moradora de rua . . . . . . . . . . . . . . . . . . . 79

$\begin{array}{llr}7 & \text { Considerações finais } & 85\end{array}$

$\begin{array}{lr}\text { A Programa } & 87\end{array}$

$\begin{array}{lr}\text { Referências bibliográficas } & 89\end{array}$ 


\section{Capítulo 1}

\section{Introdução}

O presente trabalho trata da incorporação do esquema amostral em análise de regressão. Foi realizado um estudo teórico sobre modelos lineares de regressão que incorporam o esquema amostral utilizado no processo de estimação e um estudo sobre o uso do SUDAAN (Research Triangle Institute, 2001) e da biblioteca ADAC da linguagem R (Venables et al, 2003), para a incorporação destes esquemas amostrais. Os modelos estudados foram aplicados a conjuntos de dados reais obtidos de desenhos amostrais complexos, utilizando o SUDAAN e a linguagem R, sendo que foi avaliado o impacto de ignorar o plano amostral na análise dos dados. Foram considerados, também, alguns aspectos relacionados à seleção de modelos. Para tanto, revisitamos trabalhos como os de Nascimento Silva (1996), Duarte (1999) e Vieira (2001), bem como o texto do curso de Análise de Dados Amostrais Complexos de Pessoa e Nascimento Silva (1998) realizado no $13^{\circ}$ Simpósio Nacional de Probabilidade e a coletânea de artigos organizada por Chambers e Skinner (2003) que originou o livro "Analysis of Survey Data".

Em linhas gerais, o Capítulo 2 apresenta os principais esquemas amostrais. Esquemas como estratificação, conglomeração ou amostragem por probabilidades desiguais já são considerados esquemas complexos e a combinação deles, então, torna ainda mais complicado o esquema amostral. Aqui a atenção está voltada para o 
cálculo dos pesos amostrais que são exigidos na maioria dos "softwares" que conduzem análises com dados de pesquisas amostrais.

O Capítulo 3 mostra, usando a teoria de equações de estimação, como estimar os parâmetros de um modelo de superpopulação, considerando o esquema amostral utilizado na seleção da amostra. Além disso, apresenta como obter aproximações para a variância dos estimadores. Aplicamos os resultados obtidos ao modelo de regressão normal e salientamos que estes resultados podem ser estendidos facilmente aos modelos lineares generalizados. Apresentamos, ainda, a metodologia para testes de hipóteses sobre parâmetros do modelo de regressão.

O Capítulo 4 trata do estudo do efeito do plano amostral (EPA) de Kish (1965) e do efeito do plano amostral ampliado proposto por Skinner, Holt e Smith (1989). Além disso, apresenta como a medida proposta por Kish compara planos amostrais no estágio do planejamento e, ainda, no caso do EPA ampliado, avalia se o impacto que sofre a estimativa da variância, quando não considerado o plano amostral, foi grande ou pequeno.

No Capítulo 5 apresentamos como utilizar o pacote computacional SUDAAN e a biblioteca ADAC da linguagem R e, ainda, como são feitas as chamadas dos comandos e funções que são necessários para a análise de dados de pesquisas amostrais. Por fim, mostramos algumas vantagens e desvantagens da utilização do SUDAAN e da biblioteca ADAC para a análise de dados amostrais provenientes de planos complexos, que possibilitam a estimação de várias características populacionais e de seus erros amostrais, incluindo médias, proporções, razões, quantis, tabelas cruzadas, além dos parâmetros de modelos de regressão linear normal e logística. Ambos possuem implementado o método de linearização de Taylor para a estimação de variâncias, sendo que o SUDAAN, além do método de linearização de Taylor, também permite o emprego de outros métodos como o do conglometado primário, por exemplo.

O Capítulo 6 apresenta três conjuntos de dados reais para a exploração das 
idéias expostas nos capítulos anteriores. Além disso, comparamos os resultados das análises obtidas pelo SUDAAN e R e comparamos os métodos que não consideram o plano amostral utilizado com os que o consideram.

No Capítulo 7 terminamos o trabalho com algumas das principais conclusões desta dissertação. 
CAPÍtulo 2

\section{Esquemas amostrais complexos}

\subsection{Introdução}

Na maioria da vezes, a escolha de uma amostra não se restringe à obtenção de observações da população por amostragem aleatória simples (AAS) com ou sem reposição. Em muitos casos, a própria estrutura populacional não permite a mera amostragem aleatória simples. Esquemas como estratificação, conglomeração, probabilidades desiguais ou combinações deles são, então, necessários. Neste capítulo pretendemos dar uma visão dos principais esquemas amostrais, como descrito em Särndal et al (1992), dando ênfase ao estudo da probabilidade de inclusão de uma observação na amostra dado o plano amostral utilizado.

\section{$2.2 \quad$ Principais esquemas amostrais}

\subsubsection{Amostragem aleatória simples}

Esse esquema amostral consiste na seleção de $n$ unidades, a partir de uma população com $N$ elementos, de tal forma que cada amostra tenha a mesma probabilidade de ser escolhida. Na literatura estas unidades são chamadas de unidades primárias de amostragem (UPAS's). A seleção destas unidades pode ser feita sem 
ou com reposição. Para o caso com reposição, a variável $f_{i}$, número de vezes que a unidade $i$ aparece na amostra, possui distribuição binomial com parâmetros $n$ e $1 / N$.

Das propriedades da distribuição binomial temos que

$$
E\left[f_{i}\right]=\frac{n}{N} \quad e \quad \operatorname{Var}\left[f_{i}\right]=\frac{n}{N}\left(1-\frac{1}{N}\right) .
$$

Vamos concentrar nossa atenção na probabilidade de inclusão da unidade $i$ na amostra. No caso em questão esta probabilidade é dada por

$$
\pi_{i}=1-\left(1-\frac{1}{N}\right)^{n}, \quad i=1, \ldots, N,
$$

sendo a probabilidade conjunta de inclusão das unidades $i$ e $j$ na amostra dada por

$$
\pi_{i j}=1-2\left(1-\frac{1}{N}\right)^{n}+\left(1-\frac{2}{N}\right)^{n} ; \quad i, j=1, \ldots, N .
$$

No caso sem reposição, a variável $f_{i}$, número de vezes que a unidade $i$ aparece na amostra possui distribuição de Bernoulli com probabilidade de sucesso $n / N$.

Das propriedades da distribuição de Bernoulli temos que

$$
E\left[f_{i}\right]=\frac{n}{N} \quad e \quad \operatorname{Var}\left[f_{i}\right]=\frac{n}{N}\left(1-\frac{1}{N}\right) .
$$

A probabilidade de inclusão da unidade $i$ na amostra é dada por

$$
\pi_{i}=\frac{n}{N},
$$

sendo a probabilidade conjunta de inclusão das unidades $i$ e $j$ na amostra dada por

$$
\pi_{i j}=\frac{n}{N} \frac{n-1}{N-1} ; \quad i, j=1, \ldots, N \quad \text { e } \quad i \neq j .
$$

\subsubsection{Amostragem por estratificação}

Muitas vezes a estrutura da população que queremos estudar é tal que se realizarmos uma amostragem aleatória simples haverá, possivelmente, perda de eficiência. Morton e Rolph (2000) discutem este assunto num estudo de recenseamento de 
moradores de rua, que foi realizado no condado de Orange, EUA. O condado foi dividido em 418 setores censitários. Com informação anterior ao censo, sabiam que a população de moradores de rua não era homogênea, logo existiam áreas de maior concentração de moradores de rua e áreas onde a presença de moradores de rua era irrisória. Se fosse realizada uma amostragem aleatória simples dos setores, ou seja, seleção de setores com igual probabilidade de seleção e, os moradores de rua encontrados fossem contados, a estimativa da variância do total de moradores de rua seria alta. Estratificar a população forneceria, então, um estimador com menor variabilidade.

Assim, amostragem por estratificação consiste na divisão da população em grupos disjuntos (estratos), segundo algumas características conhecidas na população e de cada um desses estratos selecionam-se amostras em proporções convenientes. No exemplo acima, poderíamos ter separado o condado de Orange em três estratos: áreas centrais, subúrbios e áreas rurais. Dentro de cada um destes estratos, poderiam ser selecionadas amostras de moradores de rua por AAS. É muito comum, por exemplo, definir-se o tamanho da amostra proporcional ao tamanho do estrato, isto será visto melhor na Seção (2.2.4). A amostragem por estratificação também é realizada por corte, onde em um ou mais estratos todas as unidades são observadas e do restante são retiradas amostras sob algum plano.

Sejam $N_{h}$ o número de unidades populacionais no estrato h e $n_{h}$ o tamanho da amostra selecionada no estrato $\mathrm{h}, \mathrm{h}=1, \ldots, \mathrm{H}$. A probabilidade de inclusão da unidade $i$ do estrato h na amostra, caso tenham sido retiradas amostras por amostragem aleatória simples com reposição de cada estrato será dada por

$$
\pi_{i h}=1-\left(1-\frac{1}{N_{h}}\right)^{n_{h}}, \quad i=1, \ldots, N_{h}
$$

e a probabilidade conjunta de inclusão das unidades $i$ e $j$ do estrato $h$ na amostra é dada por

$$
\pi_{i j h}=1-2\left(1-\frac{1}{N_{h}}\right)^{n_{h}}+\left(1-\frac{2}{N_{h}}\right)^{n_{h}} ; \quad i, j=1, \ldots, N_{h}
$$


Convém observar que a única diferença, quando comparamos a expressão da probabilidade de inclusão no caso de estratificação $\pi_{i h}$ com a probabilidade de inclusão $\pi_{i}$ na amostragem aleatória simples, é que para cada estrato haverá uma probabilidade diferente de se selecionar as unidades, que variará de acordo com $n_{h}$ e $N_{h}$. Analogamente, a probabilidade de inclusão da unidade $i$ do estrato h na amostra caso tenham sido retiradas amostras por amostragem aleatória simples sem reposição de cada estrato é dada por

$$
\pi_{i h}=\frac{n_{h}}{N_{h}},
$$

sendo a probabilidade conjunta de inclusão da unidade $i$ e $j$ do estrato $h$ na amostra dada por

$$
\pi_{i j h}=\frac{n_{h}}{N_{h}} \frac{n_{h}-1}{N_{h}-1} ; \quad i, j=1, \ldots, N_{h} \quad \text { e } \quad i \neq j .
$$

\subsubsection{Amostragem aleatória por conglomeração}

No exemplo de Morton e Rolph (2000), o condado de Orange foi dividido em 418 setores censitários. A amostragem consistiu na seleção de alguns destes setores. Para cada setor selecionado, todos os moradores de rua encontrados faziam parte da amostra. Assim, a amostragem por conglomeração consiste na seleção aleatória de grupos, chamados de conglomerados. Diferente dos planos anteriores, onde a unidade amostral correspondia a um único elemento populacional, na amostragem de conglomerados a seleção corresponde a mais de um elemento da população. Essa unidade amostral, por exemplo, pode ser um setor censitário, muito comum nas pesquisas realizadas pelo IBGE, que já tem para cada região brasileira os setores censitários (conglomerados) definidos. Algumas vezes, pode acontecer desta seleção ser feita em mais de um estágio, por exemplo, primeiro selecionam-se setores censitários e, depois dentro de cada setor censitário, são selecionados domícilios. Neste caso, cada domicílio é também um conglomerado, exceto se as variáveis de interesse se 
referirem ao domícilio, pois todos os indivíduos do domicílio pertencerão à amostra. Este último plano amostral é chamado de amostragem aleatória por conglomerados em dois estágios. O número de estágios pode ser maior que dois, embora não seja muito utilizado dada a complicação que a expressão dos estimadores de características populacionais e das precisões dos estimadores obtidos acabam tomando, à medida que o plano amostral torna-se mais e mais complexo. Outras vezes, existe a combinação de estratificação e conglomeração como no exemplo dos moradores de rua, onde primeiro a população foi estratificada e, dentro de cada estrato, foram selecionados conglomerados (setores censitários).

A amostragem por conglomeração tende a diminuir o custo por elemento, porém devido ao fato de que dentro de um mesmo conglomerado as unidades tendem a ter valores parecidos, existe entre as unidades de um mesmo conglomerado uma correlação que é chamada de correlação intraclasse.

$\mathrm{Na}$ amostragem por conglomerados pode ocorrer que a seleção das unidades amostrais no primeiro estágio ocorra por amostragem aleatória simples com reposição e, no segundo estágio sem reposição, ou outras combinações possíveis. Assim a probabilidade de inclusão da unidade $i$ na amostra vai depender de como foram realizadas as seleções em cada estágio.

\subsubsection{Amostragem com probabilidades desiguais}

É utilizada quando as unidades de amostragem têm grandes variações de tamanho e ignorar estas variações pode resultar em desenhos ineficientes, ou ainda quando o tamanho está fortemente correlacionado com variáveis de interesse. A seleção das unidades pode ainda ocorrer com ou sem reposição. No exemplo de moradores de rua, poderíamos selecionar os setores censitários com eqüiprobabilidade dentro de cada estrato. Porém, como em alguns setores o número de moradores de rua era maior que em outros setores, atribuir diferentes probabilidades para cada 
setor resulta em uma maior eficiência do desenho. Este é um exemplo de que variações no número de elementos por unidade amostral podem nos dar indicações que o uso de um esquema com probabilidades desiguais é necessário. Outro exemplo, seria querermos estimar o gasto total com salários em 2003 de um determinado setor de empresas, quando dispomos de uma variável auxiliar altamente correlacionada, por exemplo, gasto com salários por empresa em 2000. Com base nesta informação, cada empresa do setor receberia uma probabilidade de inclusão na amostra baseada nesta variável auxiliar, isto é, poderíamos dividir o gasto da empresa em 2000 pelo total do gasto das empresas no mesmo ano, de modo que empresas com maiores gastos contribuíssem com menor peso na estimação do total de interesse. Muitas vezes o uso de um esquema com probabilidades desiguais é utilizado combinado a estratificação ou conglomeração. Por exemplo, Botter et al. (2002), aplicaram um modelo de regressão logística para análise de dados obtidos por uma amostragem estratificada. Os dados foram coletados em crianças e adolescentes matriculados em escolas da cidade de Belo Horizonte, em 2000. Os estratos consistiram de escolas públicas e privadas. Em cada estrato foram selecionadas algumas escolas com probabilidade proporcional ao tamanho da escola. Dentro de cada escola, os alunos foram selecionados ao acaso e sem reposição. Observe que neste plano amostral há a combinação de estratificação com probabilidades desiguais de seleção das escolas e amostragem aleatória simples sem reposição de alunos dentro das escolas.

Os esquemas utilizados para atribuir as diferentes probabilidades de seleção são os chamados esquemas PPT que utilizam amostragem com probabilidade proporcional ao tamanho, embora seja mais comum o uso de estratificação com alocação desproporcional, que não está sendo tratado neste estudo. Estes esquemas usam o conhecimento de uma variável auxiliar $x_{i}$ conhecida para todos os elementos da população, $i \in U, U=\{1, \ldots, N\}$. Quando $x_{i}>0, \quad \forall i \in U$, podemos usar esta variável como uma medida de tamanho das unidades populacionais. No exemplo 
de moradores de rua, se o número de moradores de rua por setor já houvesse sido calculado em outra oportunidade, este número seria a variável $x_{i}$ que necessitamos para atribuirmos as diferentes probabilidades. Se $x$ (número de moradores de rua a dez anos atrás) for correlacionada com a variável de estudo y (número de moradores de rua hoje), então espera-se que haja um aumento de eficiência ao utilizar amostragem PPT em relação a AAS. Neste plano é necessário assumir que é possível selecionar amostras de acordo com um plano amostral tal que $\pi_{i} \propto x_{i} \quad \forall i=1, \ldots N$ e $\pi_{i j}>0 \quad \forall i \neq j \in U$, sendo que esta última expressão será útil para a estimação de variâncias. O uso de informação auxiliar em pesquisas amostrais foi discutido em Silva (1996).

Há ainda a possibilidade de que a amostragem PPT seja feita com reposição através do método dos totais cumulativos. O procedimento é acumular as medidas de tamanho na população através do cálculo de $X(k)=\sum_{i=1}^{k} x_{i}$, para $k=$ $1, \ldots, N$, convencionando-se $X(0)=0$. O próximo passo é determinar "intervalos de seleção" com base no tamanho de cada unidade. Assim o intervalo de seleção para a unidade $i$ será dado por $(X(i-1) ; X(i)]$, sendo o limite superior incluído. A seguir, seleciona-se um número aleatório $u$ com distribuição uniforme $[0, X(N)]$. Se $u \in(X(i-1) ; X(i)]$, então $i$ deve ser incluído na amostra com probabilidade $\pi_{i}=1-\left(1-\frac{X(i)-X(i-1)}{X(N)}\right)^{n}$. O procedimento se repetirá até que o tamanho desejado da amostra seja alcançado.

Outro método de amostragem PPT, denominado amostragem PPT de Poisson é muito utilizado em pesquisas como "U.S. Bureau of the Census's Annual Survey of Manufactures", Ogus e Clark (1971), ou pesquisas como as que calculam o índice de preços ao consumidor realizadas na Suécia antes de 1989, Ohlsson (1990), e amostragem seqüencial de Poisson, utilizada para o cálculo do mesmo índice após 1990, podem ser encontrados em Ohlsson(1998). 
CAPÍtUlo 3

\section{Métodos de estimação}

\subsection{Introdução}

Neste capítulo tratamos de métodos para a estimação dos parâmetros de um modelo de regressão no contexto de modelos de superpopulação. Antes, porém, vamos introduzir o conceito de população finita.

Uma população finita é aquela que conhecido o tamanho da população, que chamaremos de $N$, rotulamos os $\mathrm{N}$ elementos, de maneira única, com um número inteiro entre 1 e $\mathrm{N}$, de modo que duas unidades distintas não possuam o mesmo rótulo. Deste modo, a população passa a ser denotada por $U=\{1, \ldots, N\}$.

Ao elemento $i, i=1, \ldots, N$, da população associamos o valor de uma variável

de interesse Y, que denotamos por $y_{i}$. Em muitas situações, associamos também a cada elemento os valores de outras variáveis que denotaremos por $X_{1}, \ldots, X_{r}$. Em geral, estamos interessados em estimar funções das quantidades $y_{1}, \ldots, y_{N}$, como, por exemplo, o total, a média ou a variância populacionais.

Existem duas abordagens para lidarmos com dados provenientes de populações finitas. Na amostragem clássica, selecionamos uma amostra de $n$ elementos, $s=$ $\left\{i_{1}, \ldots, i_{n}\right\}$ e, conseqüentemente, de observações $y_{1}, \ldots, y_{n}$, segundo um plano amostral $\mathrm{p}(\mathrm{s})$ que norteará o processo de inferência. Esta abordagem está baseada exclusiva- 
mente na distribuição de probabilidades criada pelo planejamento amostral, sendo que a única relação existente entre as unidades da amostra e as de fora dela é a existência de uma probabilidade positiva de que todas as observações pertençam à amostra.

A outra abordagem é a de modelos de superpopulação que assume que os valores desconhecidos $y_{1}, \ldots, y_{N}$ são considerados $N$ observações de variáveis aleatórias $Y_{1}, \ldots, Y_{N}$, não necessariamente independentes com distribuição comum $f(y, \theta)$, onde $\theta \in \Theta$. A inferência é feita com base nesta distribuição $f$.

Algumas questões que surgem em cada abordagem foram discutidas em Pessoa e Silva (1998) e Chambers e Skinner (2003). Observe que a abordagem de modelos de superpopulação acaba tornando-se ineficiente do ponto de vista da análise de dados provenientes de planos amostrais complexos, pois não incorpora o plano amostral utilizado. O presente trabalho utilizará a modelagem de superpopulação como alicerce para a teoria que será apresentada, incorporando na análise inferencial o esquema amostral que foi adotado.

\subsection{Estimação dos parâmetros de um modelo de superpopulação}

Suponha uma população de $N$ elementos $U=\left\{i_{1}, \ldots, i_{N}\right\}$ onde $\mathbf{y}=\left(y_{1}, \ldots, y_{N}\right)^{\prime}$ é o vetor populacional de valores da variável de interesse em estudo $Y$. Assuma que Y é gerado de uma distribuição $f$, sendo que $f$ é conhecida e pertence a uma classe $C=\{f\}$. Esta classe é chamada modelo de superpopulação. No que segue, não faremos distinção entre $Y$ e $y$. Para referência, a teoria que descrevemos aqui pode ser encontrada com detalhes em Godambe e Thompson (1986), J $\phi$ rgensen e Laboriau (1994) e Artes (1997).

Seja $\boldsymbol{\theta} \in \Theta \subset \Re^{p}$ um parâmetro do modelo de superpopulação. Da teoria 
de funções de estimação sabemos que uma função de estimação não viciada para $\boldsymbol{\theta}$ baseada na população finita $\mathbf{y}$ é uma função $\mathbf{g}(\mathbf{y}, \boldsymbol{\theta})$ tal que para todo $f \in C$

$$
\xi_{f}\{\mathbf{g}(\mathbf{y}, \boldsymbol{\theta})\}=\mathbf{0}
$$

sendo que $\xi_{f}$ denota a esperança sob $f$.

Definição 1 Definimos uma função de estimação $\mathbf{g}(\mathbf{y}, \boldsymbol{\theta}): \Omega \times \Theta \longrightarrow \Re^{p}$ como regular se satisfaz as seguintes condições para todo $\boldsymbol{\theta} \in \Theta$ :

(i) A função é não viciada;

(ii) A derivada parcial de $\mathbf{g}(\mathbf{y}, \boldsymbol{\theta})$ com respeito a $\boldsymbol{\theta}$ existe quase certamente para todo $\mathbf{y} \in \Omega$;

(iii) É possível permutar o sinal de integração com o de diferenciação da seguinte forma: $\frac{\partial}{\partial \theta_{i}} \int_{\Omega} \mathbf{g}(\mathbf{y}, \boldsymbol{\theta}) f(\mathbf{y}, \boldsymbol{\theta}) d \mathbf{y}=\int_{\Omega} \frac{\partial}{\partial \theta_{i}} \mathbf{g}(\mathbf{y}, \boldsymbol{\theta}) f(\mathbf{y}, \boldsymbol{\theta}) d \mathbf{y} ;$

(iv) $\xi_{f}\left(g_{i}(\boldsymbol{\theta}) g_{j}(\boldsymbol{\theta})\right) \in \Re, \operatorname{com} i, j=1, \ldots, p$ e $V_{\mathbf{g}}(\boldsymbol{\theta})=\xi_{f}\left(\mathbf{g}(\boldsymbol{\theta}) \mathbf{g}^{\prime}(\boldsymbol{\theta})\right)$ é positiva definida;

(v) $\xi_{f}\left(\frac{\partial}{\partial \theta_{l}} g_{i}(\boldsymbol{\theta}) \frac{\partial}{\partial \theta_{k}} g_{j}(\boldsymbol{\theta})\right) \in \Re, \operatorname{com} l, k=1, \ldots, p$ e $S_{g}(\boldsymbol{\theta})=\xi_{f}\left(\frac{\partial}{\partial \boldsymbol{\theta}^{\prime}} \mathbf{g}(\boldsymbol{\theta})\right)$ é não singular.

Seja $\mathbf{g}(\mathbf{y}, \boldsymbol{\theta})$ uma função de estimação regular. Define-se a informação de Godambe de $\boldsymbol{\theta}$ por

$$
J_{g}(\boldsymbol{\theta})=S_{g}^{\prime}(\boldsymbol{\theta}) V_{g}^{-1}(\boldsymbol{\theta}) S_{g}(\boldsymbol{\theta})
$$

Uma função de estimação regular $\mathbf{g}^{*}(\mathbf{y}, \boldsymbol{\theta})$ é denominada ótima (Godambe 1960), no caso uniparamétrico, se minimiza a quantidade

$$
\xi_{f}\left\{g^{2}(y, \theta)\right\} /\left(\xi_{f}\left(\frac{\partial g(y, \theta)}{\partial \theta}\right)\right)^{2}
$$


entre todas as funções regulares g. Para o caso multiparamétrico, podemos entender este conceito com a introdução de alguma ordenação das matrizes de covariância assintótica propostas por Chandrasenkar e Kale (1984).

Se $C=\{f\}$ é um modelo de superpopulação tal que $y_{1}, \ldots, y_{N}$ são independentes, então em muitos casos uma função $\mathbf{g}^{*}$ existe na forma $\mathbf{g}^{*}=\sum_{i=1}^{N}\left\{\boldsymbol{\phi}_{i}\left(y_{i}, \boldsymbol{\theta}\right)\right\}$, sendo que $\boldsymbol{\phi}_{i}$ é uma função tal que $\xi_{f} \boldsymbol{\phi}_{i}=\mathbf{0}$, para $i=1, \ldots, N$. Se $\mathbf{g}^{*}(\mathbf{y}, \boldsymbol{\theta})$ é ótima então a equação $\mathbf{g}^{*}(\mathbf{y}, \boldsymbol{\theta})=\mathbf{0}$ é chamada equação de estimação ótima e sua solução é um estimador ótimo para $\boldsymbol{\theta}$. No caso particular em que temos $\boldsymbol{\phi}_{i}=\mathbf{u}_{i}$, sendo $\mathbf{u}_{i}$ o componente relativo a $\mathbf{y}_{i}$ da função escore calculada a partir de $f$, a função de estimação $\mathbf{g}^{*}=\sum_{i=1}^{N} \phi_{i}$ é ótima.

O teorema a seguir (Jørgensen e Laboriau, 1994) estabelece condições para a normalidade assintótica de estimadores obtidos de funções de estimação regulares.

Teorema 1 Seja $\mathbf{g}(\mathbf{y}, \boldsymbol{\theta})$ uma função de estimação regular. Seja $\hat{\boldsymbol{\theta}}$ um estimador de $\boldsymbol{\theta}$ obtido de $\mathbf{g}$. Sob condições de regularidade temos:

$$
\sqrt{N}(\hat{\boldsymbol{\theta}}-\boldsymbol{\theta}) \stackrel{D}{\longrightarrow} N_{p}\left(\mathbf{0}, \bar{J}_{g}^{-1}\right)
$$

em que

$$
\bar{J}_{g}=\lim _{N \rightarrow \infty} S_{N}^{\prime}(\boldsymbol{\theta}) V_{N}^{-1}(\boldsymbol{\theta}) S_{N}(\boldsymbol{\theta})
$$

com

$$
S_{N}(\boldsymbol{\theta})=\frac{1}{N} \sum_{i=1}^{N} S_{\boldsymbol{\phi}_{i}}(\boldsymbol{\theta}), \quad S_{\boldsymbol{\phi}_{i}}(\boldsymbol{\theta})=\xi_{f}\left(\frac{\partial \boldsymbol{\phi}_{i}\left(y_{i} ; \boldsymbol{\theta}\right)}{\partial \boldsymbol{\theta}^{\prime}}\right),
$$

e

$$
V_{N}(\boldsymbol{\theta})=\frac{1}{N} \sum_{i=1}^{N} V_{\boldsymbol{\phi}_{i}}(\boldsymbol{\theta}), \quad V_{\boldsymbol{\phi}_{i}}(\boldsymbol{\theta})=\xi_{f}\left(\boldsymbol{\phi}_{i}\left(y_{i} ; \boldsymbol{\theta}\right) \boldsymbol{\phi}_{i}^{\prime}\left(y_{i} ; \boldsymbol{\theta}\right)\right) .
$$

Em alguns casos onde não existe uma função de estimação ótima, podemos nos restringir a uma função linearmente ótima. Uma função de estimação $\mathbf{g}(\mathbf{y}, \boldsymbol{\theta})$ é dita linear em $\varphi_{1}, \ldots, \varphi_{N}$ se 


$$
\mathbf{g}(\mathbf{y}, \boldsymbol{\theta})=\sum_{i=1}^{N} A_{i}(\boldsymbol{\theta})\left\{\boldsymbol{\varphi}_{i}\left(y_{i}, \boldsymbol{\theta}\right)\right\}
$$

sendo $A_{i}(\boldsymbol{\theta})$ uma matriz não estocástica de posto completo e $\xi_{f}\left\{\boldsymbol{\varphi}_{i}\left(y_{i}, \boldsymbol{\theta}\right)\right\}=\mathbf{0}$. Como cada $\varphi_{i}$ tem média $\mathbf{0}$ temos que $\mathbf{g}$ satisfaz o critério de ser não viciada. A função de estimação regular $\mathbf{g}^{*}=\sum_{i=1}^{N} A_{i}^{*}(\boldsymbol{\theta})\left\{\boldsymbol{\varphi}_{i}\left(y_{i}, \boldsymbol{\theta}\right)\right\}$ é dita linearmente ótima (Crowder,1987) quando:

$$
A_{i}^{*}(\boldsymbol{\theta})=\xi_{f}\left\{\partial \boldsymbol{\varphi}_{i} / \partial \boldsymbol{\theta}^{\prime}\right\} \operatorname{Cov}^{-1}\left\{\boldsymbol{\varphi}_{i}\right\}
$$

Podemos denotar o produto $A_{i}^{*}(\boldsymbol{\theta}) \boldsymbol{\varphi}_{i}\left(y_{i}, \boldsymbol{\theta}\right)$ por $\boldsymbol{\phi}_{i}\left(y_{i}, \boldsymbol{\theta}\right)$. Quando $\mathbf{g}^{*}$ é ótima ou linearmente ótima, nós consideraremos $\boldsymbol{\theta}_{N}$, obtido de $\sum_{i=1}^{N}\left\{\boldsymbol{\phi}_{i}\left(y_{i}, \boldsymbol{\theta}_{N}\right)\right\}=\mathbf{0}$, como o estimador do parâmetro do modelo de superpopulação $\boldsymbol{\theta}$ baseado em $\mathbf{Y}$ quando assumimos todos os componentes de $\mathbf{Y}$ conhecidos. Caso contrário, $\boldsymbol{\theta}_{N}$, é dito um parâmetro populacional.

Por exemplo, suponha que a classe $C$ consiste de todas as distribuições $f$ para as quais:

(1) $y_{1}, \ldots, y_{N}$ são independentes;

(2) $\xi_{f}\left(y_{i}\right)=\theta$ para todo $i=1, \ldots, N$; e

(3) $\xi_{f}\left(y_{i}-\theta\right)^{2}$ é independente de $i$.

Nestas condições, segue que $g^{*}=\sum_{i=1}^{N} \phi_{i}$, onde $\phi_{i}=y_{i}-\theta \quad\left(\varphi_{i}=y_{i}-\right.$ $\theta$ e $A_{i}^{*}(\theta)=1$ ) é linearmente ótima. Assim, o estimador $\theta_{N}$ de $\theta$ baseado em $Y$ é a média populacional

$$
\theta_{N}=\left(\sum_{i=1}^{N} y_{i}\right) / N
$$

Seja agora $C=\{f\}$ um modelo de superpopulação tal que para cada $f \in$ $C, y_{1}, \ldots, y_{N}$ são independentes, $\xi_{f}\left(y_{i}\right)=\theta x_{i}$ e a variância de $y_{i} \propto \sigma_{i}^{2}$, onde $\sigma_{i}^{2}$ 
e $x_{i}$ são conhecidos para $i=1, \ldots, N$. Podemos interpretar $\theta$ como o coeficiente de regressão de $y$ por $x$ sob $f$. A função de estimação linearmente ótima é dada por (3.3) com $a_{i}^{*}$ obtido como em (3.4), ou seja, $\phi_{i}=\left(y_{i}-\theta x_{i}\right) x_{i} / \sigma_{i}^{2}$. Assim, o estimador

$$
\theta_{N}=\frac{\sum_{i=1}^{N}\left(y_{i} x_{i} / \sigma_{i}^{2}\right)}{\sum_{i=1}^{N}\left(x_{i}^{2} / \sigma_{i}^{2}\right)}
$$

é o estimador do parâmetro $\theta$ do modelo quando todos os $Y$ na população são conhecidos.

\subsection{Estimação simultânea dos parâmetros popula- cionais e dos parâmetros do modelo de super- população}

Vamos considerar agora o caso em que o vetor populacional Y é desconhecido. Uma amostra $s$ é então selecionada segundo um plano amostral $p(s)$. Os dados, quando a amostra $s$ é selecionada e os correspondentes valores de $\mathbf{y}$ são observados, serão denotados por :

$$
\chi_{s}=\left\{\left(i, y_{i}\right): i \in s\right\} .
$$

Seja $\boldsymbol{\theta}_{N}$ a solução de $\mathbf{g}^{*}=\mathbf{0}$ onde $\mathbf{g}^{*}$ é uma função de estimação ótima ou linearmente ótima de $\boldsymbol{\theta}$. Consideremos estimar $\boldsymbol{\theta}_{N}$ ( ou $\boldsymbol{\theta}$ ) resolvendo equações da forma $\mathbf{h}\left(\chi_{s}, \boldsymbol{\theta}\right)=\mathbf{0}$. Espera-se que a função $\mathbf{h}\left(\chi_{s}, \boldsymbol{\theta}\right)$ seja não viciada em relação ao plano amostral, ou seja, que

$$
E\left\{\mathbf{h}\left(\chi_{s}, \boldsymbol{\theta}\right)\right\}=\sum_{i=1}^{N} \boldsymbol{\phi}_{i}\left(y_{i}, \boldsymbol{\theta}\right)
$$

para cada vetor y e $\boldsymbol{\theta}$, com $E$ representando a esperança sob o plano $p(s)$. Se a probabilidade de inclusão da unidade i na amostra é dada por $\pi_{i}$, então a função

$$
\mathbf{h}\left(\chi_{s}, \boldsymbol{\theta}\right)=\sum_{i \in s} \frac{\boldsymbol{\phi}_{i}\left(y_{i}, \boldsymbol{\theta}\right)}{\pi_{i}}
$$


satisfaz (3.5).

A função $\mathbf{h}\left(\chi_{s}, \boldsymbol{\theta}\right)$ será uma função de estimação regular se satisfizer as condições da Definição 1 substituindo o operador $\xi_{f}$ por $\xi_{f} E$. Vale ressaltar que agora a informação de Godambe é dada por (3.1) considerando o operador $\xi_{f} E$.

Uma função de estimação regular $h^{*}$ é denominada ótima, no caso uniparamétrico, se minimiza a quantidade

$$
\xi_{f} E\left\{h^{2}\left(\chi_{s}, \theta\right)\right\} /\left(\xi_{f} E\left(\frac{\partial h\left(\chi_{s}, \theta\right)}{\partial \theta}\right)\right)^{2}
$$

entre todas as funções regulares $h$.

Teorema 2 Godambe e Thompson (1986). Suponha que sob o modelo de superpopulação, $\boldsymbol{\phi}_{i}\left(y_{i}, \boldsymbol{\theta}\right)$ são independentes e que $\xi_{f}\left\{\boldsymbol{\phi}_{i}\left(y_{i}, \boldsymbol{\theta}\right)\right\}=\mathbf{0}$ para todo $i=1, \ldots, N$. Considere funções de estimação h satisfazendo (3.5) para todo y e $\boldsymbol{\theta}$. Então a função de estimação regular ótima é dada por

$$
\mathbf{h}^{*}\left(\chi_{s}, \boldsymbol{\theta}\right)=\sum_{i \in s} \frac{\boldsymbol{\phi}_{i}\left(y_{i}, \boldsymbol{\theta}\right)}{\pi_{i}} .
$$

Teorema 3 J $\phi$ rgensen e Laboriau (1994). Seja $\mathbf{g}(\mathbf{y}, \boldsymbol{\theta})=\sum_{i \in s} \frac{\boldsymbol{\phi}_{i}\left(y_{i}, \boldsymbol{\theta}\right)}{\pi_{i}}$ uma função de estimação regular. Seja $\hat{\boldsymbol{\theta}}_{s}$ um estimador de $\boldsymbol{\theta}_{N}$ (ou de $\boldsymbol{\theta}$ ) obtido de $\mathbf{g}$. Sob condições de regularidade temos que $\hat{\boldsymbol{\theta}}_{s}$ converge em distribuição (para valores grandes de $n$ ) para uma distribuição normal com média $\boldsymbol{\theta}_{N}$ e variância $J_{g}^{-1}(\boldsymbol{\theta})$.

Consideremos, agora, o modelo de regressão linear simples $y_{i}=\beta x_{i}+\epsilon_{i}$ com variância $\sigma^{2}$ conhecida. Fazendo $\theta=\beta$, temos que $g^{*}=\sum_{i=1}^{N} \phi_{i}$ em que $\phi_{i}=$ $x_{i}\left(y_{i}-\theta x_{i}\right)\left(\varphi_{i}\left(y_{i}, \theta\right)=\left(y_{i}-\theta x_{i}\right)\right.$ e $\left.A_{i}^{*}(\theta)=x_{i}\right)$, é a função de estimação linearmente ótima. Nesse caso, o estimador $\theta_{N}$ de $\theta$ é

$$
\theta_{N}=\left(\sum_{i=1}^{N} x_{i} y_{i}\right) /\left(\sum_{i=1}^{N} x_{i}^{2}\right)
$$


Como $\theta_{N}$ só é calculável a menos que um censo seja realizado, temos que o estimador obtido da amostra $s$ é dado por

$$
\hat{\theta}_{s}=\frac{\sum_{i=1}^{n}\left(y_{i} x_{i} / \pi_{i}\right)}{\sum_{i=1}^{n}\left(x_{i}^{2} / \pi_{i}\right)} .
$$

A informação de Godambe de $\theta$ é dada por

$$
J_{g}(\theta)=\frac{\left(\sum_{i \in U} x_{i}^{2}\right)^{2}}{\sigma^{2} \sum_{i \in U} x_{i}^{2} / \pi_{i}} .
$$

Assim, o estimador da variância assintótica de $\hat{\theta}_{s}$ é dado por

$$
\hat{V}\left(\hat{\theta}_{s}\right)=\frac{\hat{\sigma}_{s}^{2} \sum_{i \in s} x_{i}^{2} / \pi_{i}^{2}}{\left(\sum_{i \in s} x_{i}^{2} / \pi_{i}\right)^{2}}
$$

sendo

$$
\hat{\sigma}_{s}^{2}=\frac{\sum_{i \in s}\left(y_{i}-\hat{\theta}_{s} x_{i}\right)^{2} / \pi_{i}}{\sum_{i \in s} 1 / \pi_{i}} .
$$

Substituindo $\phi_{i}$ pelo componente $\mathbf{u}_{i}$ da função escore associada a $f$ e $1 / \pi_{i}$ por $w_{i}$ na equação (3.8) temos que o estimador de $\boldsymbol{\theta}_{N}$ e, conseqüentemente de $\boldsymbol{\theta}$, obtido de

$$
\sum_{i \in s} w_{i} \mathbf{u}_{i}(\boldsymbol{\theta})=\mathbf{0}
$$

é denominado estimador de máxima pseudo-verossimilhança. O método da máxima pseudo-verossimilhança tem sido muito discutido em trabalhos como os de Silva (1996) ou Duarte (1999), por exemplo. A utilização de pesos em análise de regressão também foi apresentada por Pfeffermann (1993).

Vamos aplicar o procedimento de máxima pseudo-verossimilhança para o caso da regressão linear normal. Seja $\mathbf{Y}=X \boldsymbol{\beta}+\boldsymbol{\epsilon}$, o modelo de regressão que tem o objetivo de explicar os valores de uma variável de interesse Y, através da matriz de $p$ variáveis explicativas X. Para cada observação $i$ está associado um valor $y_{i}$ e um vetor $\mathbf{x}_{i}=\left(x_{i 1}, \ldots, x_{i p}\right)^{\prime}$. Suponha ainda, que os $Y_{i}$ são independentes, de modo que

$$
f\left(y_{i} \mid \mathbf{x}_{i}, \boldsymbol{\beta}, \sigma^{2}\right)=\frac{1}{\left(2 \pi \sigma^{2}\right)^{\frac{1}{2}}} \exp \left[-\frac{\left(y_{i}-\mathbf{x}_{i}^{\prime} \boldsymbol{\beta}\right)^{2}}{2 \sigma^{2}}\right],
$$


sendo $\boldsymbol{\beta}=\left(\beta_{1}, \ldots, \beta_{p}\right)^{\prime}$ um vetor de parâmetros e $\sigma^{2}>0$, ambos desconhecidos. A idéia é utilizar o procedimento de máxima pseudo-verossimilhança para a estimação de $\boldsymbol{\beta}$ e de $\sigma^{2}$. As funções escores para $\boldsymbol{\beta}$ e $\sigma^{2}$ são dadas por: $\mathbf{u}_{i} \boldsymbol{\beta}\left(\boldsymbol{\beta}, \sigma^{2}\right)=\frac{\partial \log [f]}{\partial \boldsymbol{\beta}}=$ $\mathbf{x}_{i}\left(y_{i}-\mathbf{x}_{i}^{\prime} \boldsymbol{\beta}\right) / \sigma^{2} \propto \mathbf{x}_{i}\left(y_{i}-\mathbf{x}_{i}^{\prime} \boldsymbol{\beta}\right)$ e $u_{i \sigma^{2}}\left(\boldsymbol{\beta}, \sigma^{2}\right)=\frac{\partial \log [f]}{\partial \sigma^{2}}=\left[\left(y_{i}-\mathbf{x}_{i}^{\prime} \boldsymbol{\beta}\right)^{2}-\sigma^{2}\right] / \sigma^{4} \propto\left(y_{i}-\right.$ $\left.\mathbf{x}_{i}^{\prime} \boldsymbol{\beta}\right)^{2}-\sigma^{2}$. Se um censo foi realizado, o estimador ótimo de $\boldsymbol{\beta}$ é $\boldsymbol{\beta}_{N}=\left(\mathbf{x}_{U}^{\prime} \mathbf{x}_{U}\right)^{-1} \mathbf{x}_{U}^{\prime} \mathbf{y}_{U}$ e o de $\sigma^{2}$ é $\sigma_{N}^{2}=N^{-1}\left(\mathbf{y}_{U}-\mathbf{x}_{U}^{\prime} \boldsymbol{\beta}_{N}\right)^{\prime}\left(\mathbf{y}_{U}-\mathbf{x}_{U}^{\prime} \boldsymbol{\beta}_{N}\right)$, sendo o índice $U$ apenas um indicador de que foram observados todos os elementos da população. No caso de termos uma amostra de tamanho $n$ precisamos calcular os pesos $w_{i}$ e encontrarmos as soluções das seguintes equações de máxima pseudo-verossimilhança:

$$
\sum_{i \in s} w_{i} \mathbf{u}_{i}\left(\hat{\boldsymbol{\beta}}_{s}, \hat{\sigma}_{s}^{2}\right)=\sum_{i \in s} w_{i} \mathbf{x}_{i}\left(y_{i}-\mathbf{x}_{i}^{\prime} \hat{\boldsymbol{\beta}}_{s}\right)=\mathbf{0}
$$

e

$$
\sum_{i \in s} w_{i} u_{i \sigma^{2}}\left(\hat{\boldsymbol{\beta}}_{s}, \hat{\sigma}_{s}^{2}\right)=\sum_{i \in s} w_{i}\left[\left(y_{i}-\mathbf{x}_{i}^{\prime} \hat{\boldsymbol{\beta}}_{s}\right)^{2}-\hat{\sigma}_{s}^{2}\right]=0 .
$$

Neste caso, as equações acima levam às seguintes soluções:

$$
\hat{\boldsymbol{\beta}}_{s}=\left(\mathbf{x}_{s}^{\prime} W_{s} \mathbf{x}_{s}\right)^{-1} \mathbf{x}_{s}^{\prime} W_{s} \mathbf{y}_{s}
$$

e

$$
\hat{\sigma}_{s}^{2}=\left(\mathbf{1}_{s}^{\prime} W_{s} \mathbf{1}_{s}\right)^{-1} \mathbf{y}_{s}^{\prime}\left[W_{s}-W_{s} \mathbf{x}_{s}\left(\mathbf{x}_{s}^{\prime} W_{s} \mathbf{x}_{s}\right)^{-1} \mathbf{x}_{s}^{\prime} W_{s}\right] \mathbf{y}_{s},
$$

sendo $W_{s}=\operatorname{diag}\left(w_{i 1}, \ldots, w_{i n}\right)$, uma matriz diagonal $n \times n$ contendo os pesos dos elementos da amostra na diagonal principal e o índice $s$, um indicador de que o cálculo está sendo realizado com base na amostra.

A matriz de informação de Godambe de $\boldsymbol{\beta}$ é dada por

$$
J_{g}(\boldsymbol{\beta})=\frac{1}{\sigma^{2}}\left(\mathbf{x}_{U}^{\prime} \mathbf{x}_{U}\right)\left(\mathbf{x}_{U}^{\prime} W_{U} \mathbf{x}_{U}\right)^{-1}\left(\mathbf{x}_{U}^{\prime} \mathbf{x}_{U}\right),
$$

sendo

$$
\hat{V}\left(\hat{\boldsymbol{\beta}}_{s}\right)=\hat{\sigma}_{s}^{2}\left(\mathbf{x}_{s}^{\prime} W_{s} \mathbf{x}_{s}\right)^{-1}\left(\mathbf{x}_{s}^{\prime} W_{s}^{2} \mathbf{x}_{s}\right)\left(\mathbf{x}_{s}^{\prime} W_{s} \mathbf{x}_{s}\right)^{-1}
$$

um estimador da matriz de covariância assintótica de $\hat{\boldsymbol{\beta}}_{s}$. 
O método de máxima pseudo-verosssimilhança pode ser aplicado a várias classes de modelos de regressão desde que se conheça o componente $\mathbf{u}_{i}(\boldsymbol{\theta})$ da função escore calculada a partir de $f$.

Uma alternativa para obter aproximações para a variância de estimadores obtidos a partir de (3.9) é o método de linearização de Taylor. Este método consiste em obter aproximações lineares para os estimadores de interesse por meio de expansões em série de Taylor, até primeira ordem, e a variância é obtida a partir da expansão encontrada para o estimador. Esse método está implementado na maioria dos programas que tratam da análise de dados provenientes de planos amostrais complexos, como foi discutido por Souza e Silva (2000) e Vieira (2001).

Em particular, para o modelo de regressão linear, Nascimento Silva (1996) apresenta uma expressão para a variância assintótica de $\hat{\beta}_{s}$ dada por:

$$
V\left(\hat{\boldsymbol{\beta}}_{s}\right)=\left(\mathbf{x}_{U}^{\prime} \mathbf{x}_{U}\right)^{-1} V_{p}\left(\sum_{i \in s} w_{i} \mathbf{x}_{i} \mathbf{e}_{i}\right)\left(\mathbf{x}_{U}^{\prime} \mathbf{x}_{U}\right)^{-1}
$$

sendo

$$
V_{p}\left(\sum_{i \in s} w_{i} \mathbf{x}_{i} \mathbf{e}_{i}\right)=\sum_{i \in U} \sum_{j \in U} \frac{\pi_{i j}-\pi_{i} \pi_{j}}{\pi_{i} \pi_{j}} \mathbf{e}_{i} \mathbf{x}_{i} \mathbf{x}_{j}^{\prime} \mathbf{e}_{j}
$$

e $\mathbf{e}_{i}=y_{i}-\mathbf{x}_{i}^{\prime} \boldsymbol{\beta}_{N}$ o vetor de resíduos.

O estimador de $V\left(\hat{\boldsymbol{\beta}}_{s}\right)$ assume a forma

$$
\hat{V}\left(\hat{\boldsymbol{\beta}}_{s}\right)=\left(\mathbf{x}_{s}^{\prime} W_{s} \mathbf{x}_{s}\right)^{-1} \hat{V}_{p}\left(\sum_{i \in s} w_{i} \mathbf{x}_{i} \hat{\mathbf{e}}_{i}\right)\left(\mathbf{x}_{s}^{\prime} W_{s} \mathbf{x}_{s}\right)^{-1}
$$

com

$$
\hat{V}_{p}\left(\sum_{i \in s} w_{i} \mathbf{x}_{i} \hat{\mathbf{e}}_{i}\right)=\sum_{i \in s} \sum_{j \in s}\left(\pi_{i}^{-1} \pi_{j}^{-1}-\pi_{i j}^{-1}\right) \hat{\mathbf{e}}_{i} \mathbf{x}_{i} \mathbf{x}_{j}^{\prime} \hat{\mathbf{e}}_{j}
$$

e $\hat{\mathbf{e}}_{i}=y_{i}-\mathbf{x}_{i}^{\prime} \hat{\boldsymbol{\beta}}_{s}$

Utilizaremos o programa SUDAAN e a linguagem $\mathrm{R}$ no Capítulo 6 para a análise de alguns conjuntos de dados. No caso da linguagem R, esta é a única opção para a estimação de variâncias. Já o SUDAAN, oferece, também, a opção de estimar 
a variância pelo método do conglomerado primário (Pessoa e Silva, 1998). O estimador de variância obtido por meio da matriz de informação de Godambe não está implementado em nenhum dos dois pacotes.

\subsection{Testes de hipóteses}

Do mesmo modo que o método de estimação dos parâmetros sofre adaptações para garantir que o plano amostral seja incorporado na análise, muitas vezes, é natural tentarmos adaptar os testes de hipóteses usuais como foi feito na derivação de estimadores de máxima pseudo-verossimilhaça. Nesta situação, é usual utilizarmos testes baseados na estatística de Wald, que mede a distância entre o estimador pontual e o valor hipotético do parâmetro numa métrica definida pela matriz de covariância do estimador. Com esta estatística, pesos e planos amostrais podem ser incorporados facilmente. Vamos apresentar esta estatística como foi apresentada em Pessoa e Nascimento e Silva (1998) e Chambers e Skinner (2003).

Em regressão, é comum estarmos interessados em testar a seguinte hipótese $H_{0}: C \boldsymbol{\beta}=\mathbf{c}$, sendo $\mathrm{C}$ uma matriz $r \times p$ de posto completo, $\boldsymbol{\beta}$ o vetor de parâmetros de interesse $p \times 1$ e $\mathbf{c}$ um vetor $r \times 1$.

A estatística de Wald para testar a hipótese nula $H_{0}$ é definida por

$$
\chi_{W}^{2}=[C \hat{\boldsymbol{\beta}}-\mathbf{c}]^{\prime}\left(C \hat{V}(\hat{\boldsymbol{\beta}}) C^{\prime}\right)^{-1}[C \hat{\boldsymbol{\beta}}-\mathbf{c}]
$$

onde o estimador $\hat{\boldsymbol{\beta}}$ é obtido pelo método de máxima pseudo-verossimilhança, discutido na Seção 3.3 e $\hat{V}(\hat{\boldsymbol{\beta}})$ é um estimador da variância de $\boldsymbol{\beta}$ obtido por algum dos métodos discutidos na Seção 3.3. Sob $H_{0}$, a estatística $\chi_{W}^{2}$ tem distribuição assintótica qui-quadrado com $r$ graus de liberdade $\left(\chi_{W}^{2}(r)\right)$, segundo Binder (1983).

Quando a variância é estimada pelo método do conglomerado primário, uma alternativa é aproximar $\chi_{W}^{2} / r$ pela distribuição F-Snedecor com $r$ graus de liberdade 
no numerador e $v$ graus de liberdade no denominador, sendo que $v=m-H$ é o número de unidades primárias de amostragem menos o número de estratos considerados no plano amostral para a seleção das unidades primárias de amostragem.

Um dos inconvenientes dos testes de Wald é que eles não são invariantes a transformações não-lineares de $\boldsymbol{\theta}$, como foi descrito por Rao e Thomas em Chambers e Skinner (2003). Além disso, temos que ajustar o modelo completo antes de testar $H_{0}$, o que pode ser uma desvantagem se o modelo possuir vários parâmetros. Rao, Scott e Skinner (1998) propuseram testes quase-escore para circundar os problemas associados ao teste de Wald. Estes testes propostos são invariantes a transformações não-lineares de $\boldsymbol{\theta}$ e precisamos apenas ajustar o modelo mais simples, ou seja, sob $H_{0}$, que representa um enorme ganho quando a dimenssão de $\boldsymbol{\theta}$ é grande.

Seja $\mathbf{T}(\boldsymbol{\beta})=\mathbf{T}\left(\boldsymbol{\beta}_{1}, \boldsymbol{\beta}_{2}\right)=\sum_{i \in s} w_{i} \mathbf{u}_{i}\left(\boldsymbol{\beta}_{1}, \boldsymbol{\beta}_{2}\right)$, sendo $\mathbf{u}_{i}\left(\boldsymbol{\beta}_{1}, \boldsymbol{\beta}_{2}\right)$ a função escore associada a $f$. Vamos particionar $\mathbf{T}(\boldsymbol{\beta})$ como $\mathbf{T}(\boldsymbol{\beta})=\left(\mathbf{T}_{1}\left(\boldsymbol{\beta}_{1}, \boldsymbol{\beta}_{2}\right), \mathbf{T}_{2}\left(\boldsymbol{\beta}_{1}, \boldsymbol{\beta}_{2}\right)\right)^{\prime}$ sendo $\mathbf{T}_{1}\left(\boldsymbol{\beta}_{1}, \boldsymbol{\beta}_{2}\right)=\sum_{i \in s} w_{i} \mathbf{u}_{i \boldsymbol{\beta}_{1}}\left(\boldsymbol{\beta}_{1}, \boldsymbol{\beta}_{2}\right)$ e $\mathbf{T}_{2}\left(\boldsymbol{\beta}_{1}, \boldsymbol{\beta}_{2}\right)=\sum_{i \in s} w_{i} \mathbf{u}_{i} \boldsymbol{\beta}_{2}\left(\boldsymbol{\beta}_{1}, \boldsymbol{\beta}_{2}\right)$ com $\mathbf{u}_{i \boldsymbol{\beta}_{1}}\left(\boldsymbol{\beta}_{1}, \boldsymbol{\beta}_{2}\right)=\frac{\partial \log [f]}{\partial \boldsymbol{\beta}_{1}}$ e $\mathbf{u}_{i \boldsymbol{\beta}_{2}}\left(\boldsymbol{\beta}_{1}, \boldsymbol{\beta}_{2}\right)=\frac{\partial \log [f]}{\partial \boldsymbol{\beta}_{2}}$. Vamos definir o escore de máxima pseudo verossimilhança $\hat{\boldsymbol{\beta}}=\left(\hat{\boldsymbol{\beta}}_{1}, \hat{\boldsymbol{\beta}}_{2}\right)$ como sendo a solução de $\mathbf{T}(\boldsymbol{\beta})=\mathbf{0}$ e o estimador de máxima pseudo verossimilhança de $\boldsymbol{\beta} \operatorname{sob} H_{0} \operatorname{como} \tilde{\boldsymbol{\beta}}=\left(\tilde{\boldsymbol{\beta}}_{1}, \mathbf{0}\right)$ em que $\tilde{\boldsymbol{\beta}}_{1}$ é a solução de $\mathbf{T}_{1}\left(\boldsymbol{\beta}_{1}, \mathbf{0}\right)=\mathbf{0}$. Definimos também $\tilde{\mathbf{T}}_{2}=\mathbf{T}_{2}\left(\tilde{\boldsymbol{\beta}}_{1}, \mathbf{0}\right)$. O teste quase-escore para testar $H_{0}: \boldsymbol{\beta}_{2}=\mathbf{0}$ baseia-se na estatística:

$$
\chi_{Q S}^{2}=\tilde{\mathbf{T}}_{2}^{\prime}\left[\tilde{V}\left(\hat{\boldsymbol{\beta}}_{2}\right)\right]^{-1} \tilde{\mathbf{T}}_{2}
$$

sendo $\tilde{V}\left(\hat{\boldsymbol{\beta}}_{2}\right)$ um estimador da matriz de covariâncias de $\boldsymbol{\beta}_{2}$ avaliado em $\tilde{\boldsymbol{\beta}}$.

A estatística $z=\hat{\beta}_{i} / \hat{V}\left(\hat{\beta}_{i}\right){ }^{1 / 2} i=1, \ldots, p$, é utilizada para verificar a significância marginal de um coeficiente de regressão e é obtida substituindo as estimativas do coeficiente de regressão e de sua variância que aparecem na expressão da estatística do teste pelos valores obtidos considerando o plano amostral utilizado. Esta estatística tem distribuição assintótica $N(0,1)$. 


\subsection{Seleção de modelos}

Na análise de regressão clássica, existem diversos procedimentos para seleção de modelos. Neter et al (1996) apresentam os métodos de seleção mais conhecidos, tais como: maior $R_{p}^{2}$, menor $s_{p}^{2}$, "foward", "backward", "stepwise". Os pacotes e linguagens computacionais que analisam dados provenientes de planos amostrais complexos ainda não têm implementado rotinas para seleção de modelos. No Capítulo 6 deste trabalho, adaptamos os métodos "forward" e "backward" da regressão clássica, utilizando a estatística de Wald. Há ainda o método do $R^{2}$ corrigido por pesos que seria um outro critério para a exclusão ordenada de efeitos, segundo Shah et al (1993). 


\section{CaPítulo 4}

\section{Efeito do plano amostral}

Neste capítulo, vamos tratar de uma medida proposta por Kish (1965) para avaliar o efeito de um plano amostral (EPA) sobre a variância de um estimador $\hat{\theta}$. Chamamos de $\hat{\theta}$ o estimador obtido de um plano amostral qualquer e $\hat{\theta}_{A A S}$ o estimador obtido por amostragem aleatória simples. O objetivo do EPA de Kish é comparar planos amostrais alternativos ANTES de selecionar a amostra. Seja $V_{V E R D}(\hat{\theta})$ a variância do estimador $\hat{\theta}$ induzida pelo plano amostral verdadeiramente utilizado

e $V_{A A S}\left(\hat{\theta}_{A A S}\right)$ a variância do estimador $\hat{\theta}_{A A S}$ induzida pelo plano de amostragem aleatória simples. O $E P A_{K i s h}$ é dado por

$$
E P A_{K i s h}(\hat{\theta})=\frac{V_{V E R D}(\hat{\theta})}{V_{A A S}\left(\hat{\theta}_{A A S}\right)} .
$$

A grande vantagem da utilização do EPA de Kish é que ele serve para comparar estratégias amostrais (combinações de plano amostral + estimador) ANTES de selecionar a amostra da pesquisa. A grande desvantagem da utilização do EPA de Kish é que ele não serve para uso analítico dos dados, já que para o uso analítico precisamos de uma amostra já selecionada.

Devido às desvantagens desta medida, Skinner, Holt e Smith (1989) propuseram o Efeito de Plano Amostral Ampliado. A idéia é propor uma medida que avalie se o afastamento entre o estimador usual de variância e a variância verdadeira é grande ou pequeno. A expressão deste EPA é dada por 


$$
\operatorname{EPA}\left(\hat{\theta}, \nu_{0}\right)=\frac{V_{V E R D}(\hat{\theta})}{E_{V E R D}\left(\nu_{0}\right)},
$$

sendo $\nu_{0}=\hat{V}_{A A S}\left(\hat{\theta}_{A A S}\right)$ um estimador consistente de $V_{A A S}\left(\hat{\theta}_{A A S}\right)$.

A interpretação deste EPA é que o $E P A\left(\hat{\theta}, \nu_{0}\right)$ mede a tendência de $\nu_{0}$ a subestimar ou superestimar $V_{V E R D}(\hat{\theta})$. Quanto mais afastado de 1 for o valor de $\operatorname{EP} A\left(\hat{\theta}, \nu_{0}\right)$, mais incorreto se torna ignorar o plano amostral.

Alguns pontos importantes que devem ser destacados é que ignorar conglomeração em $\nu_{0}$ pode inflacionar o EPA e que ignorar estratificação em $\nu_{0}$ pode reduzir o EPA. Além disso, combinações de esquemas amostrais produzem efeitos difíceis de previsão. Uma recomendação que se faz é ao menos estimar o EPA antes de concluir a análise padrão.

\subsection{Exemplo do cálculo do EPA}

O exemplo considerado foi retirado de Skinner, Holt e Smith(1989). Considere uma população formada por conglomerados de tamanho 2, isto é, pares de unidades. Exemplos de populações com essa estrutura incluem casais, gêmeos, observações emparelhadas (antes e depois) da aplicação de um tratamento, etc. Seja y uma variável de pesquisa tal que

$$
E_{M}(y)=\theta, \quad V_{M}(y)=\sigma^{2} \quad \text { e } \quad \operatorname{COR} R_{M}\left(y_{1}, y_{2}\right)=\rho
$$

A esperança, variância e correlação da variável aleatória y se referem a propriedades de um modelo $M$ especificado através das equações acima, e que supõe ainda que as observações de pares distintos são independentes. Suponha que um par é escolhido ao acaso da população e os valores $\left(y_{1}, y_{2}\right)$ da variável de pesquisa y são observados para os indivíduos nesse par, com o objetivo de fazer inferência sobre $\theta$. 
Neste exemplo o interesse é examinar o efeito de ignorar a estrutura conglomerada da população na análise dos dados. Portanto, vamos considerar o procedimento de inferência usual para $\theta$ supondo que as observações da amostra foram seleciondas por AAS. Um estimador não viciado para $\theta$ é dado por

$$
\hat{\theta}=\hat{\theta}_{A A S}=\frac{y_{1}+y_{2}}{2}
$$

A variância de $\hat{\theta}$ é dada por

$$
V_{A A S}(\hat{\theta})=\frac{\sigma^{2}}{2}
$$

e um estimador não viciado dessa variância é dado por

$$
\hat{V}_{A A S}(\hat{\theta})=\frac{\left(y_{1}-y_{2}\right)^{2}}{4}=v_{0}
$$

Analisando o modelo sob o plano amostral conglomerado o estimador $\hat{\theta}=\frac{y_{1}+y_{2}}{2}$ é também não viciado para $\theta$. No entanto, sua variância é dada por

$$
V_{V E R D}(\hat{\theta})=\frac{\sigma^{2}(1+\rho)}{2},
$$

pois $V_{V E R D}\left(\left(y_{1}+y_{2}\right) / 2\right)=\frac{1}{4}\left(V_{M}\left(y_{1}\right)+V_{M}\left(y_{2}\right)+2 \operatorname{Cov}_{M}\left(y_{1}, y_{2}\right)\right)=\frac{1}{4}\left(2 \sigma^{2}+2 \sigma^{2} \rho\right)=\frac{\sigma^{2}}{2}(1+$ $\rho)$.

Sob o plano conglomerado, o valor esperado do estimador simples da variância é dado por

$$
E_{V E R D}\left(\nu_{0}\right)=\frac{\sigma^{2}(1-\rho)}{2}
$$

pois $\frac{1}{4} E_{M}\left(y_{1}-y_{2}\right)^{2}=\frac{1}{4} V_{M}\left(y_{1}-y_{2}\right)=\frac{1}{4}\left(V_{M}\left(y_{1}\right)+V_{M}\left(y_{2}\right)-2 \operatorname{Cov}_{M}\left(y_{1}, y_{2}\right)\right)=\frac{1}{4}\left(2 \sigma^{2}-\right.$ $\left.2 \sigma^{2} \rho\right)=\frac{\sigma^{2}}{2}(1-\rho)$.

O cálculo dos EPA's nos mostra que

$$
\begin{gathered}
E P A_{K i s h}(\hat{\theta})=\frac{\frac{\sigma^{2}(1+\rho)}{2}}{\frac{\sigma^{2}}{2}}=1+\rho \quad e \\
\operatorname{EPA}\left(\hat{\theta}, \nu_{0}\right)=\frac{\frac{\sigma^{2}(1+\rho)}{2}}{\frac{\sigma^{2}(1-\rho)}{2}}=\frac{1+\rho}{1-\rho},
\end{gathered}
$$


portanto, o efeito da especificação incorreta do modelo (ou do plano amostral) pode ser severo, em alguns casos. Neste exemplo, pode-se perceber que o valor do EPA de Kish é menor que o valor do EPA ampliado. Além disso, o impacto de usar o estimador de variância supondo que as observações foram seleciondas por AAS cresce com $\rho$. Podemos, ainda, fazer as seguintes comparações:

(i) O EPA de Kish mede o efeito de plano amostral sobre a variância de um estimador. A idéia é comparar a precisão do estimador sob planos amostrais alternativos (geralmente um plano "complexo"versus AAS) ; e

(ii) O EPA ampliado mede o efeito de ignorar o plano amostral no estimador da variância usado para medir a precisão do estimador, após selecionada a amostra. 
CaPítulo 5

\section{Uso do computador na}

\section{incorporação do esquema amostral}

Neste capítulo pretendemos mostrar como utilizar algum pacote computacional ou linguagem de programação que traz consigo rotinas especiais para a incorporação do esquema amostral na análise de dados. Foram estudados o pacote SUDAAN e a biblioteca de análise de dados amostrais complexos "ADAC" que foi programada em linguagem R. Para tanto, utilizamos o manual do SUDAAN (Research Triangle Institute - 2001), o manual da biblioteca ADAC, disponível em seu "Help"e notas de aula do curso de análise de dados amostrais da Escola Nacional de Ciências Estatísticas do Instituto Brasileiro de Geografia e Estatística - 2003. A linguagem $\mathrm{R}$ possui algumas limitações, pois utiliza bastante memória e algumas rotinas da biblioteca ADAC não estão otimizadas, embora o uso do ambiente $\mathrm{R}$ possua a vantagem de ser gratuito. Já o SUDAAN, possui a vantagem de ser rápido, portável e aceitar operações de grande porte. Ambos possuem vantagens e desvantagens que serão apresentadas ao longo do capítulo. 


\subsection{O pacote SUDAAN}

A versão 8.0.1 do SUDAAN (SUrvey DAta ANalysis) está disponível para ambientes WINDOWS, MVS e UNIX. É um pacote que consiste de uma família de procedimentos usados para a análise de dados provenientes de pesquisas amostrais complexas, ou outros estudos experimentais ou observacionais que envolvam dados correlacionados.

Sua grande vantagem é a possibilidade de realizar operações de grande porte, além de suportar arquivos com formato SAS, SPSS e ASCII. Existe ainda uma versão que está integrada à versão 8.1 do SAS (Versão $S A S$-callable). Outra vantagem é que as instruções dadas ao programa podem ser salvas para seu uso posterior. Está estruturado em procedimentos. Foi programado para ser usado como o SAS, no que se refere a chamada dos procedimentos.

Suas principais desvantagens são: não possuir facilidades para a construção de gráficos, uma "Ajuda" muito resumida e saídas não tão fáceis de serem utilizadas. Uma idéia seria salvá-las como texto, por exemplo, para que possam ser utilizadas posteriormente.

\subsubsection{Fundamentos básicos}

Os principais procedimentos são:

\section{Medidas Descritivas}

(i) DESCRIPT permite estimar médias, totais, proporções, percentis etc;

(ii) RATIO estima razões; e

(iii) CROSSTAB usado para a construção de tabelas de contigência e análise de variáveis categorizadas.

\section{Modelagem}


(i) REGRESS é usado para análise de regressão linear simples ou múltipla e/ou regressão linear em dados com medidas repetidas;

(ii) LOGISTIC é usado para ajustar modelos de regressão logística;

(iii) SURVIVAL é usado para o ajuste de modelos discretos ou contínuos de riscos proporcionais;

(iv) MULTILOG para modelos de regressão multinomial logística; e

(v) LOGLINK é usado no ajuste de modelos de regressão para dados de contagem com ligação log-linear.

O SUDAAN não diferencia letras maiúsculas de letras minúsculas e os espaços entre os comandos não são necessários. Entre palavras, mais de um espaço é considerado um apenas. Há ainda a possibilidade de se colocar dois ou mais comandos na mesma linha, ou continuar um comando em várias linhas. Os comandos no SUDAAN devem começar com o nome do comando e terminar com um ponto e vírgula. Existem caracteres que são considerados símbolos especiais para o SUDAAN, por exemplo:

; usado para terminar comandos;

/ usada para separar o comando de suas opções;

. separador de extensões nos nomes dos arquivos;

= usado para dar valor a parâmetros dos comandos;

- usado para abreviar listas de variáveis. Exemplo: $x_{1}-x_{n}$, representa $x_{1}, \ldots, x_{n}$;

- - usado para abreviar listas de variáveis que não possuem o mesmo nome. Exemplo: $z_{1}-x_{n}$, representa as variáveis que vão de $z_{1}$ até $x_{n}$ na ordem em que aparecem no arquivo de dados;

* usado para indicar cruzamento de variáveis em tabelas ou efeitos de interação;

" "usadas em texto de rótulos ou nomes de arquivos; 
() usados para agrupar nomes de variáveis num comando TABLE ou MODEL. Por exemplo, "table idade*(sexo raça)" fornecerá duas tabelas de dupla entrada: uma de idade versus sexo e outra de idade versus raça. Ou ainda "model renda = idade sexo instrução idade*(sexo instrução)"é equivalente a "model renda = idade sexo instrução idade*sexo idade*instrução".

Além disso, alguns caracteres serão utilizados neste texto com significados especiais:

| operador lógico usado para indicar possíveis opções de um determinado comando;

$<>$ descrição das opções de um comando; e

[ ] indica um comando opcional.

Além disso, textos estão limitados a 254 caracteres quando forem utilizados dentro dos comandos TITLE, FOOTNOTE ou como rótulo de varíavel no comando PRINT. Para construirmos comentários colocamos o texto do comentário entre / * $* /$.

\subsubsection{Estrutura de um programa}

Os programas do SUDAAN apresentam a seguinte estrutura básica:

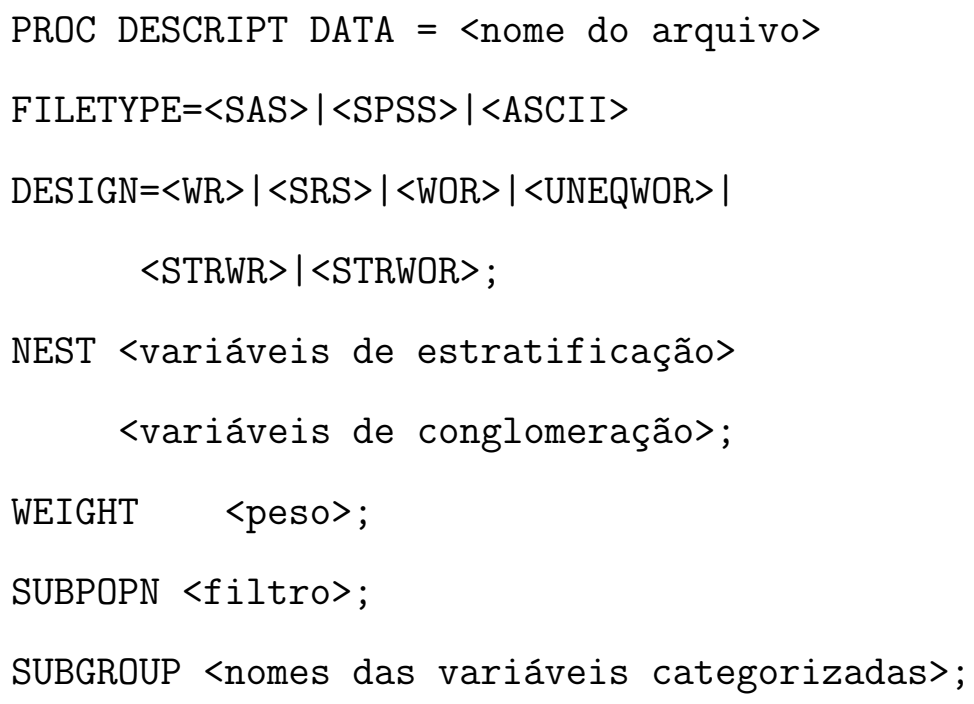




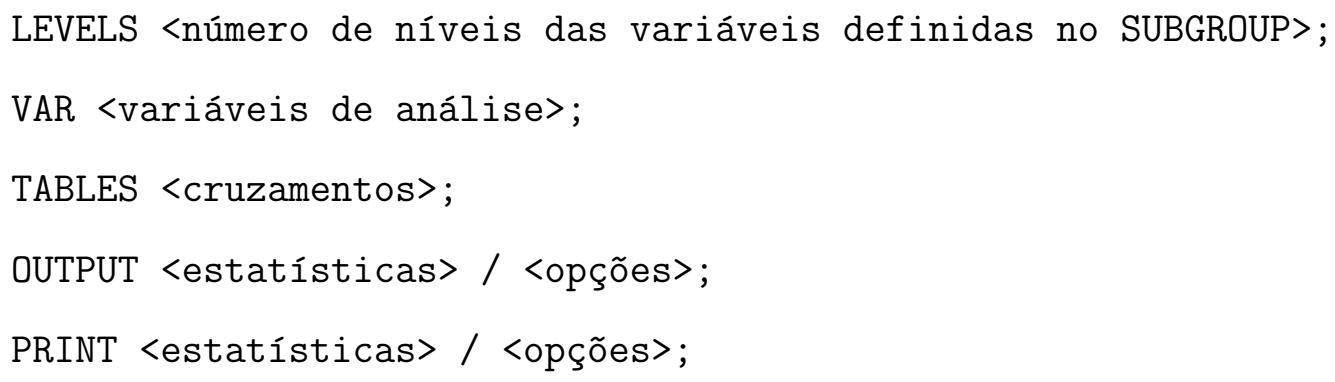

Em geral, nem todos estes comandos aparecem num procedimento. Existem procedimentos que exigem comandos específicos. Na versão SAS-callable, os procedimentos rodam dentro do ambiente de trabalho do SAS e, portanto, é imprescindível o uso do comando RUN no final do procedimento. O comando SUBPOPN é utilizado quando queremos identificar um subgrupo de registros para a análise. Por exemplo, "subpopn raça=2 \& sexo=2" filtrará o conjunto de dados e fará análises apenas para o subgrupo correspondente a raça 2 e sexo 2. Do mesmo modo, quando existem variáveis categorizadas estas devem ser especificadas no comando SUBGROUP e seus respectivos níveis no comando LEVELS. Observe que estes dois comandos podem não existir se não houverem variáveis categorizadas. Exemplo:

SUBGROUP sexo raça;

LEVELS 2 4;

As opções de esquema amostral são fornecidas no comando DESIGN. As opções SRS, STRWR e STRWOR são utilizadas para amostragem em um único estágio. Por outro lado, as opções WR, WOR e UNEQWOR são usadas em amostragem em mais de um estágio.

O uso da opção $S R S$ não requer nenhum outro comando de esquema amostral, pois considera a amostra aleatória simples. Portanto, seu uso implica:

(i) um esquema amostral em um único estágio (sem conglomeração ou estratificação); 
(ii) amostragem aleatória simples; e

(iii) que pequenas frações amostrais foram usadas, ou seja, não são necessárias correções para população finita.

O uso da opção $S T R W R$ requer o uso dos comandos WEIGHT, NEST. Seu uso implica:

(i) que há um único estágio (sem conglomeração);

(ii) amostragem estratificada aleatória com reposição (ou amostragem estratificada aleatória sem reposição, mas pequenas frações amostrais foram selecionadas dentro de cada estrato); e

(iii) probabilidades de seleção iguais ou desiguais dentro de cada estrato.

O uso da opção STRWOR requer o uso dos comandos WEIGHT, NEST e TOTCNT. Sua utilização implica:

(i) um único estágio de amostragem (sem conglomeração);

(ii) amostragem estratificada aleatória sem reposição (ou que frações amostrais não desprezíveis foram usadas em pelo menos um estrato); e

(iii) probabilidades de seleção iguais ou desiguais dentro de cada estrato.

O uso da opção $W R$ requer o uso dos comandos WEIGHT, NEST. Seu uso implica:

(i) amostragem com reposição no primeiro estágio (ou amostragem sem reposição, mas com pequenas frações amostrais usadas no primeiro estágio);

(ii) que há amostragem com ou sem reposição em cada estágio subseqüente; e

(iii) probabilidades de seleção iguais ou desiguais em todos os estágios. 
O uso da opção WOR requer o uso dos comandos WEIGHT, NEST e TOTCNT. Seu uso implica:

(i) amostragem aleatória simples sem reposição no primeiro estágio (ou que grandes frações amostrais foram usadas no primeiro estágio);

(ii) amostragem com ou sem reposição em cada estágio subseqüente; e

(iii) amostragem com probabilidades de seleção iguais ou desiguais em todos os estágios.

Por último, o uso da opção $U N E Q W O R$ requer o uso dos comandos WEIGHT, NEST e TOTCNT e JOINTPROB implicando em:

(i) amostragem sem reposição com probabilidades desiguais de seleção no primeiro estágio; e

(ii) amostragem com probabilidades de seleção iguais em estágios subseqüentes, com ou sem reposição.

A fração amostral à qual nos referimos acima é encontrada contando-se o número de unidades primárias de amostragem (UPA's) e dividindo-se pelo total de unidades primárias no estrato será considerada pequena quando for no máximo igual a dez por cento. Nas opções STRWOR, WOR e UNEQWOR é necessário que seja informado o número de unidades primárias de amostragem em cada estágio de amostragem através do comando TOTCNT. As opções STRWOR e STRWR necessitam que sejam informadas as variáveis de estratificação no comando NEST. Já as opções WR, WOR e UNEQWOR necessitam que sejam informadas as variáveis de estratificação e/ou conglomeração no comando NEST. A opção UNEQWOR também necessita que sejam informadas as probabilidades de inclusão simples e conjuntas para cada unidade primária de amostragem no primeiro estágio de amostragem através 
do comando JOINTPROB. Com exceção da opção $S R S$, o comando WEIGHT deve ser sempre informado, pois ele traz os pesos de cada observação com base na probabilidade de inclusão de cada unidade na amostra.

A Figura 5.1 pode ser útil para facilitar a escolha da opção de esquema amostral entre as seis principais que estão disponíveis no SUDAAN.

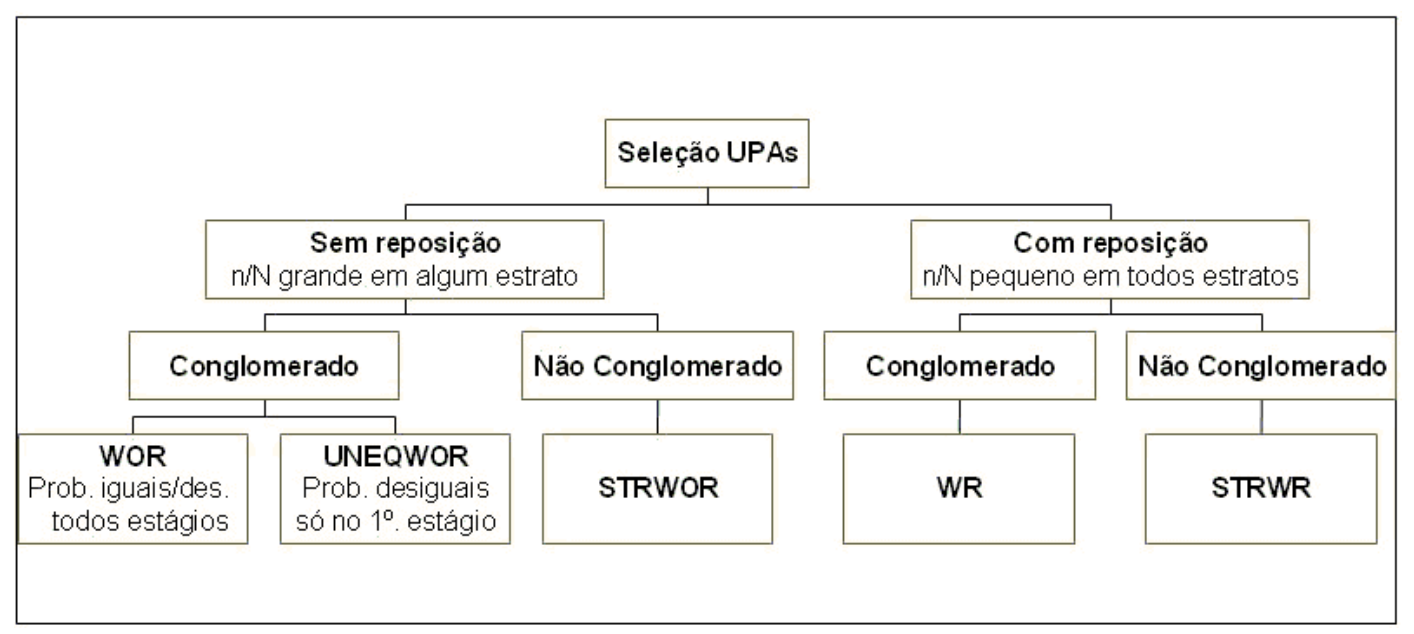

Figura 5.1: Seleção do plano amostral

No Brasil temos vários exemplos de pesquisas em que a opção WR é necessária. São elas: a Pesquisa Nacional por Amostra de Domicílio (PNAD), a Pesquisa de Padrões de Vida (PPV), etc. Vamos dar alguns exemplos que foram adaptados de Research Triangle Institute (2001). No primeiro exemplo, vamos considerar que uma amostragem em mais de um estágio e sem reposição (WOR) foi realizada, de modo que uma população foi estratificada por regiões e de cada região foram selecionados alguns estados. De cada estado foram selecionados domicílios e, por fim, dos domicílios foram selecionadas pessoas. Neste caso, devemos especificar as variáveis de estratificação e as unidades de amostragem em cada estágio da amostragem sem reposição. Por exemplo, se as variáveis REGIAO, ESTADO e DOM identificam estratificação, unidades primárias de amostragem (estados), e domicílios selecionados, 
nesta ordem, então, devemos informar o SUDAAN da seguinte maneira: ${ }^{1}$

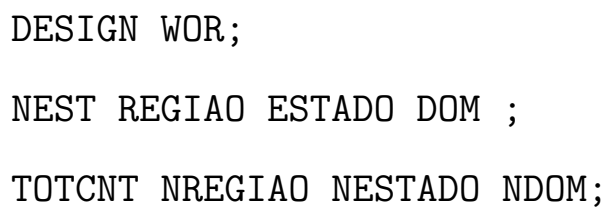

sendo que NREGIAO, NESTADO e NDOM indicam, respectivamente, o número de estados da região, o número de domicílios do estado selecionado e o número de pessoas do domicílio selecionado. Neste exemplo o conjunto de dados deveria conter uma linha por pessoa selecionada. Este conjunto de dados deveria ser, por exemplo, igual ao apresentado na Tabela 5.1:

As onze primeiras colunas da Tabela 5.1 são indicadoras do plano amostral, nesta ordem: a primeira identifica a região, a segunda e a terceira identificam o estado, as oito colunas seguintes funcionam como uma numeração para os domicílios selecionados (poderiam ser vistas como uma única coluna). A décima segunda coluna traz o total de estados dentro de cada região, a próxima o total de domicílios dentro de cada estado e, por fim, a décima quarta o número de pessoas selecionadas por domicílio.

Um outro exemplo seria estratificar um estado brasileiro em regiões e de cada região selecionar uma amostra de escolas com reposição, seguida de uma amostra de estudantes dentro de cada escola selecionada. Deveríamos passar as seguintes informações para o SUDAAN:

\section{DESIGN WR;}

\section{NEST REGIAO ESCOLAS;}

sendo que o arquivo de dados deveria conter em cada linha as informações referentes a cada estudante selecionado. Nestes dois exemplos fica claro que o estágio final de

\footnotetext{
${ }^{1}$ Foi colocado ";" após DESIGN, pois estamos considerando que esta é a última opção utilizada no procedimento
} 
Tabela 5.1: Fragmento de um conjunto de dados

\begin{tabular}{cccccccccccccc}
\hline \hline Região & \multicolumn{1}{c}{ Estado } & \multicolumn{1}{c}{ Domicílio } & & & Totest & Totdom & Totpes \\
\hline 4 & 0 & 1 & 1 & 1 & 1 & 2 & 0 & 1 & 0 & 0 & 7 & 45 & 1 \\
4 & 0 & 5 & 1 & 1 & 1 & 2 & 0 & 1 & 9 & 9 & 7 & 125 & 2 \\
4 & 0 & 5 & 1 & 1 & 1 & 2 & 0 & 1 & 9 & 9 & 7 & 125 & 2 \\
4 & 0 & 5 & 1 & 1 & 1 & 2 & 0 & 7 & 8 & 3 & 7 & 21 & 2 \\
4 & 0 & 5 & 1 & 1 & 1 & 2 & 0 & 7 & 8 & 3 & 7 & 21 & 2 \\
5 & 0 & 1 & 1 & 1 & 1 & 2 & 1 & 2 & 9 & 8 & 6 & 158 & 2 \\
5 & 0 & 1 & 1 & 1 & 1 & 2 & 1 & 2 & 9 & 8 & 6 & 158 & 2 \\
5 & 0 & 1 & 1 & 1 & 0 & 6 & 0 & 4 & 9 & 6 & 6 & 65 & 2 \\
5 & 0 & 1 & 1 & 1 & 0 & 6 & 0 & 4 & 9 & 6 & 6 & 65 & 2 \\
6 & 0 & 6 & 1 & 1 & 0 & 6 & 0 & 7 & 9 & 8 & 9 & 145 & 2 \\
6 & 0 & 6 & 1 & 1 & 0 & 6 & 0 & 7 & 9 & 8 & 9 & 145 & 2 \\
6 & 0 & 8 & 1 & 1 & 0 & 6 & 0 & 7 & 8 & 9 & 9 & 148 & 2 \\
6 & 0 & 8 & 1 & 1 & 0 & 6 & 0 & 7 & 8 & 9 & 9 & 148 & 2 \\
\hline \hline
\end{tabular}

amostragem não necessita ser especificado no comando NEST.

Suponha que uma população foi estratificada por ESTADO e, por REGIAO dentro do ESTADO e, que uma amostra aleatória de ESCOLAS foi selecionada, ou seja, as duas primeiras variáveis são de estratificação e ESCOLAS é a unidade primária de amostragem. Neste caso informamos o SUDAAN da seguinte maneira:

DESIGN WR;

NEST ESTADO REGIAO ESCOLAS / PSULEV = 3;

Do exemplo acima, notamos que podemos dar algumas instruções ao SUDAAN por meio de algumas opções do comando NEST. São elas: 
(i) FRL indica o primeiro nível de aleatorização;

(ii) MISSUNIT especifica que quando uma única unidade amostral é encontrada num estrato a contribuição de variabilidade desta unidade é estimada baseando-se na diferença entre o valor da unidade e a média de todos os valores da população;

(iii) NOSORTCK pede para que o SUDAAN não cheque se o arquivo foi ordenado pelas variáveis indicadas no comando NEST;

(iv) PSULEV especifica a posição da unidade primária de amostragem entre as variáveis especificadas no comando NEST; e

(v) STRLEV especifica a posição da variável de estrato entre as variáveis especificadas no comando NEST.

Algumas relações podem ser estruturadas entre as opções PSULEV, FRL e STRLEV. Por exemplo, se todas são omitidas, o SUDAAN assume que a primeira variável do comando NEST é uma variável de estratificação e a segunda identifica as unidades primárias de amostragem. Caso especifiquemos STRLEV e omitamos as outras duas opções, o SUDAAN considera que a variável seguinte à especificada pela opção STRLEV é a variável que contém as unidades primárias de amostragem. Por fim, se for incluso FRL ou PSULEV e STRLEV for omitida, o SUDAAN assume que a variável que antecede a que foi especificada pela opção FRL ou PSULEV, é uma variável de estratificação. Estas opções estão disponíveis para os desenhos WR e STRWR e seu uso não faz sentido para os esquemas WOR, STRWOR e UNEQWOR.

Suponha que uma amostra de alunos foi selecionada, de uma população estratificada por salas de aula e sexo. Portanto, trata-se de uma amostragem estratificada em um estágio. Informamos o SUDAAN da seguinte maneira:

DESIGN STRWOR;

NEST SALA SEXO; 
TOTCNT _ZERO_ NALUNO;

O uso da palavra-chave _ZERO_ no comando TOTCNT indica ao SUDAAN que a variável NALUNO é a contagem populacional de alunos dentro de cada sala por sexo, ou seja, o SUDAAN entende que SALA e SEXO são variáveis de estratificação que estão sendo combinadas.

Outra palavra-chave utilizada pelo SUDAAN é_MINUS1_, que indica amostragem com reposição. Quando utilizada, o SUDAAN entende que as unidades foram selecionadas com reposição naquele estágio e estágios subseqüentes. Por exemplo, suponha que o desenho WOR foi utilizado, pois uma grande fração amostral de unidades primárias de amostragem foi selecionada sem reposição (setores censitários) dentro de pelos menos um estrato no primeiro estágio. Suponha que as frações amostrais de domicílios selecionadas dentro de cada setor foram pequenas. A informação _MINUS1_ dentro do comando TOTCNT indica que os domicílios foram selecionados com reposição. Informamos o SUDAAN da seguinte maneira:

DESIGN WOR;

NEST ESTRATO SETOR DOMICILIO;

TOTCNT NSETOR_MINUS1__ZERO_;

Nos comandos NEST e TOTCNT deve ser especificado o mesmo número de variáveis.

\subsubsection{Tratamento padrão dos dados}

Os conjuntos de dados que são suportados pelo SUDAAN são aqueles com padrão SAS, SPSS e ASCII, de modo que o conjunto tenha uma forma retangular, ou seja, uma linha para cada unidade experimental. O conjunto de dados deve estar ordenado segundo as variáveis listadas no comando NEST. 
Além disso, todas as variáveis categóricas envolvidas na análise devem ser listadas no comando $S U B G R O U P$. Um ponto importante é que as variáveis devem ser todas do tipo numérico. Variáveis listadas no comando SUBGROUP precisam de uma codificação especial:

(i) são válidos apenas códigos para as categorias que vão de $1, \ldots, k$; e

(ii) valores $\leq 0$ ou $>k$ especificado, são tratados como "missing".

Desse modo devemos fazer recodificações nos valores de algumas variáveis. Por exemplo, para recodificar valores 0 e 1 para valores 1 e 2 antes de utilizar o comando SUBGROUP precisamos fazer: ${ }^{2}$

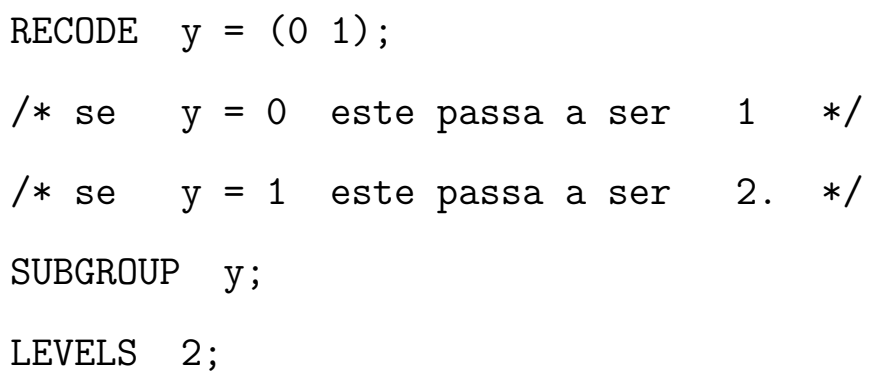

se os valores originais de uma variável "y", por exemplo, são 0,1 ou 2, podemos recodificá-los fazendo:

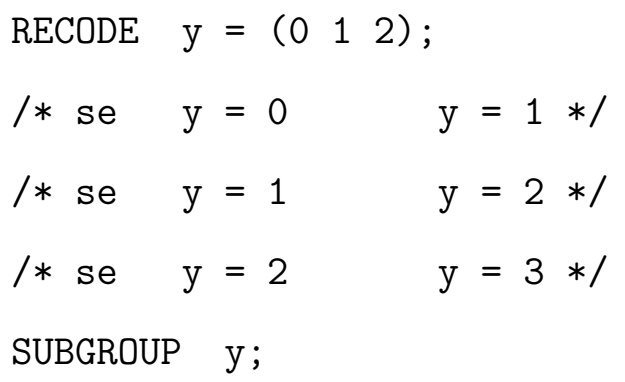

\footnotetext{
${ }^{2}$ As explicações entre comentários $/ * * /$ foram colocadas para indicar o que o comando RECODE está realizando.
} 
O comando RECODE pode ser usado em todos os procedimentos. Podemos ainda recodificar uma variável antes de utilizá-la como resposta em um modelo logístico. Note que, neste caso, é necessário o uso dos valores 1 indicando o sucesso e "0" que indicará o fracasso, por exemplo:

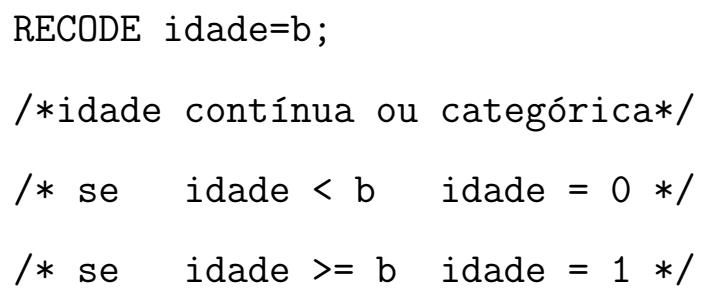

ou ainda, categorizar uma variável contínua, ou reduzir o número de categorias:

$$
\begin{aligned}
& \operatorname{RECODE} \mathrm{x}=\left(\begin{array}{lll}
\mathrm{a} 1 & \mathrm{a} 2 \ldots \mathrm{an}) ; & \\
\text { /* se } \mathrm{x}<\mathrm{a} 1 & \mathrm{x}=1 * / \\
\text { /* se } \mathrm{a} 1<=\mathrm{x}<\mathrm{a} 2 & \mathrm{x}=2 * / \\
\text { /* se } & \mathrm{a}(\mathrm{n}-1)<=\mathrm{x}<\text { an } & \mathrm{x}=\mathrm{n} * /
\end{array}\right.
\end{aligned}
$$

No comando WEIGHT o peso é o inverso da probabilidade de inclusão e deve ser fornecido no arquivo de dados.

\subsubsection{Alguns exemplos de programas no SUDAAN}

Os exemplos que apresentaremos aqui são estruturas de alguns procedimentos do SUDAAN, explicitando quais os comandos necessários para cada um deles.

(i) PROC RATIO

PROC RATIO

DATA $=\langle$ nome do arquivo $>$

FILETYPE $=\langle$ SAS $\rangle \mid\langle$ SPSS $\rangle \mid\langle$ ASCII $\rangle$

DESIGN $=\langle$ WR $\rangle \mid\langle$ SRS $\rangle \mid<$ WOR $\rangle \mid\langle$ UNEQWOR $\rangle \mid$ 


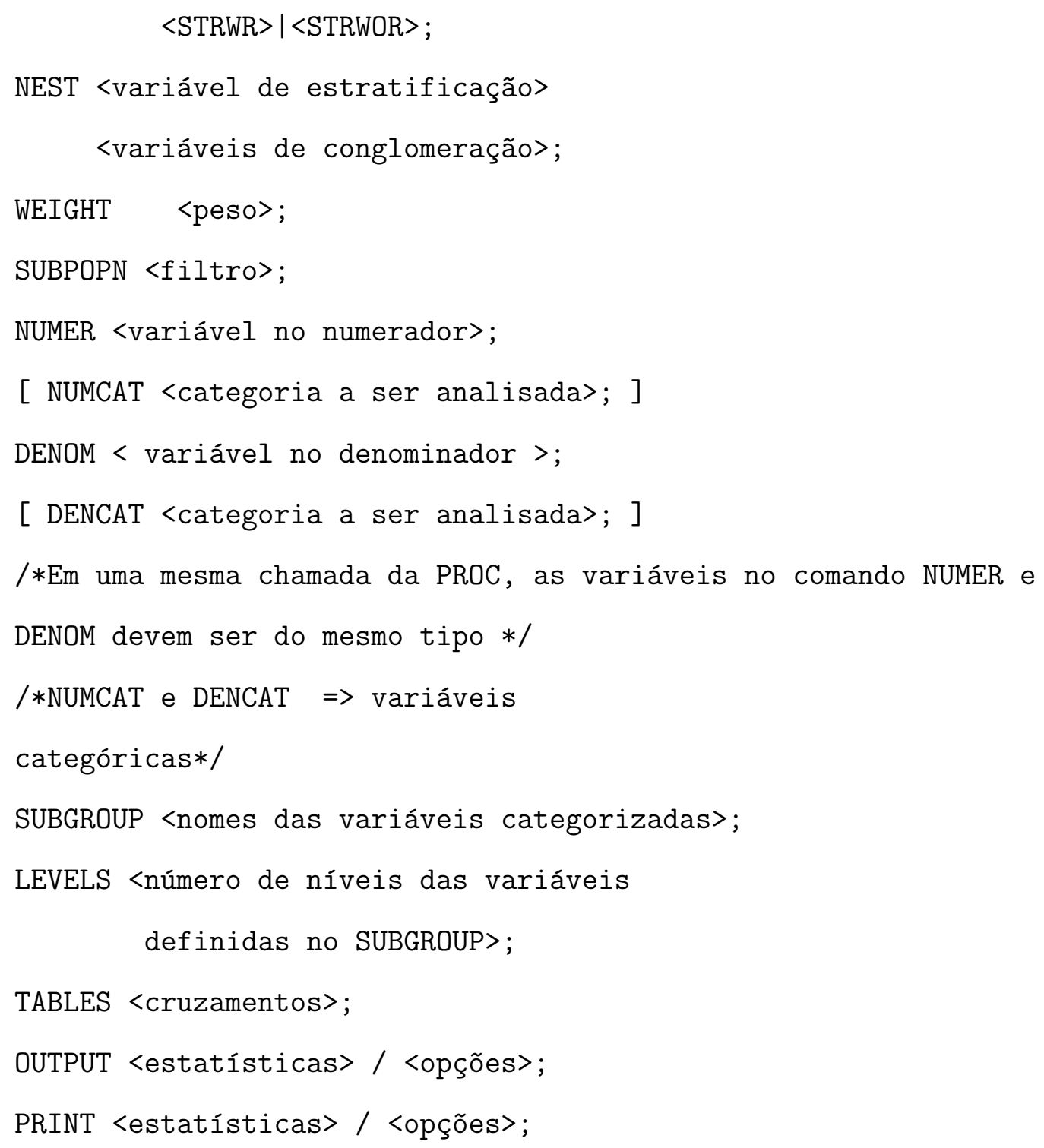

(ii) PROC CROSSTAB

PROC CROSSTAB

DATA $=\langle$ nome do arquivo $\rangle$

FILETYPE $=\langle$ SAS $\rangle \mid\langle$ SPSS $\rangle \mid\langle$ ASCII $\rangle$

DESIGN $=\langle\langle$ WR $>|<$ SRS $>|<W O R>|<$ UNEQWOR $>|$

$<$ STRWR $>\mid<$ STRWOR $>$;

NEST <variável de estratificação> 


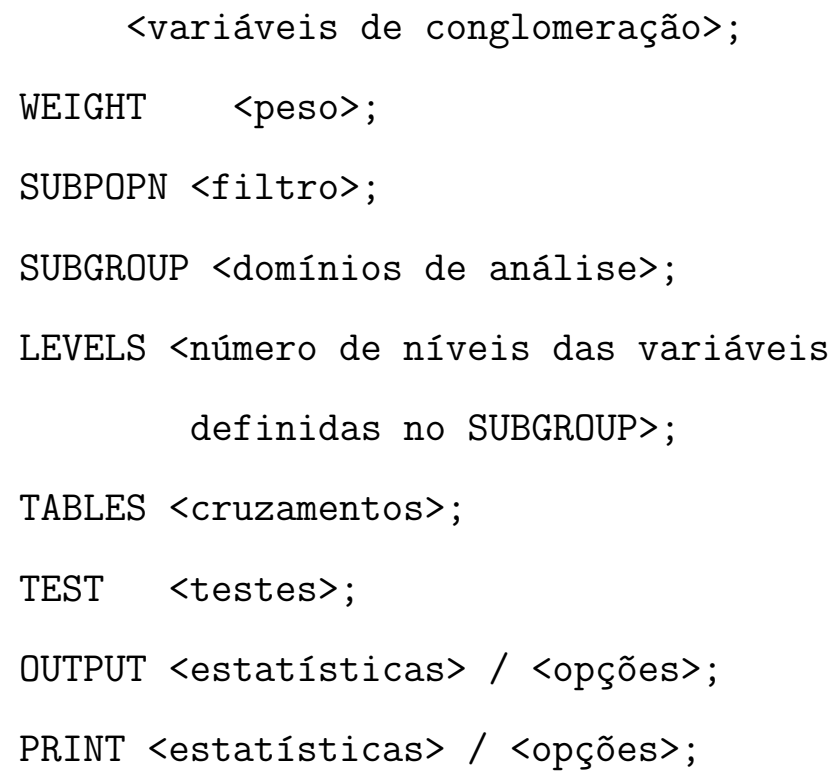

(iii) PROC REGRESS

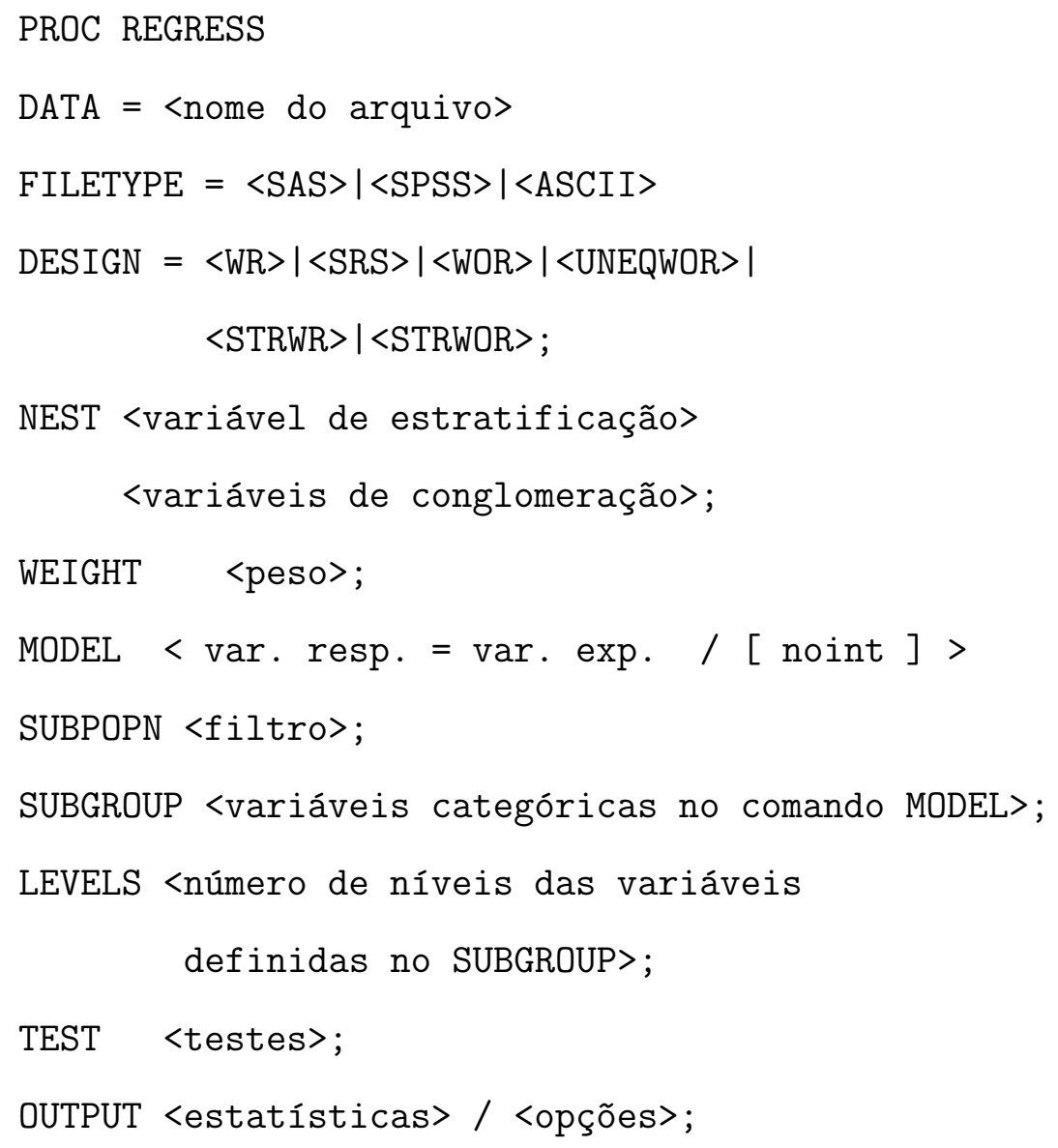


PRINT <estatísticas> / <opções>;

(iv) PROC LOGISTIC

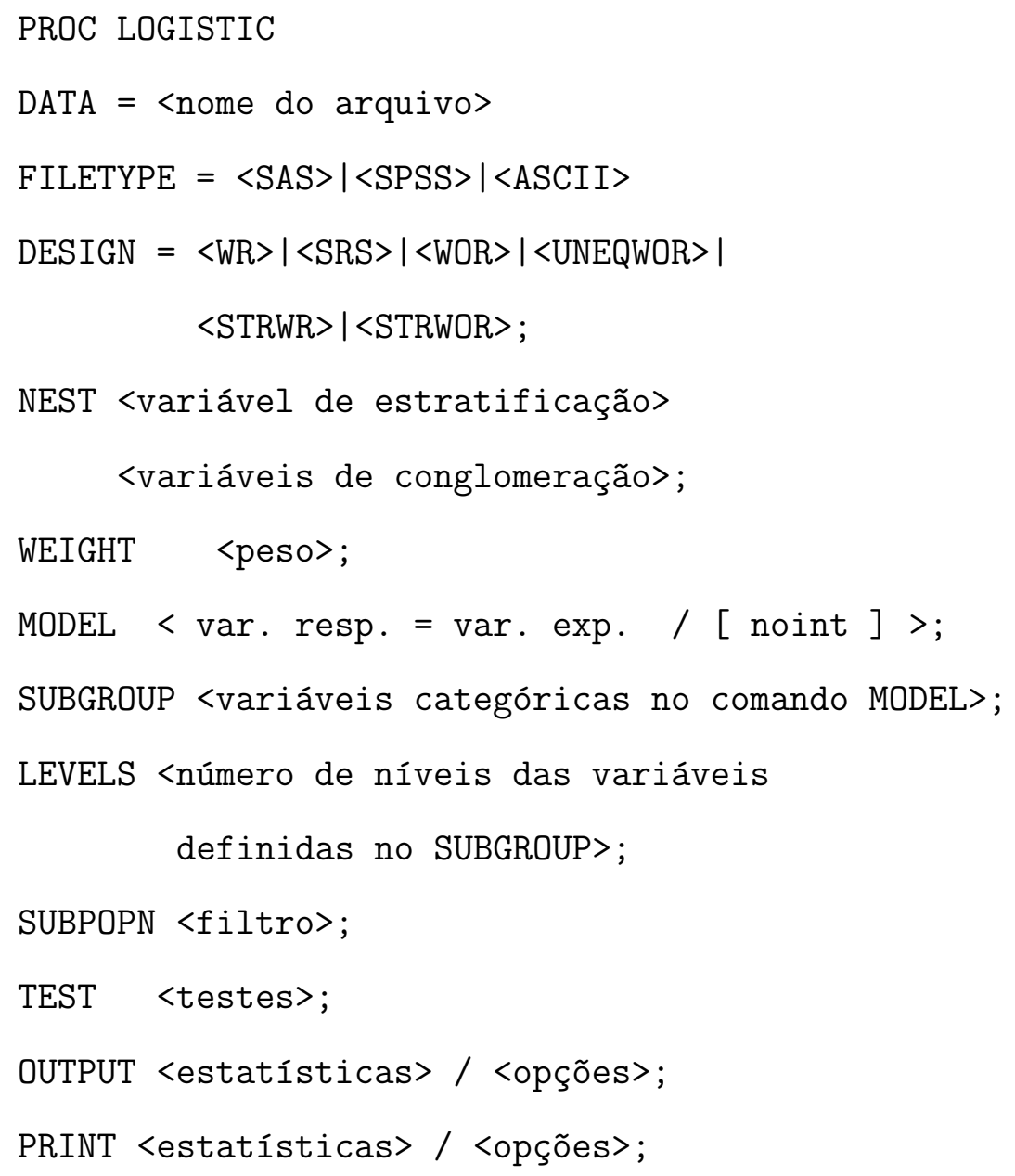

No procedimento RATIO aparecem alguns comandos que ainda não havíamos exemplificado. NUMER indica a variável que estará no numerador da razão que pretendemos estimar. Do mesmo modo, DENOM indica a variável que irá para o denominador. Por exemplo, se quisermos estimar o número médio de mulheres por tipo de ensino superior e contamos com as variáveis SEXO (homem: sexo=1, mulher: sexo=2) e ENSINO (público: ensino=1, privado: ensino=2), devemos informar o SUDAAN da seguinte maneira, dentro de um procedimento RATIO: 
NUMER SEXO;

[ NUMCAT 2; ]

DENOM ENSINO;

Os procedimentos REGRESS e LOGISTIC possuem o comando MODEL para que seja especificado o modelo que queremos ajustar aos dados e a opção NOINT que indica a inclusão ou não do intercepto. Há ainda o comando TEST para especificarmos quais os testes de hipótese que gostaríamos que o SUDAAN realizasse. O "default" deste comando é o teste F baseado na estatística qui-quadrado de Wald, vide Pessoa e Silva (1998).

No procedimento CROSSTAB o comando TEST é usado para especificar o cálculo dos testes de independência qui-quadrado (CHISQ), qui-quadrado log-linear (LLCHISQ) e Cochran-Mantel-Haenszel (CMH). No entanto, estes testes só serão realizados se todas as tabelas especificadas no comando TABLES tiverem pelo menos duas dimensões. Por exemplo, se quisermos testar a independência entre sexo e tipo de ensino utilizando o mesmo exemplo que utilizamos para o procedimento RATIO, teríamos que passar as seguintes informações para o SUDAAN dentro de um procedimento CROSSTAB:

\section{TABLES SEXO*ENSINO;}

TEST CHISQ;

Alguns problemas da utilização da estatística qui-quadrado, quando temos dados provenientes de pesquisas amostrais com desenho amostral complexo foram discutidos em Pessoa e Silva (1998). Em qualquer um dos procedimentos, se estivermos usando a versão SAS-callable, os tipos de arquivos suportados por esta versão são SAS ou ASCII, além de que devemos acrescentar o comando $<R U N$; $>$ no final de cada um deles. Em particular, o procedimento LOGISTIC deve ser utilizado com o nome RLOGIST, pois o SAS possui um procedimento de mesmo nome que trata 
os dados como selecionados por AAS.

\subsection{A biblioteca ADAC da linguagem $\mathrm{R}$}

O R é formado por oito bibliotecas básicas, os chamados "standard packages". Outras bibliotecas podem ser incorporadas a ele, uma destas foi desenvolvida por Pessoa e Moreira (2002), ambos do Departamento de Metodologia do IBGE para a análise de dados obtidos de desenhos amostrais complexos. Batizada por ADAC, algumas de suas rotinas dependem da biblioteca MASS. Foi construída para rodar na versão 1.6.1 do $\mathrm{R}$ ou versões superiores. A estrutura do arquivo de dados é igual à do SUDAAN, aceitando bancos de dados separados apenas por vírgula, ponto e vírgula ou texto, que podem ser convertidos de qualquer outro programa com facilidade. Além disto, distingüe letras maiúsculas das minúsculas. Uma vantagem é que é possível saber o que cada função está realizando, pois temos acesso a estrutura de cada uma delas. Outra vantagem é que existe a possibilidade de criarmos nossas próprias funções o que não é possível no SUDAAN. Possui facilidades gráficas que o SUDAAN não apresenta e, ainda, saídas mais fáceis de serem aproveitadas. A principal desvantagem é que não suporta conjuntos de dados muito grandes. Uma limitação do uso da ADAC é que ela só permite a análise de esquemas amostrais do tipo WOR, STRWOR, WR e STRWR, já definidos na Seção 5.1.2 para o SUDAAN. Outra limitação é que seu uso para modelagem está restrito à regressão linear múltipla e logística. Além disto, a distribuição da biblioteca ADAC ainda está restrita ao nível acadêmico brasileiro. 


\subsubsection{Principais funções da biblioteca ADAC}

Listamos abaixo o que as principais funções que constituem a biblioteca ADAC realizam, bem como a sintaxe de cada uma delas:

- CHISQ realiza um teste de independência baseado na estatística qui-quadrado; CHISQ (dados, Iin, col, peso, Est , Cong, des , N , M)

- Crosstab estima freqüências, porcentagens das linhas e colunas numa tabela; Crosstab (dados, lin, col, peso, Est, Cong, des, N, M, tot=TRUE, Pcol=FALSE, $\mathrm{Pl}$ in=FALSE)

- Logist ajusta modelos de regressão logística. Estima os coeficientes de uma regressão logística. Testa a hipótese $H: P=0$, onde $P$ é um vetor de coeficientes e H define as hipóteses de interesse;

Logist (formula, data=list(), weights, family=binomial, na.action, Est, Cong, des, N, M, H=T, method="glm.fit",...)

- Ratio estima razões; Ratio (dados, den, num, peso, Est, Cong, dom, Des, N, M)

- Regress ajusta modelos de regressão linear; Regress (formula, data=list(), weights, na.action, Est, Cong, des, $N, M, H=T$, method="qr" , $q r=T R U E, \ldots$ )

- Total fornece o estimador de Horvitz-Thompson do total; Total (dados, Var, peso, Est, Cong, Des, N , M)

- Total.grp fornece estimadores de totais para cada nível de uma variável categorizada;

Total.grp(dados, Var, peso, Est, Cong, dom, Des, N, M) 
- WALDTEST calcula a estatística qui-quadrado de Wald, bem como a estatística F de Wald e F-ajustada;

WALDTEST (Est, Cong, H, P, V, eps=1e-06)

- deff.tot fornece uma estimativa do efeito do plano amostral;

$\operatorname{deff} \cdot \operatorname{tot}(Y, w)$

- quant.samp é uma função que calcula quantis amostrais e seus intervalos de confiança;

quant.samp (dados, Var, peso, Est, Cong, des, p, N, M)

- wor2.peso calcula os pesos para amostragem WOR em 2 dois estágios;

wor2.peso(dados, Est, Cong, N, M)

- wor2.var calcula a matriz de covariância para amostragem WOR em dois estágios; wor2.var (Est, Cong, Z, N, M)

- wr2.peso calcula os pesos para amostragem WR; e wr2.peso(dados, Est, Cong, Peso1, M)

- wr2.var calcula a matriz de covariância para amostragem WR em dois estágios. wr2.var (Est, Cong, Z)

Na maioria das funções aparecem os argumentos Est, Cong, N e M , que correspondem respectivamente, a entrada para a variável de estratificação, variável de conglomeração, total de unidades primárias de amostragem em cada estrato e total de unidades secundárias de amostragem.

Possui ainda dois arquivos de dados como exemplos:

- dom32b - Dados preliminares do Censo demográfico Brasileiro, 1991; e

- ppv1 - Dados da Pesquisa sobre Padrões de Vida (PPV), vide Albieri e Bianchini (1997). 
Os dados do arquivo ppv1 correspondem a um estudo realizado em dois estágios. Trinta estratos foram formados e, no primeiro estágio, de cada um deles, setores da base geográfica do Censo Demográfico de 1991 foram selecionados com probabilidade proporcional ao tamanho do setor com reposição. No segundo estágio, foi realizada uma seleção aleatória de domicílios. A variável de estratificação foi chamada de ESTRATOF e a variável de conglomeração NSETOR. Assim como no SUDAAN, o segundo estágio não precisa ser informado ao $R$, desde que cada linha do arquivo corresponda a uma unidade experimental. Como pequenas frações amostrais foram selecionadas no primeiro estágio, foi utilizado o desenho WR .

Do indivíduo que respondeu o questionário no domicílio selecionado, foram coletadas algumas variáveis como, por exemplo, sexo, raça, peso e altura. Na verdade, foram selecionadas algumas outras variáveis, mas para exemplificar a utilização do comando Logist nos resumiremos a estas variáveis apenas. Um estudo mais detalhado deste conjunto de dados poderá ser visto no Capítulo 6. Por meio das variáveis peso e altura foram criadas as variáveis IMC (índice de massa corpórea) e ID.IMC (variável binária assumindo o valor 1, se o valor do IMC foi calculado, isto é, se o indivíduo forneceu os valores de peso e altura e 0 , caso contrário). Se o objetivo fosse encontrar a relação existente entre a variável ID.IMC e as variáveis sexo e raça, deveríamos utilizar a função Logist da seguinte maneira:

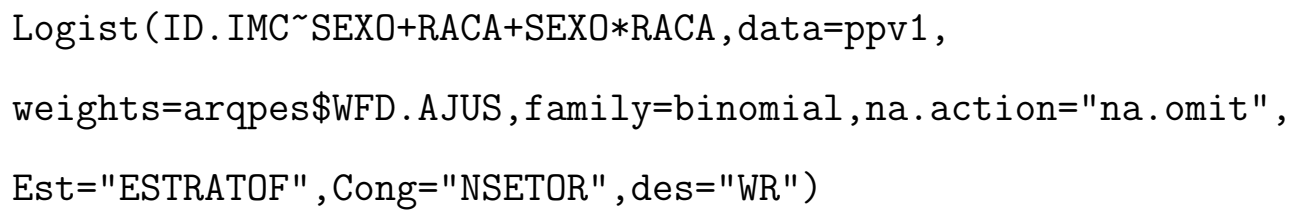

O primeiro argumento da função é a especificação do modelo, seguido do nome do objeto onde foi guardado o conjunto de dados, no caso "arqpes"; "weights"indica que a variável WFD.Ajus contém os pesos; o argumento "family=binomial" deve estar presente, indicando a distribuição utilizada e o argumento "na.action"serve para 
eliminar as linhas onde existem "missings". As variáveis ESTRATOF e NSETOR devem ser informadas nos argumentos "Est"e "Cong", respectivamente e o argumento "des"indica o desenho amostral.

Como no SUDAAN, pode-se perceber que quando há dois estágios o último não precisa ser informado ao $R$, neste caso cada linha do arquivo de dados deve corresponder aos elementos amostrados no segundo estágio. No exemplo acima, cada linha é um indivíduo que pertencia a determinado domicílio amostrado.

Vamos dar um outro exemplo. Suponha que as escolas de uma população foram estratificadas por região e esta informação está armazenada na variável REGIAO. A variável ESCOLAS traz as unidades primárias de amostragem (escolas), que foram selecionadas dentro de cada região sem reposição. Por fim, alunos são selecionados sem reposição dentro de cada escola. Suponha ainda que foram colhidas informações do número total de escolas em cada região na variável NESCOLA e, ainda, foram registrados os totais de alunos por escola na variável NALUNO. Supondo que tenham sido colhidas em cada aluno uma variável resposta de interesse e algumas variáveis explicativas e que se tenha interesse em modelar estas variáveis com um modelo de regressão linear normal, precisamos utilizar a função REGRESS da seguinte maneira:

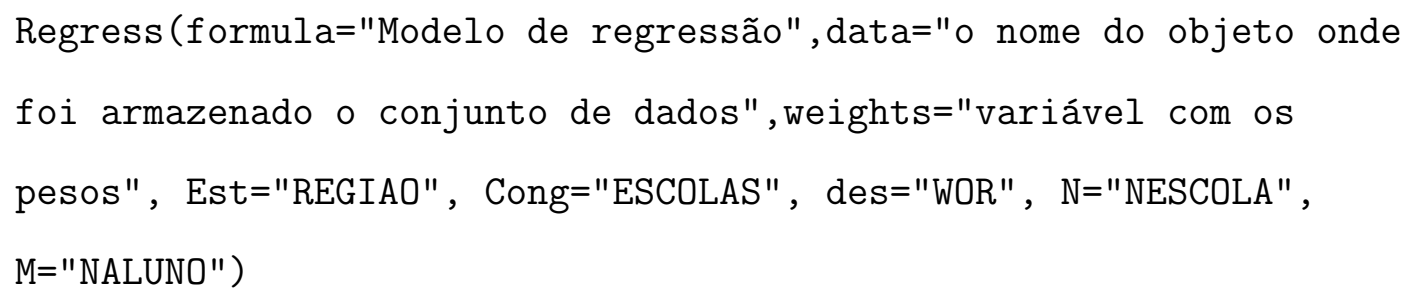


CAPÍtulo 6

\section{Aplicações}

Neste capítulo aplicaremos os métodos clássicos de regressão e o método que incorpora o esquema amostral no processo de estimação dos parâmetros de modelos de regressão a conjuntos de dados reais por meio do pacote computacional SUDAAN e da linguagem R, avaliando o impacto de ignorar o plano amostral na análise dos dados. As três primeiras aplicações baseiam-se em exemplos do curso de análise de dados amostrais da Escola Nacional de Ciências Estatísticas do Instituto Brasileiro de Geografia e Estatística - 2003 e o último conjunto de dados foi fornecido pela Fundação Instituto de Pesquisas Econômicas - USP.

\subsection{Ajuste de um modelo de regressão linear nor- mal}

Os dados analisados nesta seção são provenientes de uma parte do Censo Experimental de Limeira, realizado em 1988, discutido em Costa (1990). O conjunto de dados contém informações obtidas de 706 questionários preenchidos pelos chefes de domicílios durante o censo. Estas informações referem-se à renda e outras características socioeconômicas. Cada linha (registro) do arquivo de dados corresponde às informações dadas pelo chefe do domicílio incluído na amostra pesquisada e outras 
informações calculadas posteriormente que serão utilizadas na análise do conjunto de dados ( por exemplo, veja um fragmento do arquivo de dados na Tabela 6.1). A Tabela 6.2 apresenta as variáveis disponíveis neste conjunto de dados. A amostra foi selecionada em duas etapas: seleção de 25 setores censitários com probabilidades proporcionais ao número de domicílios (PPT), e de aproximadamente 10\% dos domicílios selecionados de cada um dos setores, segundo uma amostragem sistemática simples sem reposição.

Na Tabela 6.1 aparecem 2 dos 25 setores censitários selecionados na amostra. O setor 57 continha 274 dos 43.766 domicílios do município de Limeira. Assim, a probabilidade de inclusão do setor 57 no primeiro estágio de amostragem pode ser calculada da seguinte maneira: $\pi_{57\left(1^{\circ}\right)}=n \times($ Total de domicílios no setor 57$) /($ Total de domicílios em Limeira), sendo $n$ o número de setores selecionados, ou seja:

$$
\pi_{57\left(1^{\circ}\right)}=25 \times \frac{N P}{D O M T O T}=25 \times \frac{274}{43766}=0,1565 .
$$

Como o peso é o inverso da probabilidade de inclusão do setor 57 na amostra, temos que o peso no primeiro estágio é dado por $\pi_{57\left(1^{\circ}\right)}^{-1}=6,389$. No segundo estágio, o peso dos domicílios do setor 57 é o inverso da seguinte probabilidade: $\pi_{57\left(2^{\circ}\right)}=$ $n_{57} / N_{57}$ : o número de domicílios selecionados dividido pelo total de domicílios no setor 57 :

$$
\pi_{57\left(2^{\circ}\right)}^{-1}=\frac{274}{24}=11,4167 .
$$

Deste modo, o peso final, ou seja, o peso de cada domicílio é o produto destes dois outros pesos já calculados: $\pi_{57\left(1^{\circ}\right)}^{-1} \times \pi_{57\left(2^{\circ}\right)}^{-1}=6,389 \times 11,4167=72,94$.

Vamos ajustar um modelo de regressão linear para explicar o logaritmo da renda (variável LRENDA) em função do sexo (SEXO), idade (IDADE), anos de estudo (ESTUDO) e raça (RACA). O logaritmo da renda foi utilizado para normalizar a variável RENDA como mostram os gráficos da Figura 6.1, construídos com a ajuda do R, já que o SUDAAN não possui um ambiente gráfico que possa ser utilizado. 
Tabela 6.1: Fragmento do conjunto de dados, com variáveis auxiliares para o cálculo dos pesos.

\begin{tabular}{|c|c|c|c|c|c|c|c|}
\hline SETOR & DOMIC & NP & NA & PESO1 & PESO & PESOF & DOMTOT \\
\hline 57 & 17 & 274 & 24 & 6,38919708 & 11,41666667 & 72,94333333 & 43766 \\
\hline 57 & 27 & 274 & 24 & 6,38919708 & 11,41666667 & 72,94333333 & 43766 \\
\hline 57 & 37 & 274 & 24 & 6,38919708 & 11,41666667 & 72,94333333 & 43766 \\
\hline 57 & 47 & 274 & 24 & 6,38919708 & 11,41666667 & 72,94333333 & 43766 \\
\hline 57 & 57 & 274 & 24 & 6,38919708 & 11,41666667 & 72,94333333 & 43766 \\
\hline 57 & 67 & 274 & 24 & 6,38919708 & 11,41666667 & 72,94333333 & 43766 \\
\hline 57 & 77 & 274 & 24 & 6,38919708 & 11,41666667 & 72,94333333 & 43766 \\
\hline 57 & 87 & 274 & 24 & 6,38919708 & 11,41666667 & 72,94333333 & 43766 \\
\hline 57 & 97 & 274 & 24 & 6,38919708 & 11,41666667 & 72,94333333 & 43766 \\
\hline 57 & 107 & 274 & 24 & 6,38919708 & 11,41666667 & 72,94333333 & 43766 \\
\hline 57 & 117 & 274 & 24 & 6,38919708 & 11,41666667 & 72,94333333 & 43766 \\
\hline 57 & 127 & 274 & 24 & 6,38919708 & 11,41666667 & 72,94333333 & 43766 \\
\hline 57 & 137 & 274 & 24 & 6,38919708 & 11,41666667 & 72,94333333 & 43766 \\
\hline 57 & 147 & 274 & 24 & 6,38919708 & 11,41666667 & 72,94333333 & 43766 \\
\hline 57 & 157 & 274 & 24 & 6,38919708 & 11,41666667 & 72,94333333 & 43766 \\
\hline 57 & 177 & 274 & 24 & 6,38919708 & 11,41666667 & 72,94333333 & 43766 \\
\hline 57 & 187 & 274 & 24 & 6,38919708 & 11,41666667 & 72,94333333 & 43766 \\
\hline 57 & 217 & 274 & 24 & 6,38919708 & 11,41666667 & 72,94333333 & 43766 \\
\hline 57 & 227 & 274 & 24 & 6,38919708 & 11,41666667 & 72,94333333 & 43766 \\
\hline 57 & 237 & 274 & 24 & 6,38919708 & 11,41666667 & 72,94333333 & 43766 \\
\hline 57 & 247 & 274 & 24 & 6,38919708 & 11,41666667 & 72,94333333 & 43766 \\
\hline 57 & 257 & 274 & 24 & 6,38919708 & 11,41666667 & 72,94333333 & 43766 \\
\hline 57 & 267 & 274 & 24 & 6,38919708 & 11,41666667 & 72,94333333 & 43766 \\
\hline 57 & 287 & 274 & 24 & 6,38919708 & 11,41666667 & 72,94333333 & 43766 \\
\hline 84 & 4 & 197 & 15 & 8,886497462 & 13,13333333 & 116,7093333 & 43766 \\
\hline 84 & 14 & 197 & 15 & 8,886497462 & 13,13333333 & 116,7093333 & 43766 \\
\hline 84 & 34 & 197 & 15 & 8,886497462 & 13,13333333 & 116,7093333 & 43766 \\
\hline 84 & 44 & 197 & 15 & 8,886497462 & 13,13333333 & 116,7093333 & 43766 \\
\hline 84 & 54 & 197 & 15 & 8,886497462 & 13,13333333 & 116,7093333 & 43766 \\
\hline 84 & 64 & 197 & 15 & 8,886497462 & 13,13333333 & 116,7093333 & 43766 \\
\hline 84 & 74 & 197 & 15 & 8,886497462 & 13,13333333 & 116,7093333 & 43766 \\
\hline 84 & 84 & 197 & 15 & 8,886497462 & 13,13333333 & 116,7093333 & 43766 \\
\hline 84 & 104 & 197 & 15 & 8,886497462 & 13,13333333 & 116,7093333 & 43766 \\
\hline 84 & 144 & 197 & 15 & 8,886497462 & 13,13333333 & 116,7093333 & 43766 \\
\hline 84 & 154 & 197 & 15 & 8,886497462 & 13,13333333 & 116,7093333 & 43766 \\
\hline 84 & 164 & 197 & 15 & 8,886497462 & 13,13333333 & 116,7093333 & 43766 \\
\hline 84 & 184 & 197 & 15 & 8,886497462 & 13,13333333 & 116,7093333 & 43766 \\
\hline 84 & 194 & 197 & 15 & 8,886497462 & 13,13333333 & 116,7093333 & 43766 \\
\hline 84 & 214 & 197 & 15 & 8,886497462 & 13,13333333 & 116,7093333 & 43766 \\
\hline
\end{tabular}


Tabela 6.2: Descrição das variáveis

\begin{tabular}{|c|c|c|}
\hline Variável & Código & Descrição \\
\hline SETOR & Numérico & Número do setor \\
\hline DOMIC & Numérico & Número do domicílio no setor \\
\hline NP & Numérico & Número de domicílios no setor na população \\
\hline NA & Numérico & Número de pessoas na amostra do setor \\
\hline \multirow[t]{2}{*}{ SEXO } & 1 & Masculino \\
\hline & 2 & Feminino \\
\hline \multirow[t]{2}{*}{ RAÇA } & 1 & Pessoa de raça branca \\
\hline & 2 & Pessoa de outras raças \\
\hline \multirow[t]{3}{*}{ ESTUDO } & 1 & Até 4 anos completos de estudo \\
\hline & 2 & De 5 a 8 anos completos de estudo \\
\hline & 3 & Mais de 8 anos completos de estudo \\
\hline \multirow[t]{4}{*}{ IDADE } & 1 & Até 25 anos completos de idade \\
\hline & 2 & De 26 a 40 anos completos de idade \\
\hline & 3 & De 41 a 60 anos completos de idade \\
\hline & 4 & Mais de 60 anos de idade \\
\hline RENDA & Numérico & $\begin{array}{l}\text { Valor da renda mensal (em unidade monetária } \\
\text { vigente na época do Censo de Limeira) }\end{array}$ \\
\hline LRENDA & Numérico & Logaritmo do valor da renda mensal \\
\hline PESO1 & Numérico & Peso do setor (1o. estágio) \\
\hline PESO & Numérico & Peso do domicílio no setor (2o. estágio) \\
\hline PESOF & Numérico & Peso final do domicílio \\
\hline DOMTOT & Numérico & Número total de domicílios no município \\
\hline
\end{tabular}



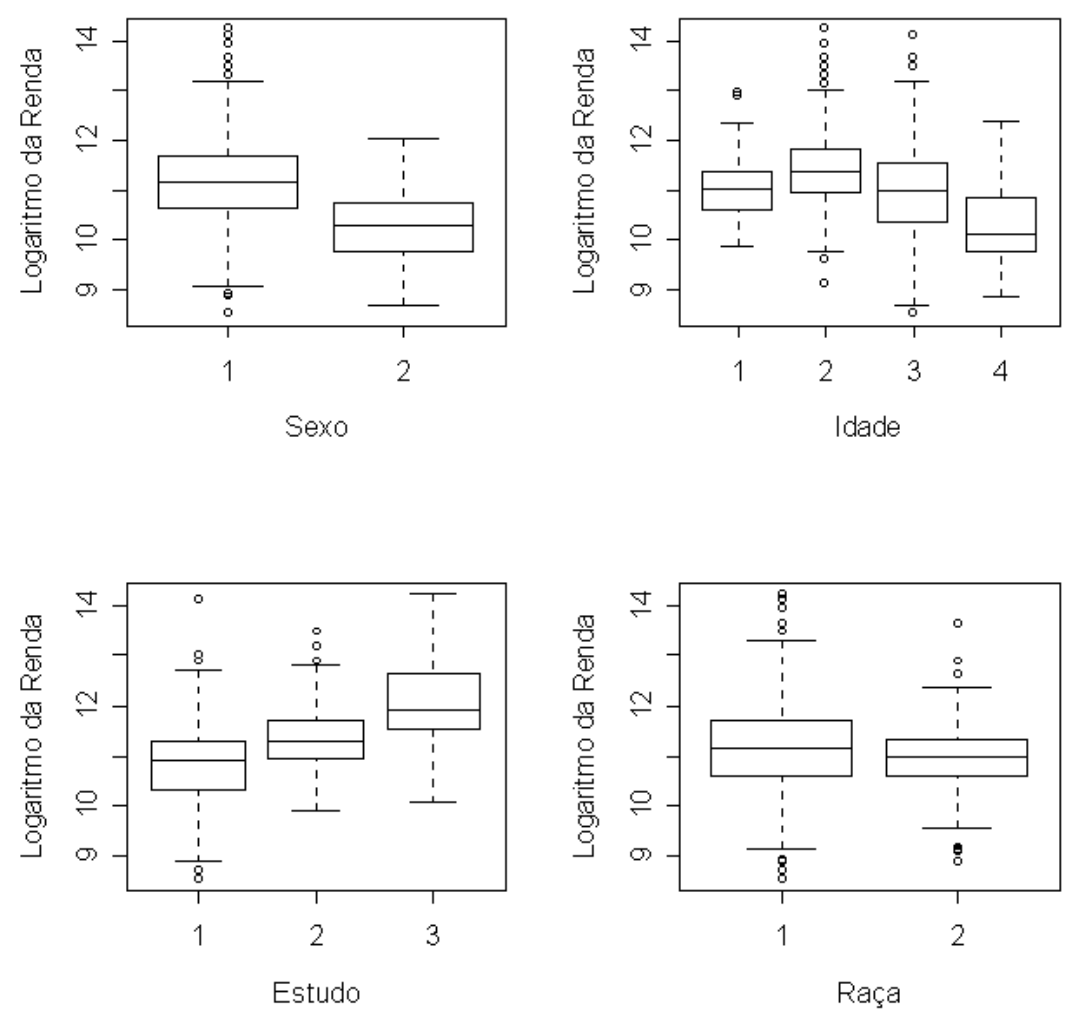

Figura 6.1: Box-plots do logaritmo da renda segundo as variáveis regressoras.

Para ajudar na escolha das interações de primeira ordem que deveriam ser incluídas no modelo foram construídos gráficos, também no $\mathrm{R}$, de perfis de médias como mostra a Figura 6.2 e, descritivamente, podemos dizer que as interações de primeira ordem IDADE*SEXO, IDADE*ESTUDO, ESTUDO*SEXO e ESTUDO*RACA deveriam ser incluídas num primeiro modelo. O único problema é que nem nos box-plots, nem nos gráficos de perfis de médias foi considerado o peso atribuído a cada observação. Assim o primero modelo a ser ajustado foi:

$\mathrm{LRENDA}=\beta_{0}+\beta_{1} \mathrm{SEXO}+\beta_{2} \mathrm{IDADE}+\beta_{3} \mathrm{ESTUDO}+\beta_{4} \mathrm{RACA}+\beta_{5} \mathrm{IDADE}{ }^{*} \mathrm{SE}-$ $\mathrm{XO}+\beta_{6} \mathrm{IDADE}^{*} \mathrm{ESTUDO}+\beta_{7} \mathrm{ESTUDO} * \mathrm{SEXO}+\beta_{8} \mathrm{ESTUDO} * \mathrm{RACA}$

Para ajustar o modelo acima no SUDAAN foi necessário fornecer as seguintes informações: 

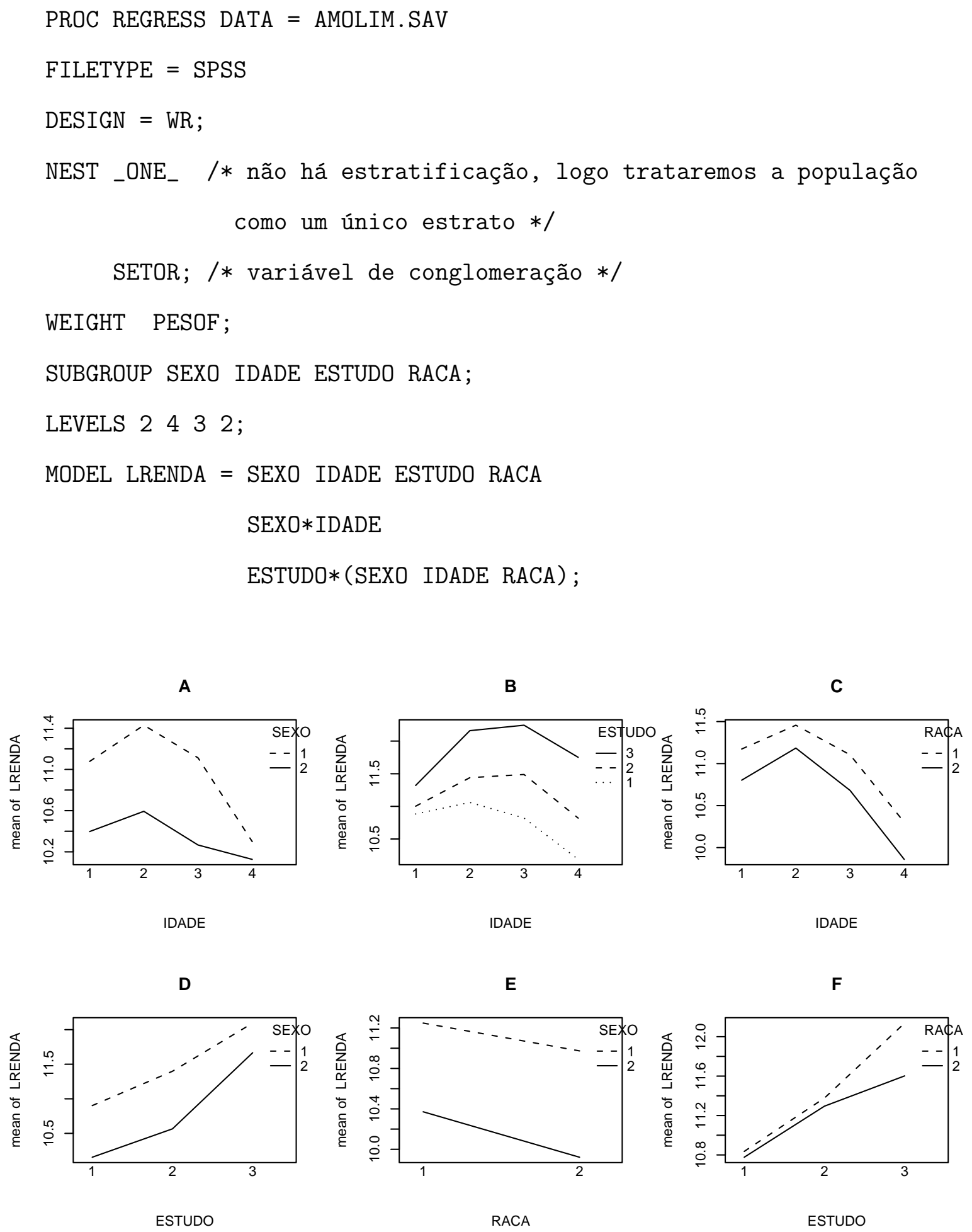

Figura 6.2: Gráficos de perfis de médias para detecção de interações. 
Tabela 6.3: Modelo completo

\begin{tabular}{lcccccccc}
\hline \hline & \multicolumn{4}{c}{ Considerando plano } & \multicolumn{3}{c}{ Considerando AAS } \\
& \multicolumn{3}{c}{ Uso do SUDAAN } & \multicolumn{2}{c}{ Utilizando $J^{-1}$} & & & \\
Variáveis & Coef. & DP & Valor P & DP* & Valor P & Coef. & DP & Valor P \\
\hline $\begin{array}{l}\text { Intercepto } \\
\text { SEXO }\end{array}$ & 11,27 & 0,29 & 0,0000 & 0,46 & 0,0000 & 11,16 & 0,38 & $0,0000^{1}$ \\
IDADE & 0,24 & 0,32 & 0,4559 & 0,41 & 0,2776 & 0,22 & 0,27 & 0,4134 \\
1 & & & & & & & & \\
2 & $-0,57$ & 0,33 & 0,0954 & 0,72 & 0,7862 & $-0,71$ & 0,45 & 0,1165 \\
3 & $-0,03$ & 0,25 & 0,9066 & 0,48 & 0,5243 & $-0,02$ & 0,34 & 0,9480 \\
ESTUDO & $-0,01$ & 0,19 & 0,9498 & 0,49 & 0,5100 & $-0,01$ & 0,36 & 0,9806 \\
1 & & & & & & & & \\
2 & $-1,57$ & 0,37 & 0,0003 & 0,48 & 0,9995 & $-1,43$ & 0,40 & 0,0004 \\
RACA & $-0,99$ & 0,45 & 0,0376 & 0,90 & 0,8629 & $-0,92$ & 0,50 & 0,0644 \\
1 & & & & & & & & \\
SEXO*IDADE & 0,42 & 0,22 & 0,0658 & 0,21 & 0,0213 & 0,52 & 0,23 & 0,0252 \\
1,1 & & & & & & & & \\
1,2 & 0,15 & 0,32 & 0,6454 & 0,55 & 0,3934 & 0,22 & 0,29 & 0,4500 \\
1,3 & 0,32 & 0,33 & 0,3485 & 0,27 & 0,1211 & 0,37 & 0,24 & 0,1249 \\
ESTUDO*SEXO & 0,40 & 0,26 & 0,1398 & 0,24 & 0,0478 & 0,40 & 0,22 & 0,0722 \\
1,1 & & & & & & & & \\
2,1 & 0,13 & 0,22 & 0,5637 & 0,38 & 0,3665 & 0,13 & 0,23 & 0,5909 \\
ESTUDO*IDADE & 0,28 & 0,37 & 0,4602 & 0,48 & 0,2840 & 0,36 & 0,33 & 0,2732 \\
1,1 & & & & & & & & \\
1,2 & 1,17 & 0,37 & 0,0046 & 0,55 & 0,0168 & 1,00 & 0,43 & 0,0030 \\
1,3 & 0,60 & 0,21 & 0,0092 & 0,47 & 0,1025 & 1,00 & 0,34 & 0,1139 \\
2,1 & 0,29 & 0,19 & 0,1405 & 0,49 & 0,2744 & 0,00 & 0,35 & 0,4408 \\
2,2 & 0,65 & 0,39 & 0,1082 & 0,85 & 0,2234 & 1,00 & 0,42 & 0,1114 \\
2,3 & 0,38 & 0,21 & 0,0837 & 0,82 & 0,3209 & 0,00 & 0,35 & 0,3791 \\
ESTUDO*RACA & 0,31 & 0,33 & 0,3615 & 0,83 & 0,3553 & 0,00 & 0,39 & 0,3422 \\
1,1 & & & & & & & & \\
2,1 & $-0,20$ & 0,25 & 0,4155 & 0,22 & 0,8244 & 0,00 & 0,24 & 0,1865 \\
\hline \hline & $-0,39$ & 0,25 & 0,1372 & 0,27 & 0,9277 & $-1,00$ & 0,27 & 0,0569 \\
\hline
\end{tabular}


Tabela 6.4: Modelo sem a interação ESTUDO*SEXO

\begin{tabular}{|c|c|c|c|c|c|c|c|c|}
\hline \multirow[b]{3}{*}{ Variáveis } & \multicolumn{5}{|c|}{ Considerando o plano } & \multicolumn{3}{|c|}{ Considerando AAS } \\
\hline & \multicolumn{3}{|c|}{ Uso do SUDAAN } & \multicolumn{2}{|c|}{ Uso de $J^{-1}$} & \multirow[b]{2}{*}{ Coef. } & \multirow[b]{2}{*}{$\mathrm{DP}$} & \multirow[b]{2}{*}{ Valor P } \\
\hline & Coef. & $\mathrm{DP}$ & Valor P & $\mathrm{DP}^{*}$ & Valor P & & & \\
\hline Intercepto & 11,22 & 0,26 & 0,0000 & 0,44 & 0,0000 & 11,12 & 0,36 & 0,0000 \\
\hline \multicolumn{9}{|l|}{ SEXO } \\
\hline 1 & 0,36 & 0,21 & 0,0901 & 0,19 & 0,0311 & 0,34 & 0,18 & 0,0510 \\
\hline \multicolumn{9}{|l|}{ IDADE } \\
\hline 1 & $-0,66$ & 0,36 & 0,0755 & 0,68 & 0,8368 & $-0,80$ & 0,41 & 0,0529 \\
\hline 2 & $-0,13$ & 0,29 & 0,6574 & 0,44 & 0,6164 & $-0,12$ & 0,32 & 0,7119 \\
\hline 3 & $-0,11$ & 0,17 & 0,5226 & 0,44 & 0,6010 & $-0,11$ & 0,32 & 0,7359 \\
\hline \multicolumn{9}{|l|}{ ESTUDO } \\
\hline 1 & $-1,53$ & 0,35 & 0,0002 & 0,46 & 0,9996 & $-1,38$ & 0,37 & 0,0002 \\
\hline 2 & $-0,79$ & 0,37 & 0,0447 & 0,83 & 0,8298 & $-0,63$ & 0,39 & 0,1111 \\
\hline \multicolumn{9}{|l|}{ RACA } \\
\hline 1 & 0,42 & 0,22 & 0,0623 & 0,21 & 0,0203 & 0,52 & 0,23 & 0,0239 \\
\hline \multicolumn{9}{|c|}{$\mathrm{SEXO} * \mathrm{IDADE}$} \\
\hline 1,1 & 0,15 & 0,32 & 0,6338 & 0,55 & 0,3894 & 0,22 & 0,28 & 0,4342 \\
\hline 1,2 & 0,34 & 0,33 & 0,3112 & 0,27 & 0,1035 & 0,39 & 0,23 & 0,0970 \\
\hline 1,3 & 0,43 & 0,26 & 0,1217 & 0,24 & 0,0379 & 0,43 & 0,22 & 0,0492 \\
\hline \multicolumn{9}{|c|}{ ESTUDO $*$ IDADE } \\
\hline 1,1 & 1,26 & 0,39 & 0,0039 & 0,50 & 0,0056 & 1,35 & 0,39 & 0,0005 \\
\hline 1,2 & 0,68 & 0,23 & 0,0076 & 0,42 & 0,0503 & 0,62 & 0,30 & 0,0394 \\
\hline 1,3 & 0,37 & 0,16 & 0,0320 & 0,43 & 0,1939 & 0,35 & 0,31 & 0,2678 \\
\hline 2,1 & 0,73 & 0,39 & 0,0738 & 0,82 & 0,1864 & 0,75 & 0,39 & 0,0517 \\
\hline 2,2 & 0,45 & 0,22 & 0,0487 & 0,79 & 0,2825 & 0,37 & 0,30 & 0,2241 \\
\hline 2,3 & 0,37 & 0,31 & 0,2341 & 0,80 & 0,3209 & 0,42 & 0,35 & 0,2264 \\
\hline \multicolumn{9}{|c|}{ ESTUDO $*$ RACA } \\
\hline 1,1 & $-0,21$ & 0,25 & 0,4055 & 0,22 & 0,8286 & $-0,32$ & 0,24 & 0,1808 \\
\hline 2,1 & $-0,40$ & 0,26 & 0,1298 & 0,27 & 0,9329 & $-0,53$ & 0,27 & 0,0517 \\
\hline
\end{tabular}


Tabela 6.5: Modelo sem a interação SEXO*IDADE considerando o plano (SUDAAN)

\begin{tabular}{lcccc}
\hline \hline Variáveis & Coef. & DP & Teste z & Valor P \\
\hline Intercepto & 11,13 & 0,30 & 37,37 & 0,0000 \\
SEXO & & & & \\
1 & 0,65 & 0,06 & 10,75 & 0,0000 \\
IDADE & & & & \\
1 & $-0,71$ & 0,30 & $-2,36$ & 0,0270 \\
2 & 0,01 & 0,22 & 0,03 & 0,9800 \\
3 & 0,11 & 0,13 & 0,82 & 0,4223 \\
ESTUDO & & & & \\
1 & $-1,66$ & 0,34 & $-4,84$ & 0,0001 \\
2 & $-0,99$ & 0,35 & $-2,84$ & 0,0091 \\
RACA & & & & \\
1 & 0,42 & 0,21 & 1,96 & 0,0620 \\
ESTUDO*IDADE & & & & \\
1,1 & 1,41 & 0,39 & 3,58 & 0,0015 \\
1,2 & 0,82 & 0,27 & 3,05 & 0,0055 \\
1,3 & 0,50 & 0,17 & 2,87 & 0,0085 \\
2,1 & 0,93 & 0,35 & 2,65 & 0,0139 \\
2,2 & 0,65 & 0,24 & 2,75 & 0,0113 \\
2,3 & 0,57 & 0,27 & 2,12 & 0,0445 \\
ESTUDO*RACA & & & & \\
1,1 & $-0,21$ & 0,24 & $-0,87$ & 0,3947 \\
2,1 & $-0,40$ & 0,26 & $-1,58$ & 0,1281 \\
\hline \hline
\end{tabular}


Tabela 6.6: Modelo final considerando AAS e usando o estimador $J^{-1}$ Considerando AAS Considerando o plano $\left(J^{-1}\right)$

\begin{tabular}{lcccccc} 
Variáveis & Coef. & DP & Valor P & DP* & Valor P & EPA \\
\hline Intercepto & 11,43 & 0,28 & 0,0000 & 0,40 & 0,0000 & 1,43 \\
SEXO & & & & & & \\
1 & 0,34 & 0,18 & 0,0508 & 0,19 & 0,0313 & 1,05 \\
IDADE & & & & & & \\
1 & $-0,85$ & 0,41 & 0,0400 & 0,68 & 0,8469 & 1,66 \\
2 & $-0,16$ & 0,32 & 0,6167 & 0,44 & 0,6423 & 1,34 \\
3 & $-0,12$ & 0,32 & 0,7020 & 0,44 & 0,6095 & 1,34 \\
ESTUDO & & & & & & \\
1 & $-1,70$ & 0,28 & 0,0000 & 0,41 & 0,9999 & 1,46 \\
2 & $-1,16$ & 0,29 & 0,0001 & 0,78 & 0,9356 & 2,69 \\
RACA & & & & & & \\
1 & 0,20 & 0,06 & 0,0007 & 0,06 & 0,0006 & 1,00 \\
SEXO*IDADE & & & & & & \\
1,1 & 0,22 & 0,28 & 0,4338 & 0,55 & 0,3894 & 1,96 \\
1,2 & 0,39 & 0,23 & 0,0982 & 0,27 & 0,1024 & 1,17 \\
1,3 & 0,43 & 0,22 & 0,0487 & 0,24 & 0,0380 & 1,09 \\
ESTUDO*IDADE & & & & & & \\
1,1 & 1,41 & 0,39 & 0,0003 & 0,50 & 0,0048 & 1,28 \\
1,2 & 0,66 & 0,30 & 0,0268 & 0,42 & 0,0438 & 1,40 \\
1,3 & 0,36 & 0,31 & 0,2490 & 0,43 & 0,1887 & 1,39 \\
2,1 & 0,88 & 0,38 & 0,0214 & 0,82 & 0,1572 & 2,16 \\
2,2 & 0,45 & 0,30 & 0,1412 & 0,79 & 0,2587 & 2,60 \\
2,3 & 0,45 & 0,35 & 0,1992 & 0,80 & 0,3130 & 2,29 \\
\hline \hline
\end{tabular}


Tabela 6.7: Modelo final considerando o plano amostral (SUDAAN)

\begin{tabular}{lccccc}
\hline \hline Variáveis & Coef. & DP & Teste z & Valor P & EPA \\
\hline Intercepto & 11,35 & 0,19 & 59,99 & 0,0000 & 0,20 \\
SEXO & & & & & \\
1 & 0,65 & 0,06 & 10,68 & 0,0000 & 0,44 \\
IDADE & & & & & \\
1 & $-0,74$ & 0,31 & $-2,42$ & 0,0235 & 0,42 \\
2 & $-0,02$ & 0,22 & $-0,11$ & 0,9161 & 0,25 \\
3 & 0,10 & 0,13 & 0,73 & 0,4722 & 0,09 \\
ESTUDO & & & & & \\
1 & $-1,87$ & 0,19 & $-9,67$ & 0,0000 & 0,20 \\
2 & $-1,39$ & 0,17 & $-8,24$ & 0,0000 & 0,04 \\
RACA & & & & & \\
1 & 0,21 & 0,07 & 3,00 & 0,0062 & 1,14 \\
ESTUDO*IDADE & & & & & \\
1,1 & 1,44 & 0,40 & 3,62 & 0,0014 & 0,60 \\
1,2 & 0,84 & 0,26 & 3,25 & 0,0034 & 0,35 \\
1,3 & 0,51 & 0,17 & 2,93 & 0,0073 & 0,14 \\
2,1 & 1,02 & 0,33 & 3,09 & 0,0051 & 0,16 \\
2,2 & 0,71 & 0,22 & 3,19 & 0,0039 & 0,08 \\
2,3 & 0,58 & 0,27 & 2,18 & 0,0395 & 0,11 \\
\hline \hline
\end{tabular}

Tabela 6.8: Significância dos efeitos de interação no modelo completo

Considerando o plano Considerando AAS

\begin{tabular}{lccccc} 
CONTRASTES & G.L. & Wald & Valor P & Wald & Valor P \\
\hline Modelo completo & 20 & 297803,22 & 0,0000 & 12693,64 & 0,0000 \\
SEXO*IDADE & 3 & 1,27 & 0,3066 & 1,20 & 0,3078 \\
ESTUDO*SEXO & $\mathbf{2}$ & $\mathbf{0 , 3 0}$ & $\mathbf{0 , 7 4 2 4}$ & $\mathbf{0 , 6 1}$ & $\mathbf{0 , 5 4 2 5}$ \\
ESTUDO*IDADE & 6 & 2,44 & 0,0549 & 3,04 & 0,0061 \\
ESTUDO*RACA & 2 & 1,58 & 0,2269 & 1,90 & 0,1505 \\
\hline \hline
\end{tabular}


Tabela 6.9: Significância dos efeitos de interação excluindo ESTUDO*SEXO Considerando o plano Considerando AAS

\begin{tabular}{lccccc} 
CONTRASTES & G.L. & Wald & Valor P & Wald & Valor P \\
\hline Modelo completo & 18 & 111164,32 & 0,0000 & 32424,83 & 0,0000 \\
SEXO*IDADE & 3 & $\mathbf{1 , 3 6}$ & $\mathbf{0 , 2 8 0 2}$ & $\mathbf{1 , 4 6}$ & $\mathbf{0 , 2 2 4 6}$ \\
ESTUDO*IDADE & 6 & 2,25 & 0,0725 & 3,34 & 0,0030 \\
ESTUDO*RACA & 2 & 1,67 & 0,2096 & $\mathbf{1 , 9 9}$ & $\mathbf{0 , 1 3 7 5}$ \\
\hline \hline
\end{tabular}

Tabela 6.10: Significância dos efeitos de interação excluindo SEXO*IDADE considerando o plano

\begin{tabular}{lcc}
\hline \hline CONTRASTES & Wald & Valor P \\
\hline Modelo completo & 147357,82 & 0,0000 \\
SEXO & 115,49 & 0,0000 \\
ESTUDO*IDADE & 2,42 & 0,0572 \\
ESTUDO*RACA & $\mathbf{1 , 6 3}$ & $\mathbf{0 , 2 1 6 1}$ \\
\hline \hline
\end{tabular}


Tabela 6.11: Significância dos efeitos de interação excluindo SEXO*IDADE considerando o plano

\begin{tabular}{lcc}
\hline \hline CONTRASTES & Wald & Valor P \\
\hline Modelo completo & 202157,55 & 0,0000 \\
SEXO & 114,11 & 0,0000 \\
RACA & 9,00 & 0,0062 \\
ESTUDO $*$ IDADE & 2,70 & 0,0382 \\
\hline \hline
\end{tabular}

As estimativas dos parâmetros e de seus respectivos desvios padrão para o modelo considerando o plano amostral e considerando AAS com todas as variáveis aparecem na Tabela 6.3. Efetuado este ajuste, procuramos selecionar o melhor modelo. A seleção das variáveis foi realizada da seguinte maneira: a partir do modelo completo, fomos verificando qual seria a primeira interação a sair do modelo ao nível de 5\% de significância. Há dois tipos de tabelas. O primeiro tipo traz as estimativas dos coeficientes e seus desvios-padrão e mostra os testes marginais para a permanência/saída de cada coeficiente (Tabelas 6.3 a 6.7) para o caso de AAS e considerando o plano. O segundo tipo (Tabelas 6.8 a 6.11) traz o teste conjunto baseado na estatística de Wald para cada efeito de interação. Embora o primeiro tipo de tabela é o que nos dá as evidências de qual efeito principal ou de interação permanece/sai do modelo, é no segundo tipo de tabela que obtemos a ordem de permanência/saída.

Por exemplo, observamos na Tabela 6.8 que a interação entre as variáveis estudo e sexo deve ser a primeira a ser eliminada do modelo no caso de AAS e considerando o plano, por apresentar o maior nível descritivo. A seguir, observamos a Tabela 6.3 para verificar se marginalmente esta interação realmente deve sair do modelo. No próximo passo, observamos na Tabela 6.9 que a interação entre sexo e idade deveria sair de ambos os modelos, porém a Tabela 6.4 mostra que no caso de 
AAS a interação entre sexo e idade deve permanecer no modelo ao nível de $5 \%$ de significância, devido aos níveis 1 e 3. Deste ponto em diante, teremos dois modelos distintos, pois no caso de AAS a próxima interação a sair do modelo é a interação entre estudo e raça e não entre sexo e idade (Tabela 6.4). As tabelas restantes (Tabelas 6.5, 6.6, 6.7, 6.10 e 6.11) mostram o final do processo de seleção de variáveis. Observemos, então, que teremos dois modelos finais distintos, pois as estimativas dos parâmetros são diferentes em cada caso e, além disso, no caso AAS, o modelo traz a interação entre sexo e idade. Considerando o plano amostral efetivamente utilizado, temos o seguinte modelo:

LRENDA $=11,35+0,65$ SEXO - 0,74 IDADE1 - 0,02 IDADE2 + 0,10 IDADE3 1,87 ESTUDO1 - 1,39 ESTUDO2 + 0,21 RACA + 1,44 ESTUDO1 IDADE1 + 0,84 ESTUDO1 IDADE2 + 0,51 ESTUDO1 IDADE3 + 1,02 ESTUDO2 IDADE1 + 0,71 ESTUDO2 IDADE2 + 0,58 ESTUDO2 IDADE3.

O modelo final no caso AAS é:

LRENDA $=11,43+0,34$ SEXO - 0,85 IDADE1 - 0,16 IDADE2 - 0,12 IDADE3 1,70 ESTUDO1 - 1,16 ESTUDO $2+$ 0,20 RACA + 1,41 ESTUDO1 IDADE1 + 0,66 ESTUDO1 IDADE2 + 0,36 ESTUDO1 IDADE3 + 0,88 ESTUDO2 IDADE1 + 0,45 ESTUDO2 IDADE2 + 0,45 ESTUDO2 IDADE3 + 0,22 SEXO IDADE1 + $\mathbf{0 , 3 9}$ SEXO IDADE2 + 0,43 SEXO IDADE3.

As Tabelas 6.3, 6.4 e 6.6 apresentam também as estimativas para os desviospadrões $\left(\mathrm{DP}^{*}\right)$ calculadas com base na matriz de informação de Godambe, como foi apresentado no Capítulo 3. A utilização destas estimativas leva ao mesmo modelo final quando consideramos AAS, como podemos ver na Tabela 6.6.

Uma recomendação que fizemos no final do Capítulo 4 é que deveríamos estimar o EPA antes de concluir as análises. A Tabela 6.7 traz as estimativas dos EPA's para cada coeficiente que permaneceu no modelo. Observe que estes valores estão distantes de 1, mostrando que ignorar o plano amostral faz com que o modelo de AAS 
especificado acima seja incorreto, trazendo interpretações errôneas da relação entre as variáveis de pesquisa, além de que, neste caso, a variabilidade dos coeficientes de regressão foi superestimada. O mesmo vale para os EPA's que foram calculados para o estimador da matriz de covariância assintótica do vetor de parâmetros que estão apresentados na Tabela 6.6.

Vale lembrar, ainda, que seria necessário realizar algum tipo de validação destes modelos por métodos de diagnósticos que verificariam se as suposições que impomos, ao utilizarmos uma análise de regressão, estão satisfeitas.

\subsection{Ajuste de um modelo de regressão logística}

As próximas análises baseiam-se nos arquivos FAVDOM.SAV e FAVPES.SAV que contêm as informações obtidas na Pesquisa Sócio-Econômica das Comunidades de Baixa Renda (PCBR) da Cidade do Rio de Janeiro. A PCBR é uma pesquisa de múltiplos propósitos que investiga características sócio-econômicas da população das comunidades integrantes do projeto Favela/Bairro. Esta pesquisa é domiciliar e tem por objetivo fornecer estimativas de totais e proporções para um elenco de variáveis de interesse referentes aos domicílios e respectivos moradores das diversas comunidades possuindo, então, duas unidades de análise: o domicílio e a pessoa. Sendo assim, a população alvo da pesquisa é constituída por domicílios de cada uma das comunidades e seus respectivos moradores. Também ajustamos um modelo de regressão para estudar a relação entre um indivíduo ser trabalhador por conta própria e suas características sócio-econômicas e demográficas coletadas.

Investiga-se, sobre os moradores, características sócio-demográficas tais como idade, sexo, local de nascimento, nível educacional, condição de atividade, renda mensal, bem como informações específicas quanto a treinamento profissional já realizado e residência em outra comunidade de baixa renda do município. Sobre os domicílios, 
a pesquisa obtém informações referentes às características físicas e estruturais, bem como sobre a classe econômica dos domicílios.

$\mathrm{O}$ arquivo FAVDOM.SAV foi obtido de uma amostragem estratificada. Os estratos foram representados pelas comunidades de baixa renda sendo que em cada estrato os domicílios (unidade amostrais) foram selecionados por amostragem sistemática. Cada linha do arquivo traz informações referentes ao domicílio amostrado. No arquivo FAVPES.SAV cada linha representa um morador do domicílio, ou seja, o domicílio é tratado como um conglomerado e, em cada domicílio, todas as pessoas são entrevistadas. Nesta pesquisa, amostras independentes foram selecionadas em cada uma das comunidades. As variáveis relevantes para a análise estão descritas nas Tabelas 6.12 e 6.13 .

Tabela 6.12: Dicionário de variáveis disponíveis no arquivo FAVDOM.SAV

\begin{tabular}{lll}
\hline \hline Variável & Código & Descrição \\
\hline FAVELA & Numérico & Código da comunidade de baixa renda $(\mathrm{CBR})$ \\
QUEST & Numérico & Número do domicílio na CBR \\
PESO & Numérico & Peso do domićlio na CBR \\
NDOM & Numérico & Número de domicílios na CBR na população \\
TOT.COMODOS & Numérico & Número de cômodos no domićlíio \\
AEC & Numérico & Anos de estudo do chefe do domicílio \\
TOTCRIAN & Numérico & Número de crianças no domicílio $(\leq 16$ anos $)$ \\
TOT.MORADOR & Numérico & Número de moradores por domicílio \\
\hline \hline
\end{tabular}


Tabela 6.13: Dicionário de variáveis disponíveis no arquivo FAVPES.SAV

\begin{tabular}{|c|c|c|}
\hline Variável & Código & Descrição \\
\hline IDENT & Numérico & Número do domicílio na CBR \\
\hline PESO & Numérico & Peso da pessoa na $\mathrm{CBR}$ \\
\hline NDOM & Numérico & Número de domicílios na CBR na população \\
\hline NPES & Numérico & Número de pessoas no domicílio na população \\
\hline \multirow[t]{2}{*}{ SEX } & 1 & Masculino \\
\hline & 2 & Feminino \\
\hline IDADE & Numérico & Idade da pessoa \\
\hline \multirow[t]{7}{*}{ ID } & 1 & Idade da pessoa entre 15 e 19 anos \\
\hline & 2 & Idade da pessoa entre 20 e 29 anos \\
\hline & 3 & Idade da pessoa entre 30 e 39 anos \\
\hline & 4 & Idade da pessoa entre 40 e 49 anos \\
\hline & 5 & Idade da pessoa entre 50 e 59 anos \\
\hline & 6 & Pessoa com 60 anos de idade e mais \\
\hline & 10 & Outros \\
\hline \multirow[t]{7}{*}{ INSTR } & 1 & Sem instrução \\
\hline & 2 & Pre-escolar \\
\hline & 3 & 1 serie 1 grau \\
\hline & 4 & 2 serie 1 grau \\
\hline & 5 & 3 serie 1 grau \\
\hline & 6 & 4 serie 1 grau \\
\hline & 7 & 5 serie 1 grau \\
\hline
\end{tabular}


Tabela 6.13: continuação

\begin{tabular}{|c|c|c|}
\hline Variável & Código & Descrição \\
\hline & 8 & 6 serie 1 grau \\
\hline & 9 & 7 serie 1 grau \\
\hline & 10 & 8 serie 1 grau \\
\hline & 11 & 1 serie 2 grau \\
\hline & 12 & 2 serie 2 grau \\
\hline & 13 & 3 serie 2 grau \\
\hline & 14 & 3 grau incompleto \\
\hline & 15 & 3 grau completo \\
\hline & 16 & Mestrado/Doutorado \\
\hline & 99 & Não respondeu \\
\hline \multirow[t]{2}{*}{ SALARIO } & Numérico & Salário da pessoa (em unidade \\
\hline & & monetária vigente na época) \\
\hline \multirow[t]{2}{*}{ REG } & 1 & Pessoa originou do Rio de Janeiro \\
\hline & 2 & Pessoa originou de outro Estado \\
\hline \multirow[t]{2}{*}{$\mathrm{CP}$} & 0 & Pessoa não trabalha por conta-própria \\
\hline & 1 & Pessoa trabalha por conta-própria \\
\hline \multirow[t]{2}{*}{ CRIAN } & 0 & Não há crianças no domicílio ( $\leq 16$ anos) \\
\hline & 1 & Há crianças no domicílio \\
\hline \multirow[t]{3}{*}{ SIT.OCUP } & 1 & Pessoa ocupada \\
\hline & 2 & Pessoa desocupada \\
\hline & 3 & Pessoa fora da força \\
\hline TOT.MORADOR & Numérico & Número de moradores por domicílio \\
\hline
\end{tabular}


Um dos interesses era estimar o total de moradores das comunidades de baixa renda do Rio de Janeiro. Utilizando a bibilioteca ADAC do R, procederíamos da seguinte maneira:

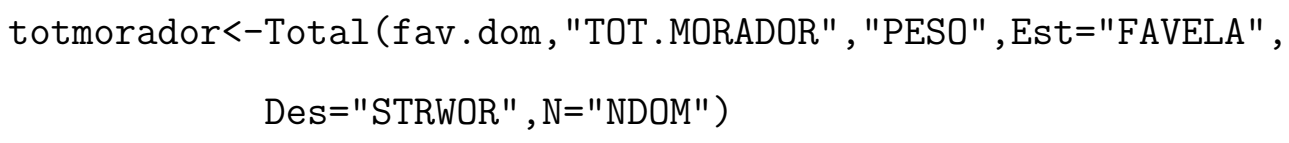

Foi utilizado o desenho STRWOR, pois se trata de uma amostragem estratificada sem reposição. A estimativa para o total de moradores é 254615,8 com desvio padrão igual a 842,27 e EPA igual a 1,02. Observe que este valor de EPA nos dá indicações de que o plano amostral utilizado não exerceu grande influência na estimativa da precisão do estimador do total de moradores quando comparado com a amostragem aleatória simples. Logo, se o mesmo fosse estimado com os programas usuais que consideram AAS, não teríamos grandes surpresas. Havia o interesse de estimar o total de moradores por cômodo. Neste caso, procederíamos da seguinte maneira no R:

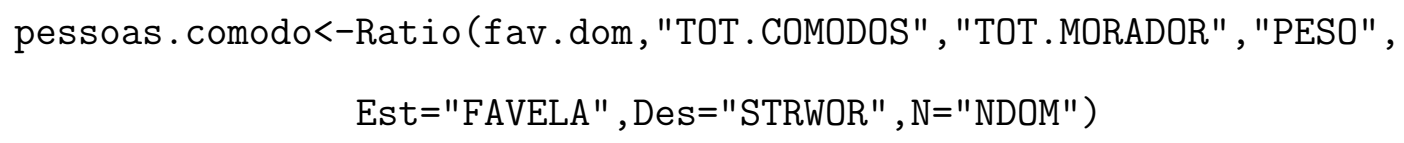

O número estimado de pessoas por cômodo é 0,84 com desvio padrão $(0,003)$. A estimativa do EPA também está bem próxima de $1(0,94)$ indicando a pouca influência do plano amostral na estimativa do número de pessoas por cômodo. Uma explicação para isto é que a estratificação por comunidade não tem grande efeito.

Além disso, ajustamos um modelo para estudar a relação entre a probabilidade $\pi$ de um indivíduo ser trabalhador por conta-própria (CP) e as características demográficas e sócio-econômicas dos indivíduos em estudo.

Antes do ajuste do modelo vamos criar novas variáveis, com o auxílio do SPSS, que facilitarão a interpretação do modelo. SITNOVA é a nova variável que 
indica a situação ocupacional dos entrevistados, assumindo 1 quando o entrevistado estava ocupado e 2, quando o entrevistado estava desocupado ou estava fora da força. Também recodificamos a variável ID. A nova variável IDNOVA agrupou as categorias pessoas entre 50 e 59 anos (5 - ID), pessoas com mais de 60 anos (6 - ID) e outros (10 - ID) numa mesma categoria (5 - IDNOVA). A variável salário foi categorizada da seguinte maneira: 1 representa pessoas que ganham até 240 unidades monetárias (UM); 2 pessoas que ganham de 240 a 1200 UM; 3 para aqueles que ganham de 1200 a 2400 UM; e, por fim, 4 para aqueles que ganham mais de 2400 UM.

A variável CRIAN foi recodificada (0->1, 1->2), pois para o ajuste usamos o SUDAAN e isto torna-se necessário para que o SUDAAN possa entender esta variável como categórica. A categoria 99 da variável INSTR foi transformada em "MISSING", sendo que esta variável foi tratada como numérica discreta. O modelo de regressão que utilizamos para o ajuste foi o de regressão logística, pois a variável resposta CP é binária. Para simplificar o modelo e a interpretação dos parâmetros não iremos incluir no modelo as interações de primeira ordem, trataremos este exemplo apenas como um modelo com os efeitos principais. O primeiro modelo que ajustamos foi o seguinte:

$\ln \left(\frac{\pi}{1-\pi}\right)=\beta_{0}+\beta_{1} \mathrm{SEX}+\beta_{2} \mathrm{REG}+\beta_{3} \mathrm{CRIAN}+\beta_{4} \mathrm{IDNOVA}+\beta_{5} \mathrm{SITNOVA}+$ $\beta_{6}$ SALNOVO $+\beta_{7}$ INSTR.

As informações passadas ao SUDAAN foram:

PROC LOGIST DATA="g:/Favpes.sav" FILETYPE=SPSS DESIGN=WOR;

WEIGHT PESO;

NEST FAVELA IDENT;

TOTCNT NDOM NPES;

SUBGROUP SEX REG CRIAN IDNOVA SITNOVA SALNOVO;

LEVEL $\quad 22225224$;

MODEL $\quad \mathrm{CP}=$ SEX REG CRIAN IDNOVA SITNOVA SALNOVO INSTR; 


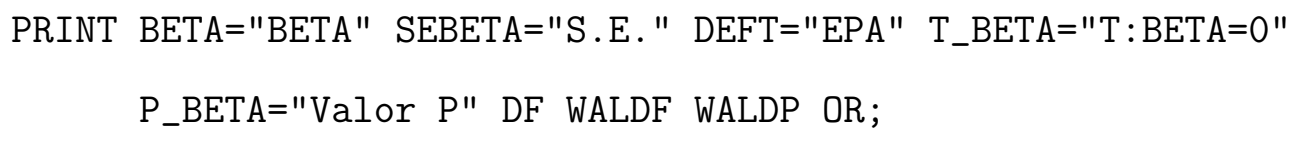

Observe que neste caso, estamos usando o arquivo FAVPES.SAV, onde as unidades primárias de amostragem são conglomerados, selecionados sem reposição. Assim utilizamos o desenho WOR.

A Tabela 6.14 mostra os valores das estatísticas de Wald calculados bem como os respectivos Valores P. No caso da variável SEX temos um Valor P 0,4019. Podemos perceber que a variável SEX não influencia a probabilidade de um indivíduo ser ou não trabalhador por conta própria, logo deve sair do modelo. Eliminada esta variável, não há evidências de que nenhuma outra variável deva sair do modelo. A Tabela 6.15 mostra as significâncias do modelo final ajustado.

\section{Tabela 6.14: Significância dos efeitos}

\begin{tabular}{lccccc}
\hline & \multicolumn{4}{c}{ Considerando o plano } & \multicolumn{2}{c}{ Considerando AAS } \\
CONTRASTES & G.L. & Wald & Valor P & Wald & Valor P \\
\hline Modelo completo & 13 & 698,32 & 0,0000 & 794,99 & 0,0000 \\
SEX & $\mathbf{1}$ & $\mathbf{0 , 7}$ & $\mathbf{0 , 4 0 1 9}$ & $\mathbf{1 , 2 1}$ & $\mathbf{0 , 2 7 1 3}$ \\
REG & 1 & 7,51 & 0,0062 & 5,06 & 0,0245 \\
CRIAN & 1 & 15,46 & 0,0001 & 11,44 & 0,0007 \\
IDNOVA & 4 & 204,12 & 0,0000 & 209,53 & 0,0000 \\
SITNOVA & 1 & 255,41 & 0,0000 & 186,12 & 0,0000 \\
SALNOVO & 3 & 20,62 & 0,0000 & 17,52 & 0,0000 \\
INSTR & 1 & 24,78 & 0,0000 & 41,02 & 0,0000 \\
\hline \hline
\end{tabular}


Tabela 6.15: Significância dos efeitos

\begin{tabular}{|c|c|c|c|c|c|}
\hline \multirow[b]{2}{*}{ CONTRASTES } & \multirow[b]{2}{*}{ G.L. } & \multicolumn{2}{|c|}{ Considerando AAS } & \multicolumn{2}{|c|}{ Considerando o plano } \\
\hline & & Wald & Valor P & Wald & Valor P \\
\hline Modelo completo & 12 & 756,57 & 0,0000 & 861,60 & 0,0000 \\
\hline REG & 1 & 7,59 & 0,0059 & 4,96 & 0,0259 \\
\hline CRIAN & 1 & 15,73 & 0,0001 & 11,09 & 0,0009 \\
\hline IDNOVA & 4 & 204,95 & 0,0000 & 210,37 & 0,0000 \\
\hline SITNOVA & 1 & 255,16 & 0,0000 & 186,30 & 0,0000 \\
\hline SALNOVO & 3 & 20,99 & 0,0000 & 17,29 & 0,0000 \\
\hline INSTR & 1 & 24,2 & 0,0000 & 42,46 & 0,0000 \\
\hline
\end{tabular}

Tabela 6.16: Modelo final considerando o plano amostral

\begin{tabular}{lccc}
\hline \hline CONTRASTES & Coeficiente & DP & EPA \\
\hline Intercepto & $-8,87$ & 0,61 & 0,73 \\
1 & & & \\
CRIAN & $-0,1$ & 0,04 & 1,12 \\
1 & & & \\
IDNOVA & 0,61 & 0,15 & 1,02 \\
1 & & & \\
2 & $-1,87$ & 0,11 & 1,08 \\
3 & $-1,4$ & 0,05 & 1,06 \\
4 & $-0,66$ & 0,05 & 1,05 \\
SITNOVA & $-0,39$ & 0,05 & 1,07 \\
1 & & & \\
SALNOVO & 8,02 & 0,5 & 0,72 \\
1 & & & \\
2 & $-0,32$ & 0,33 & 0,78 \\
3 & $-0,44$ & 0,33 & 0,78 \\
INSTR & 0,74 & 0,36 & 0,8 \\
\hline \hline
\end{tabular}


O modelo final de efeitos principais ajustado foi o seguinte:

$\ln \left(\frac{p_{i}}{1-p_{i}}\right)=-8,87-0,1 *$ REG $+0,61 *$ CRIAN $-1,87^{*}$ IDNOVA1 - 1,4*IDNOVA2

- 0,66*IDNOVA3 - 0,39*IDNOVA4 - 0,32*SALNOVO1 - 0,44*SALNOVO2 + 0,74*SALNOVO3 - 0,03INSTR $+8,02 *$ SITNOVA.

Comparando o modelo acima com o que seria ajustado caso a amostra fosse considerada aleatória simples, podemos perceber que, neste caso, chegaríamos a um mesmo modelo como mostram as Tabelas 6.14 e 6.15, porém os coeficientes de regressão seriam outros. O modelo ajustado no caso de AAS seria o seguinte:

$\ln \left(\frac{p_{i}}{1-p_{i}}\right)=-8,37-0,08 * \mathrm{REG}+0,49^{*} \mathrm{CRIAN}-1,77 *$ IDNOVA1 - 1,32*IDNOVA2

- 0,62*IDNOVA3 - 0,36*IDNOVA4 - 0,66*SALNOVO1 - 0,74*SALNOVO2 + 0,25*SALNOVO3 - 0,03INSTR + 7,96*SITNOVA.

Note que existem diferenças nas estimativas dos parâmetros que levariam a interpretações diferentes quando comparadas com as estimativas do modelo que considera o plano amostral utilizado. Ainda assim, para o modelo ajustado segundo o plano efetivamente utilizado precisaríamos de um análise de resíduos para verificarmos a qualidade deste ajuste. As estimativas dos EPA's mostram que a variância verdadeira, segundo o plano amostral utilizado, está próxima da variância usual quando consideramos amostragem aleatória simples, pois as estimativas dos EPA's estão próximas de 1, como mostra a Tabela 6.16. Isto pode ter ocorrido pois há pouco efeito de conglomeração, uma vez que os domicílios são conglomerados pequenos e a estratificação ocorreu por meio de favelas que não são diferentes entre si. 


\subsection{Comparação entre a biblioteca ADAC e o SUDAAN utilizando um modelo de regressão logística}

Nesta seção foi ajustado um modelo de regressão logística para a análise de dados provenientes de uma amostra complexa. Nosso objetivo é comparar a biblioteca ADAC com o pacote SUDAAN. Comparou-se também o método que incorpora o esquema amostral com o que assume que as observações da amostra são independentes e identicamente distribuídas. Souza e Silva (2000) fizeram comparações de vários "softwares" para problemas do mesmo tipo.

Os dados utilizados neste trabalho fazem parte da Pesquisa sobre Padrões de Vida (PPV), realizada pelo IBGE nas Regiões Nordeste e Sudeste do Brasil nos anos de 1996-1997. Foram considerados 10 estratos geográficos a saber: Região Metropolitana de Fortaleza, Região Metropolitana de Recife, Região Metropolitana de Salvador, restante da área urbana do Nordeste, restante da área rural do Nordeste, Região Metropolitana de Belo Horizonte, Região Metropolitana do Rio de Janeiro, Região Metropolitana de São Paulo, restante da área urbana do Sudeste e restante da área rural do Sudeste. Cada um destes estratos foi subdividido em 3 estratos de acordo com a renda salarial média do chefe de família totalizando, então, 30 estratos. O plano amostral foi realizado em dois estágios: no primeiro estágio foram selecionados, de cada estrato, setores censitários e no segundo estágio foram selecionados domicílios de cada setor censitário escolhido no primeiro estrato. Para cada estrato foi fixado um tamanho de amostra de 480 domicílios, seguindo a seguinte ordem: seleção de 60 setores e em cada um deles a escolha de 8 domicílios. As exceções foram as áreas rurais onde fixou-se a seleção de 30 setores e de cada um deles 16 domicílios. Mais informações sobre o plano vide Albieri e Bianchini (1997). 
Tabela 6.17: Dicionário de variáveis disponíveis no arquivo ARQPES.SAV

\begin{tabular}{|c|c|c|}
\hline Variável & Código & Descrição \\
\hline ESTRATOF & Numérico & Número do estrato \\
\hline NSETOR & Numérico & Número do setor no estrato \\
\hline \multirow[t]{2}{*}{ ID.IMC } & 0 & Índice de massa corporal é diferente de "missing" \\
\hline & 1 & Índice de massa corporal é "missing" \\
\hline \multirow[t]{2}{*}{ SEXO } & 1 & Masculino \\
\hline & 2 & Feminino \\
\hline \multirow[t]{4}{*}{ FAIXA } & 1 & Idade da pessoa entre 20 a 29 anos \\
\hline & 2 & Idade da pessoa entre 30 a 39 anos \\
\hline & 3 & Idade da pessoa entre 40 a 49 anos \\
\hline & 4 & Idade da pessoa acima de 50 anos \\
\hline \multirow[t]{2}{*}{ RACA } & 1 & Branca \\
\hline & 2 & Não branca \\
\hline \multirow[t]{2}{*}{ CONDICAO } & 1 & Não é chefe de família \\
\hline & 2 & É chefe \\
\hline \multirow[t]{2}{*}{ TRABALHA } & 1 & Tinha trabalho \\
\hline & 2 & Não tinha trabalho \\
\hline \multirow[t]{5}{*}{ GAEST2 } & 1 & Menos de 1 ano de estudo \\
\hline & 2 & De 1 a 7 anos de estudo \\
\hline & 3 & De 8 a 11 anos de estudo \\
\hline & 4 & 11 anos de estudo \\
\hline & 5 & Mais de 12 anos de estudo \\
\hline WFD.AJUS & Numérico & Peso final de domicílio ajustado \\
\hline
\end{tabular}

Um dos nossos objetivos era determinar quais entre as variáveis coletadas (sexo, faixa, raça, condição, trabalha e gaest2) estavam relacionadas com o fato de não ter sido calculado o índice de massa corporal de algum indivíduo, ou seja, não 
termos informação sobre o peso ou altura de um indivíduo. A descrição de cada uma das variáveis estudadas aparece na Tabela 6.17.

\subsubsection{Ajuste do modelo}

Um modelo de regressão logística será ajustado utilizando o comando Logist. $\mathrm{Na}$ ADAC, antes da utilização da função Logist devemos ler o conjunto de dados e criar fatores para as variáveis que estão categorizadas nesta pesquisa (o comando utilizado é o as.factor):

arqpes<-read.csv ("g: /arqpes. csv", header=T, sep=" , " , dec=" . ")

arqpes $\$$ SEXO<-as . factor (arqpes $\$$ SEXO)

arqpes \$FAIXA<-as. factor (arqpes\$FAIXA)

arqpes $\$ R A C A<-$ as . factor (arqpes $\$ R A C A$ )

arqpes $\$ C O N D I C A O<-$ as . factor (arqpes\$CONDICAO)

arqpes \$TRABALHA<-as . factor (arqpes\$TRABALHA)

arqpes\$GAEST2<-as . factor (arqpes\$GAEST2)

O passo seguinte seria a chamada da função Logist:

Logist (ID . IMC $\sim$ SEXO+RACA+CONDICAO+TRABALHA+SEXO*RACA , data=arqpes , weights=arqpes\$WFD . AJUS , family=binomial, na . action="na . omit" , Est="ESTRATOF" , Cong="NSETOR" , des="WR" )

No SUDAAN a chamada da função LOGISTIC seria realizada da seguinte maneira:

PROC LOGISTIC DATA $=$ arqpes. sav FILETYPE $=$ SPSS DESIGN $=$ WR;

WEIGHT wfd_ajus;

NEST estratof nsetor;

SUBGROUP sexo faixa raca condicao trabalha gaest2 ; 


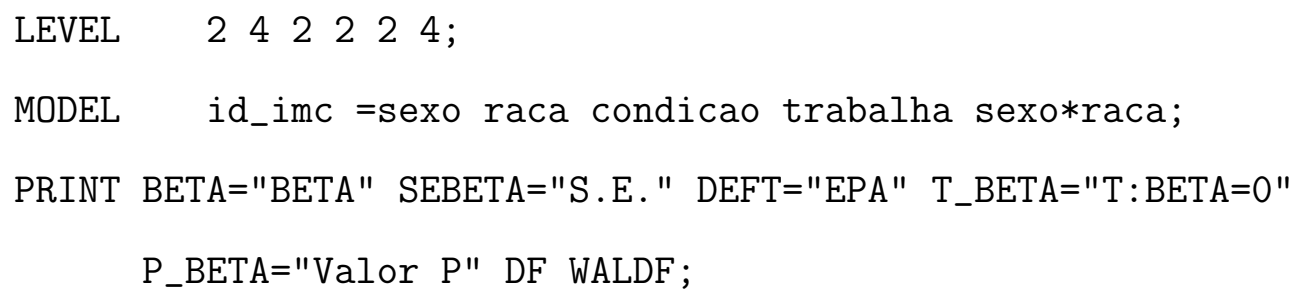

Antes do modelo que aparece acima, foi ajustado um modelo de regressão logística com todas as variáveis do problema e todas as interações de primeira ordem. A seguir, selecionamos quais variáveis e interações deveriam ou não permanecer no modelo, baseados na estatística de Wald.

As Tabelas 6.18 a 6.21 apresentam os resultados das estimativas dos parâmetros e de seus desvios-padrão calculadas pela ADAC e pelo SUDAAN, bem como o valor das estatísticas de teste calculadas em ambos.

Tabela 6.18: Estimativas dos parâmetros e desvios padrão calculados pela ADAC

\begin{tabular}{ccccc}
\hline \hline & \multicolumn{2}{c}{ Considerando o plano } & \multicolumn{2}{c}{ Considerando AAS } \\
& Parâmetro & DP & Parâmetro & DP \\
\hline Intercepto & $-3,8100$ & 0,158 & $-3,40006$ & 0,11329 \\
sexo & 1,1200 & 0,160 & 0,87716 & 0,11229 \\
raça & $-0,0719$ & 0,171 & $-0,15059$ & 0,11346 \\
condicao & 0,8410 & 0,114 & 0,68248 & 0,07831 \\
trabalha & 0,2560 & 0,122 & 0,24957 & 0,07948 \\
sexo*raça & 0,4840 & 0,189 & 0,54649 & 0,14245 \\
\hline \hline
\end{tabular}

Destas tabelas observamos que:

- Quando consideramos as observações da amostra selecionadas por AAS, há uma diminuição nas estimativas dos $\mathrm{DP}^{\prime}$ s como mostra a Tabela 6.20. Observe que os EPA's são todos maiores que 1, mostrando que ignorar conglomeração inflaciona as estimativas dos EPA's. Além disso, estaríamos sendo levados a crer que a variabilidade dos coeficientes de regresssão é menor do que na realidade; 
Tabela 6.19: Estatísticas de Wald calculadas pela ADAC Considerando o plano

\begin{tabular}{ccc} 
Contraste & Wald & Valor P \\
\hline sexo & 48,600 & 0,00000 \\
raça & 0,176 & 0,67500 \\
condicao & 54,400 & 0,00000 \\
trabalha & 4,390 & 0,03660 \\
sexo*raça & 6,560 & 0,01070 \\
\hline \hline
\end{tabular}

Tabela 6.20: Estimativas dos parâmetros e desvios padrão calculadas pelo SUDAAN

\begin{tabular}{cccccc}
\hline & \multicolumn{3}{c}{ Considerando o plano } & \multicolumn{3}{c}{ Considerando AAS } \\
& Parâmetro & DP & EPA & Parâmetro & DP \\
\hline Intercepto & $-3,81$ & 0,16 & 1,72 & $-3,4$ & 0,12 \\
sexo & 1,12 & 0,16 & 1,94 & 0,88 & 0,11 \\
raça & $-0,07$ & 0,17 & 1,76 & $-0,15$ & 0,11 \\
condicao & 0,84 & 0,11 & 1,86 & 0,68 & 0,08 \\
trabalha & 0,26 & 0,12 & 2,03 & 0,25 & 0,08 \\
sexo*raça & 0,48 & 0,19 & 1,45 & 0,55 & 0,14 \\
\hline \hline
\end{tabular}

Tabela 6.21: Estatísticas de Wald calculadas pelo SUDAAN

Considerando o plano Considerando AAS

\begin{tabular}{ccccc} 
Contraste & Wald & Valor P & Wald & Valor P \\
\hline Modelo Completo & 247,98 & $<0,0001$ & 711,6 & $<0,0001$ \\
condicao & 54,43 & $<0,0001$ & 72,79 & $<0,0001$ \\
trabalha & 4,39 & 0,0366 & 9,83 & 0,0017 \\
sexo*raça & 6,57 & 0,0107 & 14,62 & 0,0001 \\
\hline \hline
\end{tabular}

- Os valores das estimativas da estatística de Wald calculados pelo SUDAAN e ADAC foram os mesmos; 
- A ADAC não calcula a estatística de Wald automaticamente, no caso AAS;

- A ADAC não fornece a estatística de Wald para o modelo completo;

- O SUDAAN não realiza o teste para a significância de uma variável, quando há interação desta com outra variável.

O modelo final foi o seguinte:

$$
\begin{aligned}
\ln \left(\frac{p_{i}}{1-p_{i}}\right) & =-3,81+1,12 \text { sexo }-0,07 \text { raca }+0,84 \text { condicao }+0,26 \text { trabalha } \\
& +0,48 \text { sexo } * \text { raca }
\end{aligned}
$$

onde $p_{i}$ é a probabilidade de não possuir a informação sobre o IMC para o indivíduo $i$.

\subsection{Uso de regressão linear para a caracterização sócio-econômica da população moradora de rua}

Os dados analisados são provenientes de um estudo realizado pela Fundação Instituto de Pesquisas Econômicas (FIPE) - USP para a caracterização sócio-econômica da população moradora de rua da cidade de São Paulo. Nesta pesquisa, foi considerado morador de rua tanto o indivíduo que utilizava os logradouros públicos (incluindo mocós) para dormir, como aquele que utilizava os albergues da cidade. Através de levantamentos bibliográficos e outras informações que foram colhidas de entidades que assistem essa população, bem como de informações de técnicos da Secretaria de Assistência Social, averiguou-se a existência de diferenças entre a população usuária de albergues e a população que usualmente dorme em logradouros públicos. Por conta destas diferenças foram selecionadas amostras aleatórias para cada caso, seguindo metodologias diferentes . 
Tabela 6.22: Descrição das variáveis

\begin{tabular}{|c|c|c|}
\hline Variável & Código & Descrição \\
\hline NQUEST & Numérico & Número do questionário \\
\hline ESTRATO & Numérico & Número do estrato \\
\hline QUADRA & Numérico & Número do quadrante no estrato \\
\hline NP & Numérico & Número de domicílios no setor na população \\
\hline DISTRITO & Numérico & Número do distrito \\
\hline \multirow[t]{2}{*}{ SEXO } & 1 & Masculino \\
\hline & 2 & Feminino \\
\hline \multirow[t]{5}{*}{ COR } & 1 & Pessoa de cor branca \\
\hline & 2 & Pessoa de cor parda \\
\hline & 3 & Pessoa de cor preta \\
\hline & 4 & Pessoa de cor amarela \\
\hline & 5 & Pessoa de cor vermelha \\
\hline \multirow[t]{4}{*}{ ESTUDO } & 1 & Analfabeto \\
\hline & 2 & Até 4 anos completos de estudo \\
\hline & 3 & De 5 a 8 anos completos de estudo \\
\hline & 4 & Mais de 8 anos completos de estudo \\
\hline \multirow[t]{4}{*}{ IDADE } & 1 & De 18 a 25 anos completos de idade \\
\hline & 2 & De 26 a 40 anos completos de idade \\
\hline & 3 & De 41 a 55 anos completos de idade \\
\hline & 4 & Mais de 56 anos de idade \\
\hline RENDA & Numérico & Valor da renda (em reais) \\
\hline LRENDA & Numérico & Logaritmo do valor da renda \\
\hline PESO & Numérico & Peso final \\
\hline TOTAL & Numérico & Número total de moradores de rua nos 26 distritos \\
\hline
\end{tabular}


Na ilustração que vamos fazer aqui, utilizamos apenas o segmento da população de moradores de rua que dormia em logradouros públicos. A metodologia utilizada para a seleção da amostra teve como base o primeiro censo de moradores de rua da cidade de São Paulo. Particularidades desta pesquisa podem ser encontradas em Schor e Artes (2001). Neste censo, foi constatado que 85\% da população de rua adulta, ou seja, com idade superior a 17 anos, estava distribuída em 26 distritos da cidade de São Paulo. Desta forma, estes 26 distritos foram estratificados por proximidade geográfica, de modo que a coleta dos dados pudesse ser realizada em cinco noites, contando com cinco equipes de quatro entrevistadores. Os catorze estratos resultantes foram subdivididos em pequenas áreas correspondentes aos quadrantes do Mapa Oficial da Cidade e, de cada estrato, quatro quadrantes (conglomerados) foram sorteados com probabilidade de sorteio proporcional ao número de moradores lá encontrados no censo. Em cada quadrante selecionado, os moradores de rua foram escolhidos através de uma amostragem sistemática com fração amostral fixa por estrato.

A Tabela 6.22 mostra algumas variáveis que selecionamos para esta ilustração, além de que informa outras variáveis existentes no conjunto de dados e que foram necessárias para o uso da biblioteca ADAC.

Primeiramente, ajustamos um modelo de regressão linear normal para determinar quais entre as variáveis coletadas (sexo, estudo, cor e idade) estavam relacionadas com o logaritmo da renda do morador de rua, utilizando a função REGRESS da biblioteca ADAC com todas as variáveis explicativas citadas acima. No caso dos moradores de rua, a variável renda possui muitos "zeros", dado que a maioria deles não possui renda. Para solucionar este problema, antes da criação da variável logaritmo da renda, fizemos a suposição que estes moradores tinham pelo menos a renda de $\mathrm{R} \$ 1,00$ e, por consegüinte, a variável logaritmo da renda passou a valer "zero". O ajuste, usando a biblioteca ADAC, foi realizado da seguinte maneira: 
Regress (LRENDA SEXO+COR+ESTUDO+IDADE, data=rua, weights=rua $\$$ PESO, na. action="na.omit", Est="ESTRATO", Cong="QUADRA", des="WR" )

A seguir, selecionamos quais efeitos deveriam, ou não, permanecer no modelo. As Tabelas 6.23 e 6.24 mostram os resultados do ajuste do modelo considerando AAS e considerando o plano amostral, respectivamente. Vale notar que a Tabela 6.24 também traz as estimativas dos desvios padrões obtidas por meio de $J^{-1}$. Observe que ao considerarmos AAS a variável COR não é significante para explicar o logaritmo da renda, que torna-se significante quando consideramos na análise o plano amostral efetivamente utilizado. O modelo final considerando o plano amostral é o seguinte:

$$
L R E N D A=2,50-0,84 S E X O 2-0,07 C O R 2+0,64 C O R 3-2,50 C O R 4
$$

Após o ajuste da regressão linear normal, consideramos a variável renda como dicotômica para tentarmos entender qual a relação das variáveis acima com o fato do morador possuir, ou não, renda. Nesta nova variável, foi atribuído o valor "1"para os moradores de rua que possuíam algum tipo de renda e "0" para os moradores que não possuíam renda. O próximo passo foi ajustar um modelo de regressão logística da seguinte maneira:

Logist (RENDA $\sim$ SEXO+COR+IDADE+ESTUDO, data=ruela, weights=ruela $\$ P E S O$, family =binomial, na.action="na.omit", Est="ESTRATO" , Cong="QUADRA", des="WR" )

Após retirarmos as variáveis não significativas do modelo, chegamos ao seguinte modelo de regressão logística:

$$
\ln \left(\frac{p_{i}}{1-p_{i}}\right)=0,654-0,932 S E X O 2-0,270 C O R 2+0,593 C O R 3-5,13 C O R 4
$$

Para o cálculo da estimativa de $J^{-1}$ para o caso de regressão linear normal foi utilizado o programa que se encontra no Apêndice A. Note que no caso de regressão 
logística, não dispomos ainda da expressão do estimador da matriz de covariância assintótica dos parâmetros.

Podemos perceber que ao considerarmos a amostra selecionada através de amostragem aleatória simples, teríamos que retirar a variável COR também no caso de regressão logística como mostra a Tabela 6.25. Do mesmo modo que no caso normal, ao considerarmos o plano amostral na análise, a variável COR, não deve ser retirada do modelo de regressão logística como podemos ver na Tabela 6.26. Além disso, os valores do Efeito do Plano Amostral (EPA) para os dois modelos de regressão (normal e logística) são bem distantes de um. Logo, há indicação de que não devemos ignorar o plano amostral na análise destes dados.

Tabela 6.23: Regressão normal considerando AAS

\begin{tabular}{lcccc}
\hline \hline & Parâmetro & DP & Teste z & Valor P \\
\hline INTERCEPTO & 2,46 & 0,16 & 15,63 & 0,000 \\
SEXO2 & $-1,06$ & 0,26 & $-4,00$ & 0,000 \\
COR2 & $-0,09$ & 0,22 & $-0,43$ & 0,670 \\
COR3 & 0,27 & 0,24 & 1,11 & 0,268 \\
COR4 & $-2,46$ & 1,98 & $-1,25$ & 0,214 \\
\hline \hline
\end{tabular}

Tabela 6.24: Regressão normal considerando o plano

\begin{tabular}{lcccccc}
\hline \hline & Parâmetro & DP & Teste z & Valor P & EPA & $J^{-1}$ \\
\hline INTERCEPTO & 2,89 & 0,17 & 17,50 & 0,000 & 1,57 & 0,17 \\
SEXO2 & $-0,53$ & 0,32 & $-1,68$ & 0,094 & 2,11 & 0,29 \\
COR2 & $-0,12$ & 0,29 & $-0,41$ & 0,681 & 2,65 & 0,26 \\
COR3 & 0,43 & 0,25 & 1,71 & 0,088 & 1,48 & 0,26 \\
COR4 & $-1,89$ & 0,17 & $-11,40$ & 0,000 & $¡ 0,01$ & 1,61 \\
\hline \hline
\end{tabular}


Tabela 6.25: Regressão logística considerando AAS

\begin{tabular}{lcccc}
\hline \hline & Parâmetro & DP & Teste z & Valor P \\
\hline INTERCEPTO & 0,68 & 0,17 & 4,02 & 0,000 \\
SEXO2 & $-1,11$ & 0,28 & $-4,01$ & 0,000 \\
COR2 & $-0,25$ & 0,23 & $-1,08$ & 0,281 \\
COR3 & 0,18 & 0,26 & 0,66 & 0,507 \\
COR4 & $-5,23$ & 5,99 & $-0,87$ & 0,383 \\
\hline \hline
\end{tabular}

Tabela 6.26: Regressão logística considerando o plano

\begin{tabular}{lccccc}
\hline \hline & Parâmetro & DP & Teste z & Valor P & EPA \\
\hline INTERCEPTO & 0,75 & 0,25 & 3,01 & 0,003 & 2,05 \\
SEXO2 & $-0,86$ & 0,36 & $-2,38$ & 0,017 & 1,68 \\
COR2 & $-0,42$ & 0,33 & $-1,28$ & 0,201 & 1,97 \\
COR3 & 0,44 & 0,34 & 1,28 & 0,201 & 1,44 \\
COR4 & $-5,07$ & 1,02 & $-4,95$ & 0,000 & 0,02 \\
\hline \hline
\end{tabular}




\section{CAPÍtulo 7}

\section{Considerações finais}

Neste trabalho revisitamos vários estudos que tratam da incorporação do esquema amostral em análise de regressão. Apresentamos um método para incorporar o esquema amostral via equações de estimação com o objetivo de estimar os parâmetros de um modelo de regressão. O método baseia-se na abordagem de modelos de superpopulação; além disso, mostramos que o método de máxima pseudo-verossimilhança é um caso particular desta teoria.

Fornecemos subsídios para a utilização de ferramentas computacionais tais como o SUDAAN e a biblioteca ADAC desenvolvida na linguagem $\mathrm{R}$ de modo a facilitar a análise de conjuntos de dados provenientes de esquemas amostrais complexos. Do estudo que fizemos, comparando ambas as ferramentas computacionais mencionadas, pudemos perceber vantagens e desvantagens.

Dentre as vantagens da utilização da biblioteca ADAC, podemos enfatizar que por estar escrita em uma linguagem aberta e gratuita, torna-se de fácil acesso. A biblioteca suporta bancos de dados gerados de qualquer outro programa, desde que especifiquemos como está organizado o conjunto de dados. Além disto, o acesso à estrutura de cada função está disponível. As desvantagens surgem do fato que algumas rotinas não estão otimizadas e, portanto há uma grande ocupação de memória; aceita apenas alguns tipos de desenhos amostrais e sua estrutura de análise para regressão se 
restringe à regressão linear normal e logística. Já o SUDAAN exige pouca memória da máquina em que estamos realizando as análises e suporta arquivos gerados pelo SAS, SPSS ou codificados em ASCII. Possui implementados procedimentos para análise de sobrevivência, dados longitudinais, etc., que incorporam o esquema amostral. Por outro lado, todos os seus procedimetos são fechados e não conseguimos saber como operam. Não possui ambiente gráfico e suas saídas são difíceis de serem utilizadas.

O estudo de modelos de regressão aplicados a dados provenientes de planos amostrais complexos não pára por aqui. Embora não incluídos neste trabalho, os métodos Bayesianos de análise, discutidos em Chambers e Skinner (2003), poderiam ser abordados num trabalho futuro. Outro tópico a ser estudado seria a validação dos modelos por meio de técnicas de diagnóstico que não foram tratadas neste estudo pelo fato de não estarem desenvolvidas na literatura pesquisada. Finalmente, uma outra tarefa importante seria implementar no SUDAAN ou na biblioteca ADAC o cálculo da matriz de covariância assintótica baseada na matriz de informação de Godambe e métodos automáticos de seleção de modelos. 


\section{APÊNDICE A}

\section{Programa}

\section{Cálculo de $J^{-1}$}

Apresentamos aqui o programa utilizado para o cálculo da estimativa da matriz de covariância assintótica dos parâmetros $J^{-1}$ desenvolvido na linguagem de programação R.

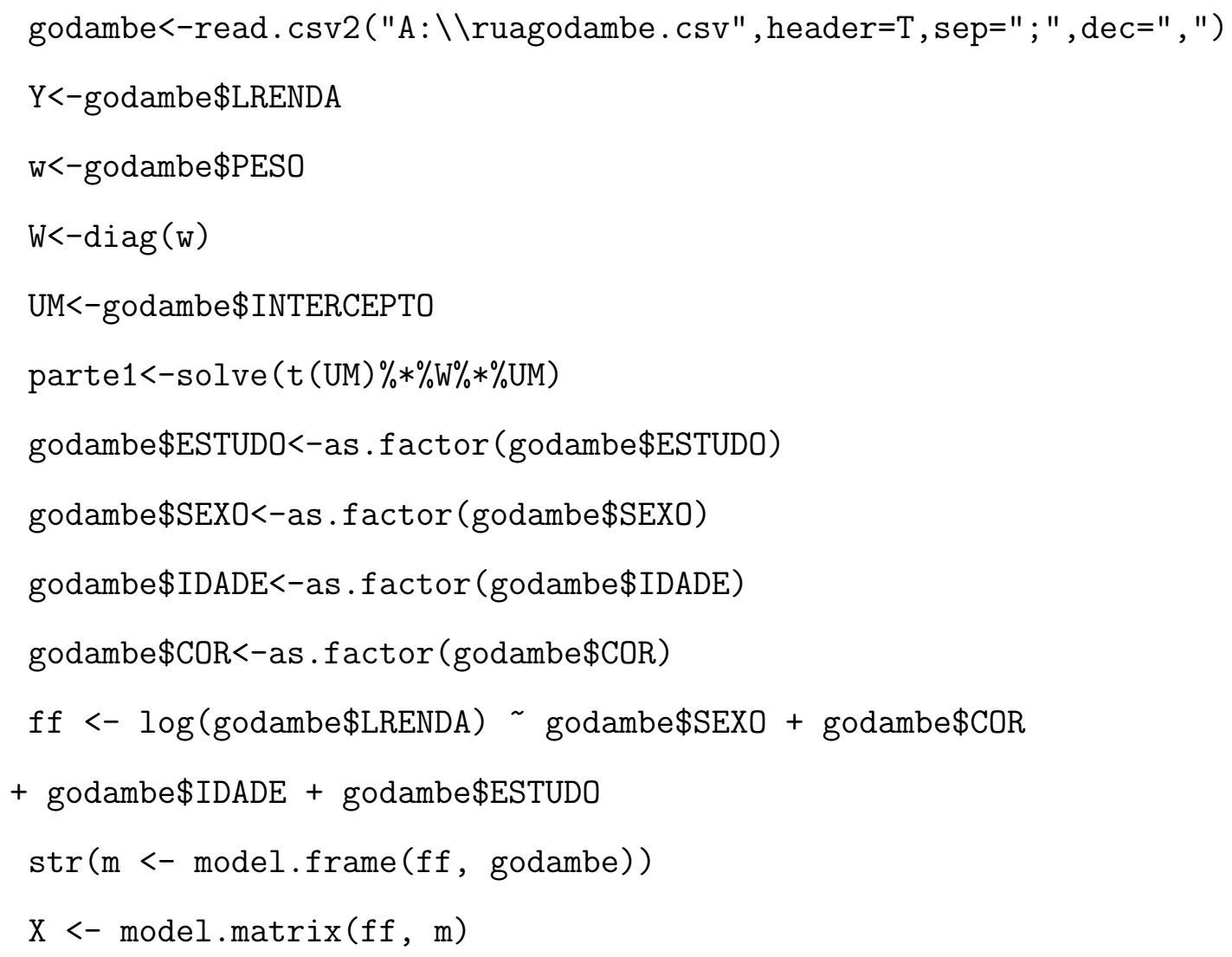




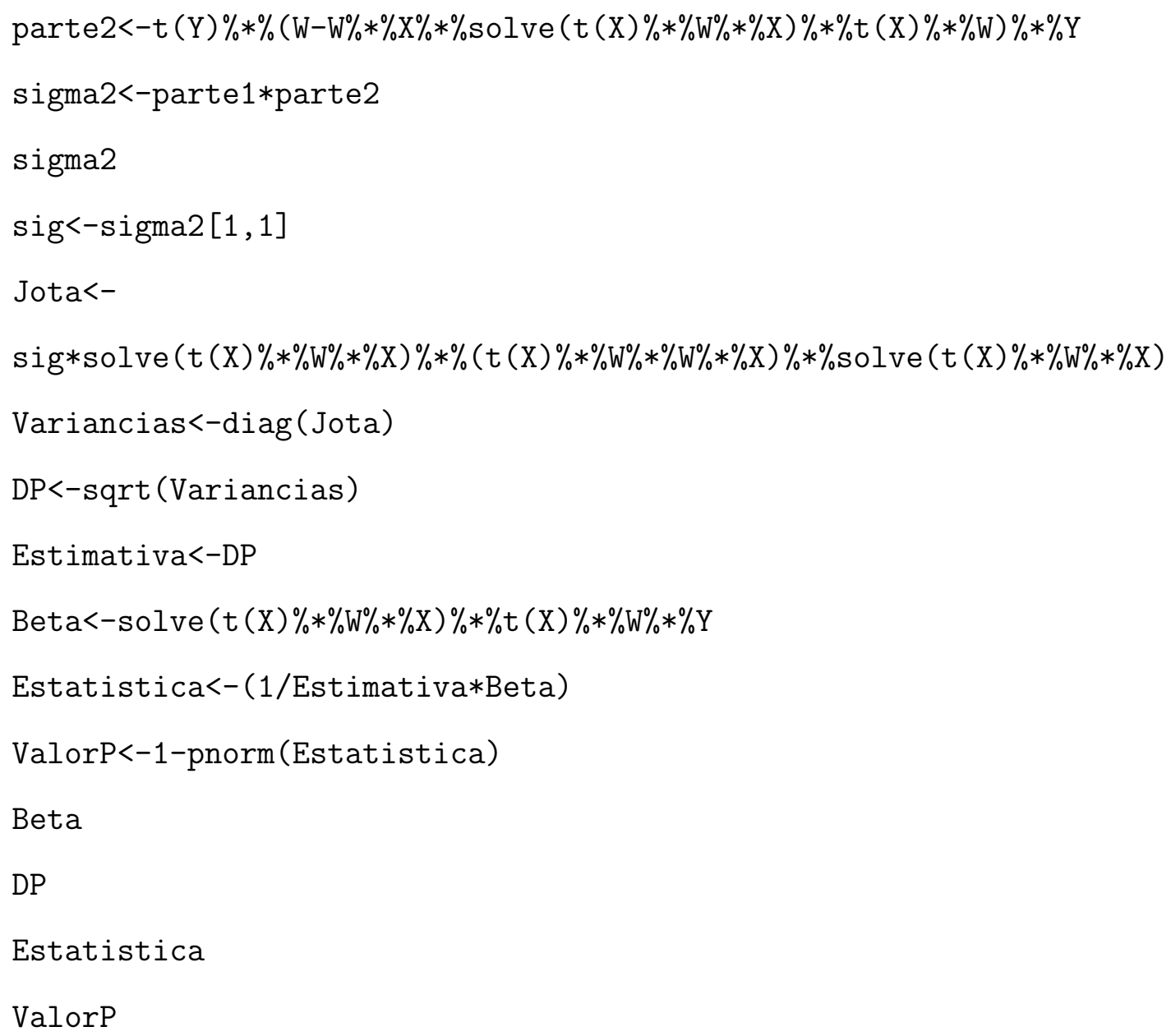




\section{Referências Bibliográficas}

[1] Albieri, S. e Bianchini Z.M. (1997). Aspectos de amostragem relativos à pesquisa domiciliar sobre padrões de vida. Rio de Janeiro: IBGE.

[2] Artes, R. (1997). Extensões da teoria das equações de estimação generalizadas a dados circulares e modelos de dispersão. São Paulo: IME-USP. Tese de doutorado.

[3] Binder, D.A. (1983). On the variances of asymptotically normal estimators International Statistical Review, 51, 279-292.

[4] Botter, D.A., Sandoval, M.C., Auricchio, C.A., Sznelwar, M. (2002). Relatório de análise estatística sobre o projeto: Fatores de risco cardiovascular em crianças e adolescentes de Belo Horizonte. São Paulo: IME-USP.

[5] Chambers, R.L. e Skinner, C.J. (2003). Analysis of Survey Data. Chichester: John Wiley.

[6] Chandrasenkar, B. e Kale, B.K. (1984). Unbiased statistical estimation functions for parameter in presence of nuisance parameter. Journal of Statistical Planning and Inference, 9, 45-54.

[7] Costa, L.N. (1990). Texts for discussion, 34. Rio de Janeiro: IBGE.

[8] Crowder, M. (1987). On linear and quadratic estimating equations. Biometrika, 74, 591-597.

[9] Duarte, R.P.N. (1999). Ajuste de modelos lineares usando estimadores de regressão para amostras complexas. São Paulo: IME-USP. Dissertação de mestrado. 
[10] Godambe, V.P. (1960). Estimation in survey sampling: robustiness and optimality. Journal of the American Statistical Association, 77, 393-403.

[11] Godambe, V.P. e Thompson, M.E. (1986). Parameters of superpopulation and survey population: their relationship and estimation. International Statistical Review, 54, $127-138$.

[12] J $\phi$ rgensen, B. e Laboriau, R.S. (1994). Exponential families and theoretical inference. Lecture notes, Department of Statistics, University of British Columbia.

[13] Kish, L. (1965). Survey Sampling. New York: John Wiley.

[14] Morton, S.C. e Rolph, J.E. (2000). Public policy and statistics: Case studies from $R A N D$. New York: Springer-Verlag.

[15] Notas de aula do curso de análise de dados amostrais. Rio de Janeiro: Escola Nacional de Ciências Estatísticas.

[16] Nascimento Silva, P.L.D. (1996). Utilizing auxiliar information for estimation and analysis in sample surveys. Southampton: University of Southampton. Tese de doutorado.

[17] Neter, J., Kutner, M. H., Nachtsheim, C. J., e Wasserman, W. (1996). Applied Linear Statistical Models. 4.ed. Illinois: Richard D. Irwin, Inc..

[18] Ogus, J.L. e Clark, D.F. (1971). The annual survey of manufactures: A report on methodology. Washington, DC.: U.S. Bureau of the Census. Technical paper $n^{\circ} 24$.

[19] Ohlsson, E. (1990). Sequencial poisson sampling from a business register and its application to the Swedish consumer price index. Stockholm: Statistics Sweden. R\&D Report (1990:6).

[20] Ohlsson, E. (1998). Sequencial poisson sampling. Journal of Official Statistics, 14, $149-162$.

[21] Pessoa, D.G.C. e Nascimento Silva, P.L.N. (1998). Análise de Dados Amostrais Complexos. Caxambu: Associação Brasileira de Estatística. $13^{\circ}$ Simpósio Nacional de Probabilidade e Estatística. 
[22] Pessoa, D.G.C. e Moreira, G.G. (2002). Biblioteca ADAC - Análise de Dados Amostrais Complexos. Rio de Janeiro: IBGE.

[23] Pfeffermann, D. (1993). The role of sampling weights when modelling survey data. International Statistical Review, 61, 317-337.

[24] Rao, J.N.K., Scott, A.J. e Skinner, C.J. (1998). Quasi-score tests with survey data. Statistica Sinica, 8, 1059-1070.

[25] Research Triangle Institute (2001). SUDAAN User's Manual, Release 8.0. Research Triangle Park, NC: Research Triangle Institute.

[26] Särndal, C.E., Swensson, B. e Wretman, J.H. (1992). Model assisted survey sampling. New York: Springer-Verlag.

[27] Shah, B.V., Folson, R.E., LaVange, L.M., Wheeless, S.C., Boyle, K.E. e Williams, R.L. (1993). Statistical Methods and Mathematical Algorithms Used in SUDAAN. Research Triangle Park, NC: Research Triangle Institute.

[28] Skinner, C.J., Holt, D. e Smith, T.M.F. (1989). Analysis of Complex Surveys. Chichester: John Wiley.

[29] Souza, M.H. e Silva, N.N. (2000). Comparação de softwares para a análise de dados de levantamentos complexos. Revista de Saúde Pública, 34, 646-653.

[30] Schor, S.M. e Artes, R. (2001). Primeiro censo de moradores de rua da cidade de São Paulo: Procedimentos metodológicos e resultados. Brazilian Journal of Applied Economics, 5, n. 4.

[31] Venables, W.N., Smith, D.M. et al. (2003). An introdution to R. Version 1.7.0.

[32] Vieira, M.T. (2001). Um estudo comparativo das metodologias de modelagem de dados amostrais complexos - Uma aplicação ao SAEB 99. Rio de Janeiro: Pontifícia Universidade Católica do Rio de Janeiro. Dissertação de Mestrado. 